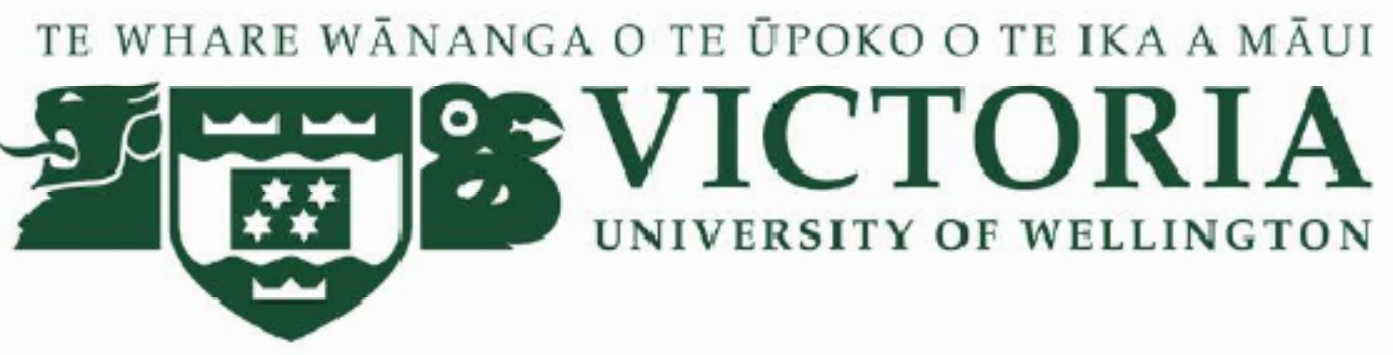

\title{
Impact of Unexploded Ordnance (UXO) on Rural Communities' Livelihoods in Xiengkhouang Province, Lao PDR
}

\author{
by
}

Sopha Soulineyadeth

A 120-point thesis submitted to Victoria University of Wellington, as partial fulfilment of requirements for the degree of Master of Development Studies 


\begin{abstract}
For over 30 years since the end of the Second Indochina War, UXO (Unexploded Ordnance) contamination in Laos has been a major issue. Laos is considered the most heavily bombed country in the world in terms of quantity of ammunition per capita. Aproximately 25 percent of the villages are contaminated with UXO, and a third of the country's total area is covered by UXO contamination, comprising around 87 thousand square kilometres.This severely limits the expansion of agricultural production, which leads to scarcity of food supplies, and limits local people's ability to achieve sustainable livelihoods. Thus, UXO is both a significant challenge to community development and national social and economic development. UXOs are also the cause of many accidents in Laos, the casualties are often farmers who are involved in agricultural activities. Between 1999 and 2012, 934 casualties which was divided into 655 injuries and 279 deaths.

This study was conducted in Xienkhouang province, Lao PDR, a region heavily affected by UXO. The aim of this thesis is to explore the policies and institutions working on UXO in this province, the major difficulties rural communities face in their livelihoods in relation to UXO and the strategies they are using to cope with these difficulties, and to provide a reflection on how to improve support for these communities.

Applying the sustainable livelihood framework as its conceptual framework, this research followed a qualitative approach involving the conduction of 24 semi-structured interviews, including 15 villagers and 9 interviews from organisations working on the UXO domain.

Understanding of the impact of UXO on rural communities' livelihoods an their coping mechanism is crucial to expand debates within development studies in post-conflict settings, as well as for both practitionersand policy makers.
\end{abstract}




\section{Acknowledgements}

This research is the product of co-operation and assistance of many people. I would like to acknowledge the following people without whom my study would not have been successful.

I would like to present my special thanks to my supervisors Dr Marcela PalominoSchalscha who has not only provided valuable academic guidance throughout this research but also has encouraged me to overcome numerous difficulties and challenges. I would like also thank for her patient support for keeping me on track.

I would like to thank the interviewed organizations in Vientiane and in Xiengkhouang province to provide essential data for this research. I, especially, would like to thank NRA, UXO Lao office in Vientiane and Xiengkhouang province for facilitating my fieldwork.

My appreciation goes to the interview participants in two villages in Xienghouang province for sharing the stories, the experiences and opinions about this research topic.

I deeply express my appreciation to my family, first Tick my wife and daughter Omery being part of me even when things were very difficult in New Zealand. I also thank my grandparents in-law and relatives in Laos for continued parental support even at this age

My deepest gratitude should go to NZAID for funding my studies and making life easier in Wellington. 


\section{TABLE OF CONTENTS}

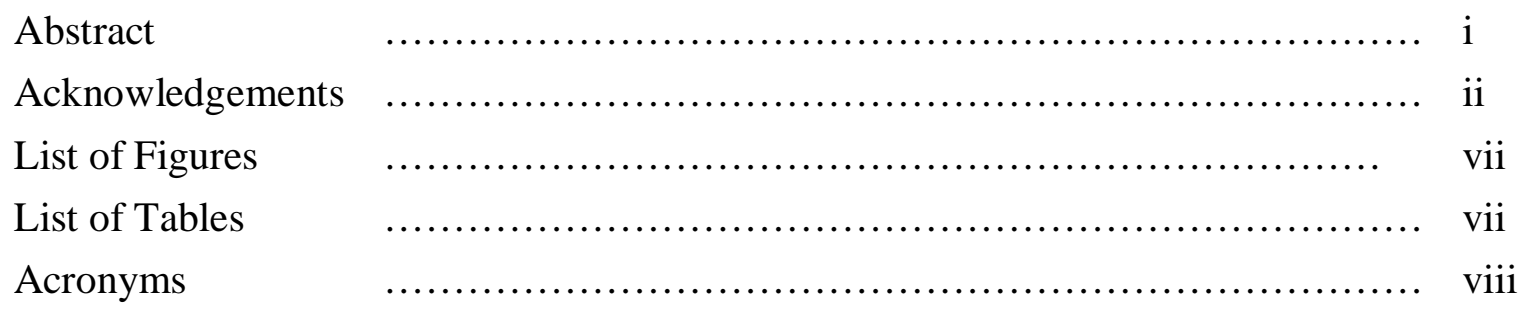

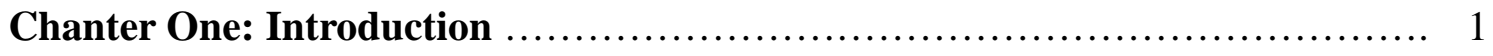

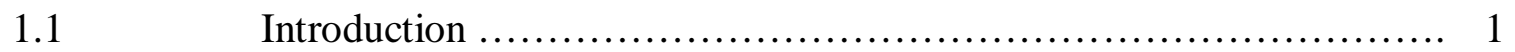

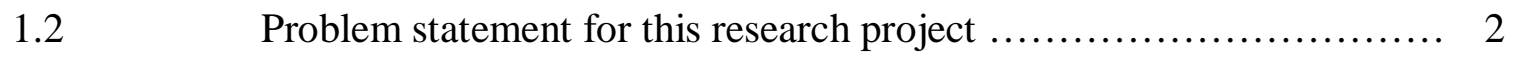

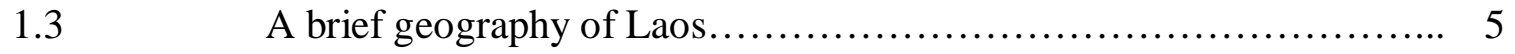

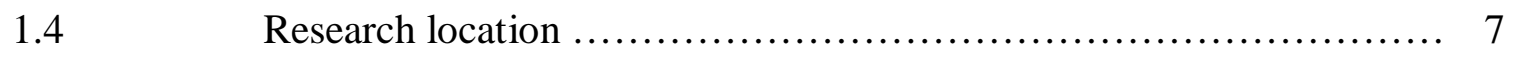

$1.5 \quad$ Theoretical framework ............................................. 9

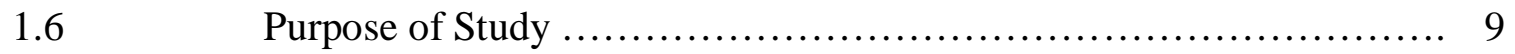

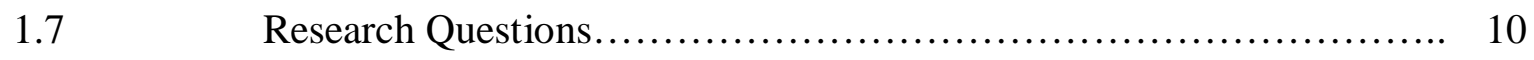

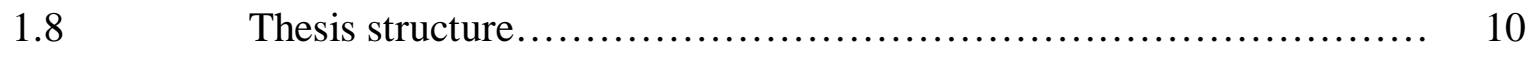

$1.9 \quad$ Conclusion......................................................... 12

Chapter Two: Literature review......................................... 13

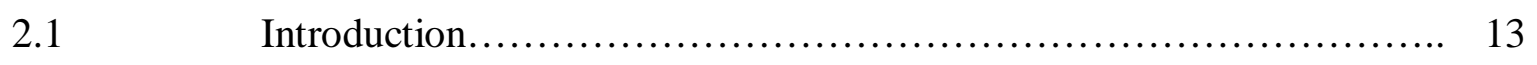

2.2 Theoretical framework.......................................... 13

2.3 Sustainable livelihood........................................... 14

2.3.1 The origination of sustainable livelihood............................ 14

2.3.2 Sustainable livelihood approaches................................ 16

2.3.3 The Sustainable livelihood framework tool......................... 17

$2.4 \quad$ Vulnerability after conflict......................................... 21

2.4.1 UXO impacts globally ......................................... 22

2.4.2 UXO impacts in Laos........................................... 24

2.5 Structures, policies and institutions concerning UXO................ 27

2.5.1 Global UXO policies and institutions............................. 27

2.5.2 Lao UXO policies and institutions................................. 29 
2.5.3 Interesting cases of UXO policies and institutions from around the 30 world......

2.5.3.1 Case of Cambodia........................................... 31

2.5.3.2 Case of Mozambique....................................... 33

$2.6 \quad$ Conclusion..................................................... 35

Chapter Three: Research methodology ............................... 37

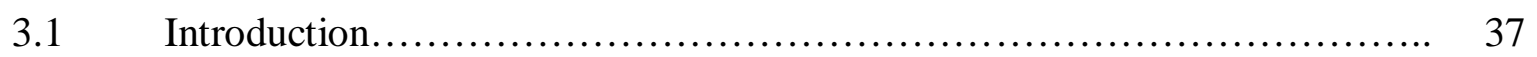

$3.2 \quad$ Research epistemology ......................................... 37

Research design................................................ 38

3.3.1 Qualitative methods............................................ 38

3.3.2 Individual semi-structured interviews............................... 39

3.3.3 Sampling and research participants selection......................... 40

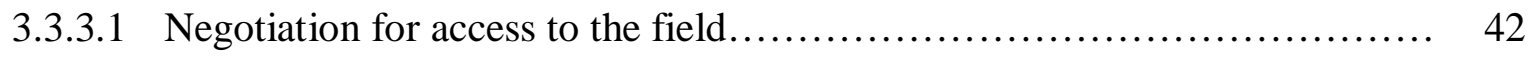

3.4 Data analysis and writing process................................. 43

Ethical considerations......................................... 44

$3.6 \quad$ Positionality..................................................... 45

$3.7 \quad$ Conclusion.......................................................... 46

Chapter Four: Relationship between structures, processes and people livelihood 47

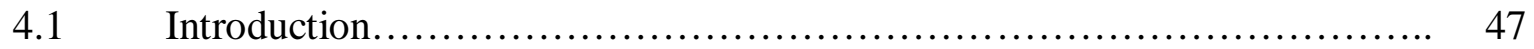

4.2 Structures and processes of UXO/mine action program in Laos............ 47

4.2.1 The interrelatedness between UXO clearance strategies and the livelihood of 49 people in Xiengkhouang province....

4.3 Impact from strategies to UXO operators and livelihood................ 57

4.3.1 Impact from funding allocation in strategies......................... 57

4.3.1.1 Source of funding................................................ 57

4.3.1.2 Impact from funding allocation................................. 59

4.3.2 Impact from key terms in strategic plan............................ 67

4.3.2.1 Impact of the term "development" .............................. 67

4.3.2.2 Impact prioritizing land for clearance.............................. 70

$4.4 \quad$ Conclusion..................................................... 71 


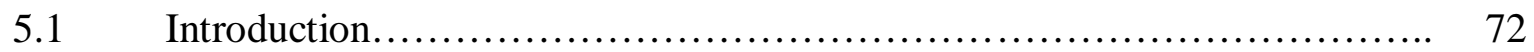

5.2 Village case studies, Xiengkhouang province............................ 72

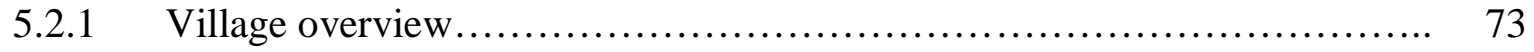

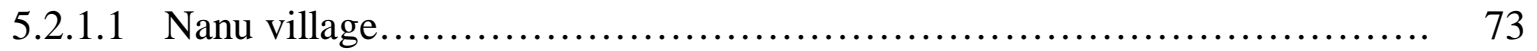

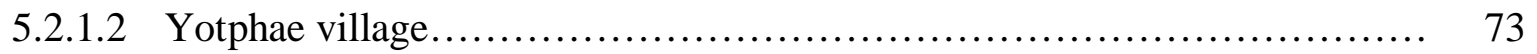

5.2.2 UXO impact on villages livelihoods.................................. 74

5.2.2.1 Key finding number 1: Fear caused by UXO leading to lower agricultural 74

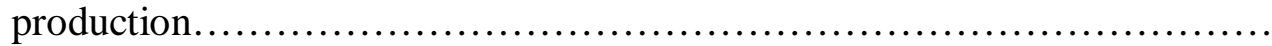

5.2.2.2 Key finding number 2: Loss of labour force............................. 76

5.2.2.3 Key finding number 3: Emotional and psychological impacts............... 77

5.2.2.4 Key finding number 4: Diminished child education....................... 78

5.2.2.5 Key finding number 5: Constraining national policies..................... 79

5.2.2.6 Key finding number 6: Limited potential full use of land 80

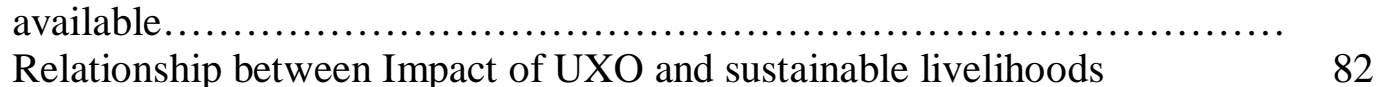

5.2.3 Relationship between Impact of UXO and sustainable livelihoods $\quad 82$

5.3 Coping strategies used to overcomes the issues.......................... 85

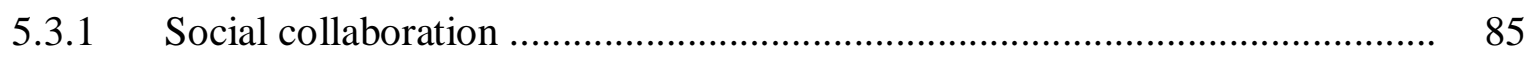

5.3.2 Productive diversification......................................... 86

5.3.3 Connection between coping strategies and sustainable livelihoods 90

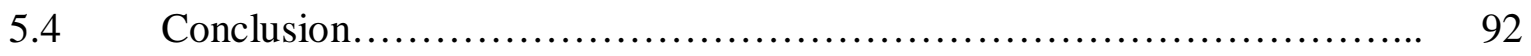

Chapter Six: Conclusions and recommendations ………….................................. 94

$6.1 \quad$ Introduction.............................................................. 94

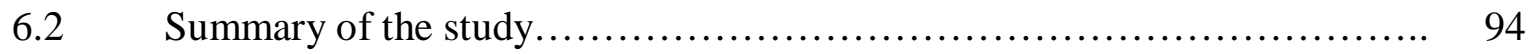

6.2.1 Research background................................................. 94

6.2.2 Important ideas and concerns from the literature review................... 95

6.2.3 Research methodology.............................................. 96

6.3 Main findings with regard to research questions........................ 97

6.3.1 What are the institutions and policies dealing with the impacts of UXO in 97 Laos and how do they play out in Xiengkhouang province?...................

6.3.2 What are the major difficulties rural community members face for their 98 livelihoods with UXO in terms of the agriculture sector and family labour? ..

6.3.3 How do rural communities cope with these difficulties?.................... 100 
6.4 Research limitations and further research possibilities.................. 101

$6.5 \quad$ Recommendations................................................. 102

6.5.1 Specific fund allocation into victim assistance........................ 102

6.5.2 Response to land clearance resulting from unspecifiedterm "development" 103

6.5.3 Community funding for communities in affected areas.................. 103

6.6 Conclusions......................................................... 103

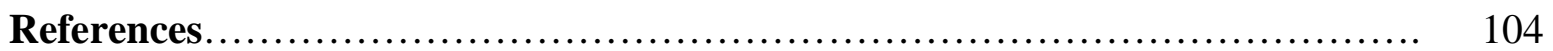

Appendix I: Information sheet (English) ............................... 112

Appendix II: Information sheet (Lao) .................................. 114

Appendix III: Informed consent form (English) ............................ 116

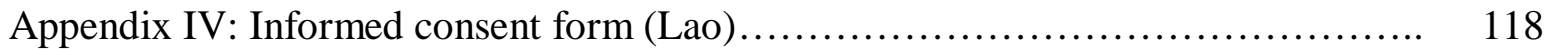

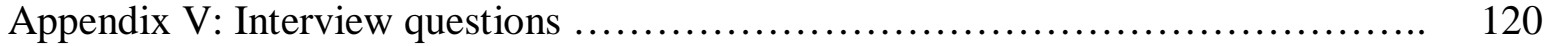




\section{LIST OF FIGURES}

Figure 1.1 Activities causing UXO related to accidents ................... 5

Figure 1.2 Place where UXO accidents............................ 5

Figure $1.3 \quad$ Laos in the world map....................................... 6

Figure $1.4 \quad$ Research location map..................................... 8

Figure 2.1 Sustainable livelihoods framework........................... 18

Figure 2.2 Map of areas affected by UXO........................... 25

Figure 4.1 UXO Structures (institutions) and Processes (policies/strategies) in 48 the Sustainable Livelihood Framework.......................

Figure 5.1 Potential of rice production with assumption that land without $\quad 81$

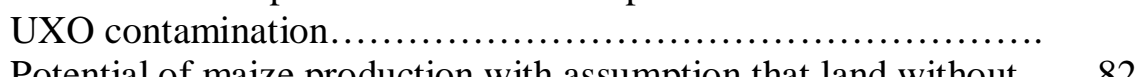

Figure 5.2 Potential of maize production with assumption that land without 82 UXO contamination

Figure 5.3 Connection between UXO impact in the villages and sustainable livelihood framework.

Figure 5.4 Connection between coping strategies in the villages and 91 sustainable livelihood framework

\section{LIST OF TABLES}

Table 2.1 Countries with the most landmines in the world................ 23

Table 4.1 Major donors for UXO and mine action sector in Laos ............ 58

Table $4.2 \quad$ Majors donors of COPE..................................... 61 


\section{ACRONYMS}

$\begin{array}{ll}\text { Aus AID } & \text { Australian Agency for International Development } \\ \text { CCM } & \text { Convention on Cluster Munitions } \\ \text { CMAA } & \text { Cambodian Mine Action and Victim Assistance Authority } \\ \text { CMAC } & \text { Cambodian Mine Action Centre } \\ \text { DFID } & \text { British Department for International Development } \\ \text { GDP } & \text { Gross Domestic products } \\ \text { GNI } & \text { Gross national income } \\ \text { IDS } & \text { Institute for Development Studies } \\ \text { MAC } & \text { Mine Action Centres } \\ \text { MBT } & \text { Mine Ban Treaty } \\ \text { MDGs } & \text { Millennium Development Goals } \\ \text { MDRs } & \text { Mine detection Rats } \\ \text { MRE } & \text { Mine Risk Education } \\ \text { MSA } & \text { Management Services Agreement } \\ \text { NGPES } & \text { National Growth and Poverty Eradication Strategy } \\ \text { NMAA } & \text { National Mine Action Authority } \\ \text { NRA } & \text { National Regulatory Authority for the UXO/Mine Action Sector } \\ \text { NSEDP } & \text { National Social Economic Development } \\ \text { QLA } & \text { Quality of Life Association Xiengkhouang } \\ \text { RCAF } & \text { Royal Cambodian Armed Forces } \\ \text { SLA } & \text { Sustainable Livelihoods approach } \\ \text { SLF } & \text { Sustainable Livelihood Framework } \\ \text { SPF } & \text { Safe Path Forward } \\ \text { UNDP } & \text { United Nations Development Programme } \\ \text { UNICEF } & \text { United Nations Children's Fund } \\ \text { UNMAS } & \text { United Nations Mine Action Service } \\ \text { UNOPS } & \text { United Nations Office for Project Services } \\ \text { UXO } & \text { Unexploded Ordnance } \\ \text { UXO Lao } & \text { National Unexploded Ordnance Programme } \\ \text { VTF } & \text { Voluntary Trust Fund for Assistance in Mine Action } \\ & \end{array}$




\section{Chapter One}

\section{Introduction}

\subsection{Introduction}

Development in Laos relies on the export of natural resources and international support in the form of aid. The most important of these resources are timber from forests, produce from agricultural lands, hydroelectric potential, and minerals. Together they can make a major contribution to the country's long-term economic development. For example, infrastructure to support mining, hydroelectricity power and timber production has been invested in by both the government and foreign companies, resulting in overseas exports. The forestry and agricultural sector has contributed to the majority of the population's livelihood within the country. The agricultural sector grew on average 4.1 percent in the 2010s, with a 50 percent share in the gross domestic products (GDP) (World Health Organisation (WHO), 2014). Over 80 percent of the total population are rural and engaged in the agricultural sector (Regional Office for Asia Pacific of FAO, 2013). Therefore, government and international support has focused on rural development. In this sense, improvement of rural people livelihoods would guarantee the nation's prosperity. The majority of development programs in rural areas are mainly focused on infrastructure to facilitate the businesses, as well as public places for local people such as schools, health care centres, roads, markets and tourist sites.

Boosting and supporting development programs in the agricultural and business sector can be challenging. One of the most pressing issues is the Unexploded Ordnance (UXO) contamination which is a consequence of the Second Indochina War between 1964 and 1974. UXO prevents access to potential farmable land andUXO restricts many aspects of community development and nation building. These activities need to progress and socio-economic developmentiseither suspended or delayed by UXO impact. It also can prolong and exacerbate the conditions of poverty due to its blockage for livelihood activity implementation which clearly contributes to food insecurity. These challenges caused by 
UXO render it difficult for communities to achieve a sustainable livelihood; andvillagers still take risks every day in cultivating in UXO contaminated land.

To date, the response to the UXO issue has focused on clearance, aiming to provide more farmable and secured land to people, and development projects. There is also mine risk education aiming to reduce the UXO accident rates and victim assistance which aims to support the UXO survivors for their living condition improvement. Unfortunately, slow progress of these tasks indicate that the impact of UXO is still ongoing without knowing the time frame of the clearance (Quang, 2010). This is important to realise for the intervention of programs or projects and to consider the associated impacts from UXO to support people's livelihood. Understanding how UXO's impact on local people's livelihoods is significantly important for any intervention activities. In this sense, in order to understand the impact of UXO, information about the difficulties that local people face and how they cope with these difficulties is essential. In the light of this, this research will explore the impact of UXO about a specific location, Xiengkhouang province, Laos, to provide information in this field.

\subsection{Problem statement for this research project}

Landmines and other Explosive Remnants of War (ERWs) are considered among the most serious obstacles for both war and post-war societies. They have hindered the sustainable development of societies in many countries across the world (Mishra, 2011). Unexploded Ordnance (UXO) is one type of explosive remnant of war (ERW) that fails to operate and it refers to a wide range of explosive weapons in many different conditions: artillery shells, grenades, mortars, rockets and air dropped bombs as well as explosive submunitions that form the contents of cluster munitions, either air-dropped or delivered from land-based systems (Moyes, Lloyd, McGrath, \& Action, 2002). The contamination of Unexploded Ordnance (UXO) presents a wide range of impact in almost all post-conflict environments which threaten civilian communities and holds back reconstruction. This can instil fear, and seriously challenge the livelihood of many post-conflict communities and how they interact with their environment. Globally, there is a vast amount of deaths and 
injuries from UXO. Determination of accurate numbers of deaths and injuries is hard to obtain both globally and locally.

In Laos, the majority of UXO are cluster munitions (known as bombies by the local people), is a big challenge and hinders development projects and local communities' livelihoods(EU, 2011). UXO resulted from the Second Indochinese War between 1964 and 1973. The war began with the USA when they violated the 1954 Geneva Convention on war to protect civilians and the 1962 Geneva Agreements that prohibited the presence of foreign military personnel or advisors in neutral Laos. The bombing mission was undertaken by United States (US) military because they were countering the illegal presence of North Vietnamese troops in Laos (Khamvongsa \& Russell, 2009; Shoemaker, 1994). North-eastern and southern provinces were targeted bombing areas.

In the north eastern part, the US military mission was to prevent the use of territory, particularly the Plain of Jars, by the communist Pathet Lao Forces and North Vietnamese forces as combat base. In the southern part, the mission intended to block Vietnamese supply lines, known as the Ho Chi Minh Trail which crossed the border in the east of Laos (Khamvongsa \& Russell, 2009; Shoemaker, 1994). During the war, it is estimated that around two million tons of ordnance was dropped on the Lao territory. An estimated 30 per cent of this ordnance did not detonate, which makes Lao PDR the most heavily bombed nation per capita on earth, around one ton per person (NRA, 2010). Since the end of the war until 2008, approximately 12,000 UXO-related accidents occurred. It was only just from 1999 to 2012, the figures shown that 934 casualties which was divided into 655 injuries and 279 deaths. Interestingly, more than 50 percent of the victims are children and more than 81 percent are male (UXOLAO, 2013)Every year, there are still around 100 victims injured or killed by UXO accidents in Laos (EU, 2011; Reporters, 2013).

At international level, Lao PDR became the first of the Asian countries to sign and ratify an international treaty, known as the Convention on Cluster Munitions (CCM). This was to address the humanitarian consequences and unacceptable harm to civilians caused 
by cluster munitions, through a categorical prohibition and a framework for action. The Convention aims to prohibit all use, production, transfer and stockpiling of cluster munitions. In addition, it establishes a framework for cooperation and assistance to ensure adequate care and rehabilitation to survivors and their communities, clearance of contaminated areas, risk reduction education and destruction of stockpiles. In a parallel action with the international treaty, the Lao Government announced National Millennium Development Goal 9 (MDG 9) at the first States Party meeting for the Convention on Cluster Munitions in November 2010 in Vientiane. This MDG is a specific goal addressing the UXO issue which aims to reduce the impact of UXO in accordance with the National Strategic Plan for the UXO sector called “The Safe Path Forward II" from 2011-2020 (Durham, 2012). The MDG9 and SPF II target an increase in effort and support in order to meet CCM obligations stating that "each State Party undertakes to clear and destroy, or ensure the clearance and destruction of cluster munitions remnants located in contaminated areas not later than ten years after the entry into force of the Convention" (Landmine Action, 2002).

Once, a large area of the country was affected by UXO, it affected people's livelihoods improvement and prevented community development activities even during post conflict times. Interestingly, UXO impact has been involved in a large area and diverse activities (see figure 1.1 and 1.2). Looking closely at these statistics, the kinds of places and activities are related to the daily life of local communities where the agricultural sector plays an important role in their livelihood improvement. 


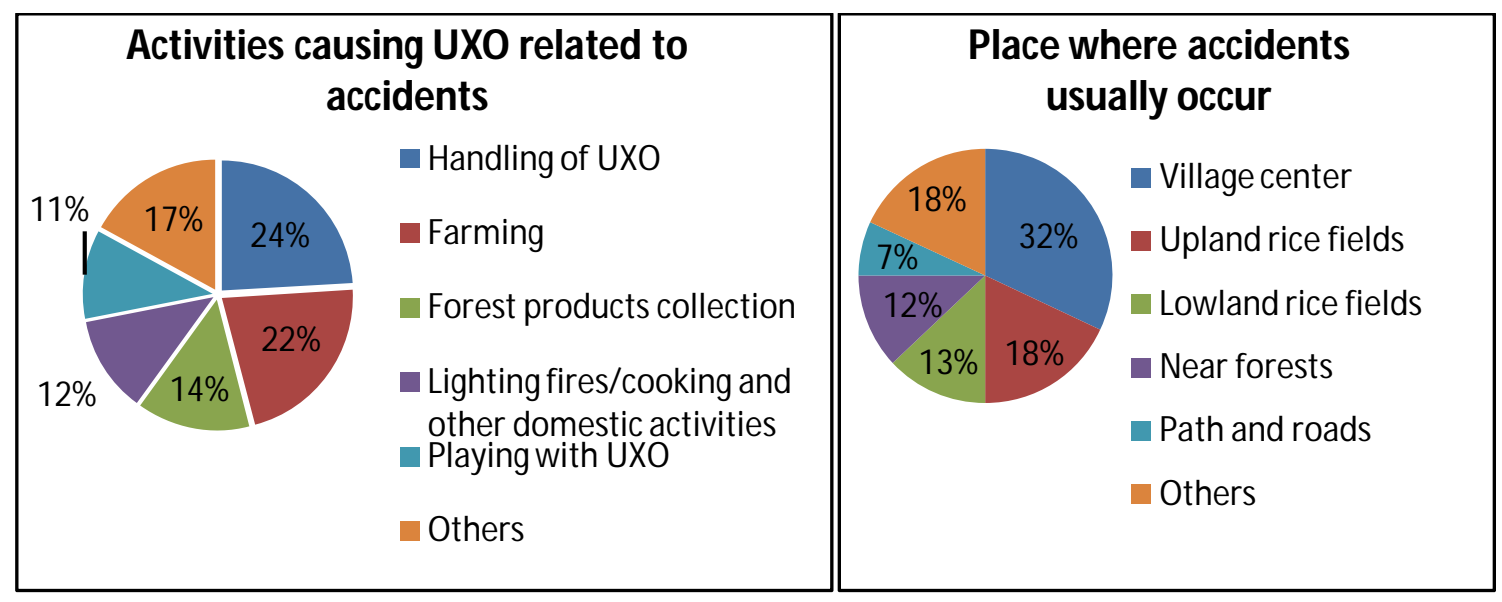

Source: Adapted fromhttp://uxolao.org/index.php/en/the-uxo-problem/uxo-victims

This research project aims to explore the impact of UXO on rural communities' livelihoods in terms of impacts on agriculture and family labour in particular. The research will also focus on the strategies they adopt to cope with these impacts. The project is based in Xiengkhuang province, Lao PDR, which has been one of the most heavily bombed provinces in the nation (Burchett, 1970; Mishra, 2011). Additionally, for this research, I have identified people affected by UXO as those people who have been killed or suffered physical or psychological injury, economic loss, social marginalisation or substantial impairment of the realisation of their rights caused by an accident with UXO. They include those persons directly impacted by an accident with UXO as well as their affected families and communities (UXO Lao, 2010).

In this research, I have applied a qualitative research approach by using individual semi-structured interviews. In addition, I applied sustainable livelihood concepts including sustainable livelihoods principles and sustainable livelihoods framework as tool for data analysing and scoping this research (Frameworks, 2001).

\subsection{A brief geography of Laos}

Lao People's Democratic Republic (Lao PDR) is land-locked and a less developed country (LDC) in Southeast Asia (see figure 1.3 for location). Laos has the surface of 
236,800 square $\mathrm{km}$ with a population of 6,646,000 (World Health Organisation (WHO) 2012), the average population density is 18 persons per square $\mathrm{km}$, and GNI per capita is around USD 1,130 (World Bank, 2011). Laos shares borders with Cambodia to the south, and China to the north, Myanmar and Thailand to the west and Vietnam to the east (see figure 1.3) (Regional Office for Asia Pacific of FAO, 2013). Laos has one of the fastest growing economies in the region, with an average growth of 7.8 percent since a decade, with the main exports products of clothing, timber products, coffee, gold, copper and electricity (Regional Office for Asia Pacific of FAO, 2013). Even though the economic growth is fast comparing to other countries in South East Asia, the scale of economic growth is still small and affected by constraint conditions such as the UXO contamination across the country. For this reason, the livelihood and infrastructure improvement such as health care service and education are challenging for the government. Inefficient access to and quality of health services spread across the country, which make the life expectancy of people still low, as 64 years for male and 67 years for female (WHO, 2012).

\section{Figure 1.3: Laos in the world map}

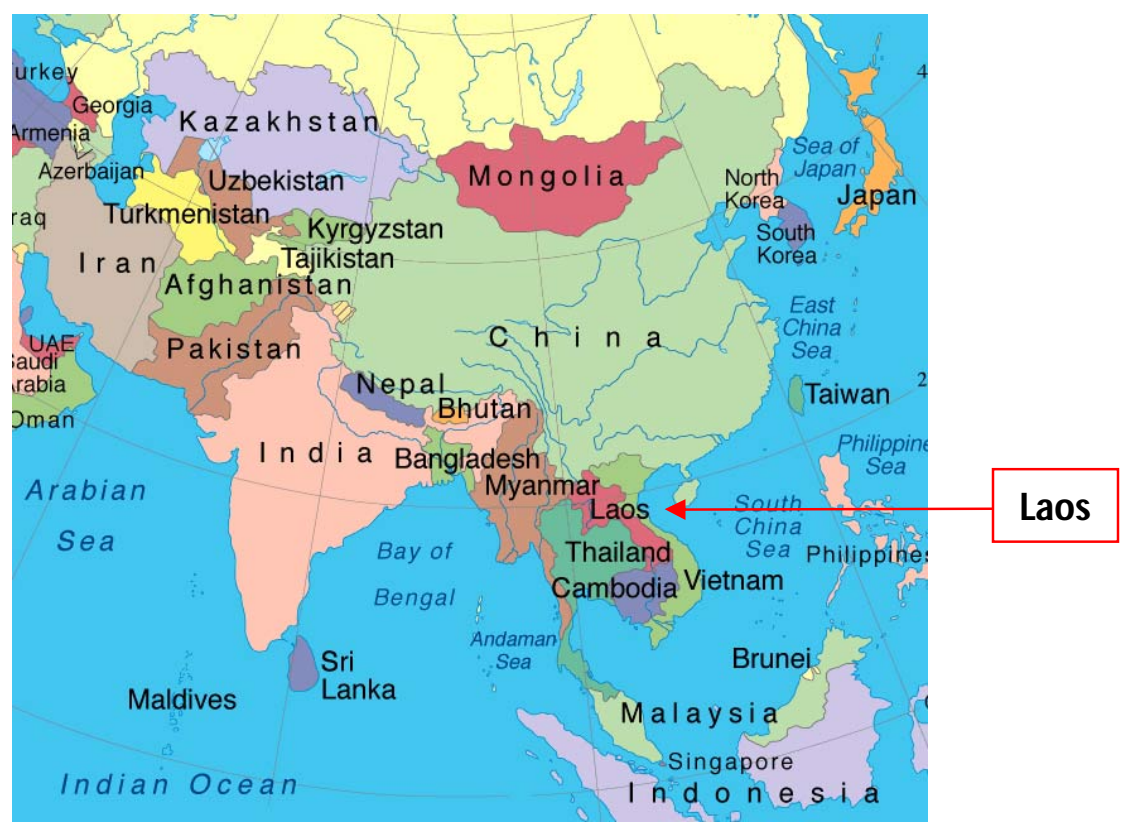

Source:http://www.archaeology.lk/http://www.archaeology.lk/wp-content/uploads/2010/09/asia-map.jpg 


\subsection{Research location}

The field research is conducted Xiengkhouang province in Laos, with two village case studies from two different districts, Phoukoud and Paek districts .Xiengkhouang province is located in the northern part of Laos which is $400 \mathrm{~km}$ north-east of Vientiane Capital sharing borders with Vietnam to the east, Bolikhamxay and Vientiane provinces to its south, Luang Phrabang province to its north-west and Houaphanh province to the north (see figure 1.4) (Sibylle \& Julie, 2009). The province composes eight districts Paek, Phaxay, PhokKoud, Kham, NongHet, Khoun, Thathom and Mokmai. With the population 240,000 (2005) spread over the area of 15,880 squares km (Sibylle \& Julie, 2009). Characteristics of the landscape are high green mountains, rugged karsts formations and verdant valleys with plenty of rivers, caves and waterfalls. The valley bottoms and plateau areas are usually converted into paddy fields, and cattle and buffalo roam freely. Upper slope areas and mountain ridges are used for upland farming in a rotation of swidden and fallows. The temperate highlands are dominated by extensive pine forests; oaks and chestnuts are the dominant tree species in moist evergreen and dry evergreen forests. In Xiengkouang the most important crops are rice and maize alongside cash crops such as cassava and peanuts, and animal husbandry is a significant contributor to rural household income (Madhavi, 2008).

UXO history has occurred for a long time in Xiengkhoaung province. During the Second Indochina War that raged in Laos during the 1960's and early 1970's Xiengkhoung suffered heavy aerial bombardment and intense ground battles due to its strategic importance. Xiengkhouang was used as a base by the communist Pathet Lao Forces and the North Vietnamese forces to fight back against US military. Currently, as the results of the war, around 30-50 UXO accidents in Xiengkhouang people are killed and injured in UXO accidents, it made up 12 percent of total UXO accident across the nation per year. UXO presence also prevents safe access to agricultural land. Extra resources for clearance are also required before development can take place (Reporters, 2013). With an estimated 300,000 tons of explosives dropped in this province, it makes up around two tons per 
person (Madhavi, 2008).Despite the high rate of accidents, and because of a high potential of economic value, in the agricultural sector especially, people have continued their daily lives in affected areas for more than three decades. These kinds of reasons make it interesting to explore what difficulties people faced and how people adapt to the situations.

Figure1.4: Research location map

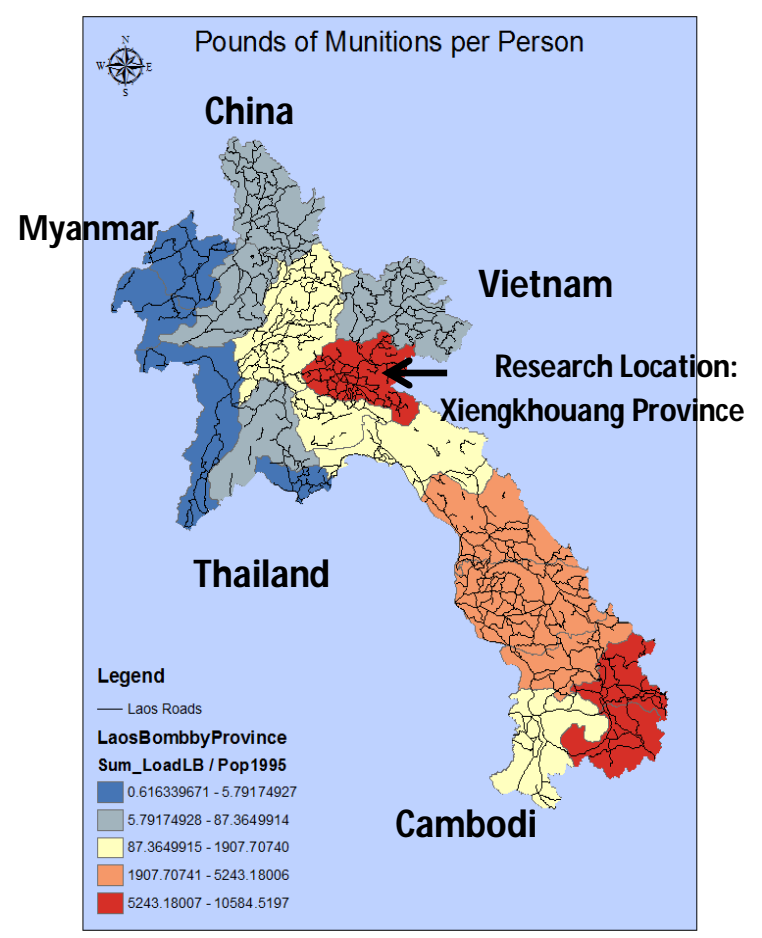

Source:http://pslarson2.files.wordpress.com/2010/12/laospoundspop.png 


\subsection{Theoretical framework}

This study applies sustainable livelihoods (SL) which a way of thinking about the objectives, scope and priorities for development in order to enhance progress in poverty elimination (Johnson \& Christensen, 2008. p1). In the SL concept, there are two main components: the Sustainable livelihood framework (SLF) and the sustainable livelihoods approach (SLA). Sustainable livelihood framework (SLF) is a tool for development work to analyse the complexity of the issues and describe the major factors affecting the livelihoods of vulnerable people (Petersen, 2010). The Sustainable Livelihoods Approach (SLA) is a tool in order to help the understanding and analysis of the livelihoods of impoverished people, in order to enhance the effectiveness of livelihoods-related development assistance (Ashley, Carney, \& Britain, 1999b). The essential idea of SLA is putting the thinking around people rather than the technical inputs of development, and this might provide an opportunity to the affected people to improve their living conditions situation (Krantz, 2001). In sustainable livelihoods concept, SLF has a strong connection to support SLA. In this sense, the understanding of the poverty issue analysed by the framework will be a valuable input for intervention action designed by SLA.

I apply the sustainable livelihoods frame work to identify the impacts of UXO and to allow for a better analysis of the links within the framework. Three main components: livelihoods' assets, structures and processes and livelihoods' strategies are used in this study. In the frame work, UXO is defined as any vulnerable context as entry point for the framework, and then I link this to the three main components that I selected for the research.

\subsection{Purpose of Study}

This research project aimed to track and trace the problems occurring from the impact of UXO on rural communities' livelihoods in terms of the impacts on agriculture and family labour in particular and the strategies used to cope with these impacts. The 
research investigates two case studies in different villages in the Xiengkhouang province. The interviews were conducted with a variety of participants including villagers and staff from relevant organisations both in provincial level and national level. Data collected from the field was analysed through the sustainable livelihoods framework as lens to respond the research questions. I believe that the research bring better understanding of UXO impacts on community livelihood. A better understanding of the impact of UXO is essential to finding suitable intervention programmes or assistance in responding to the challenges that communities faced and to strengthen their coping strategies.

\subsection{Research Questions}

With the purposes stated above in mind, the research questions for this project are:

- What are the institutions and policies dealing with the impacts of UXO in Laos and how do they play out in Xiengkhouang province?

- What are the major difficulties rural community members face for their livelihoods with UXO in terms of the agriculture sector and family labour?

- How do rural communities cope with these difficulties?

- How are national policies around UXO addressing these difficulties and strengthening coping mechanisms?

\subsection{Thesis structure}

This thesis is divided into six chapters.

The Introduction chapter presents an introduction to the issues under examination and the geographical context of the specific research location. The chapter describes the research questions, objectives of study and thesis structure.

In the literature chapter reviews the relevant documents to UXO issues at a global, regional and national level. Additionally, the chapter also describes the existing research, and other research projects that have been conducted in the country and other places. 
In the following chapter, on my chosen research methodology I discuss the research methodology and research methods used in this thesis. The chapter also presents the context of research epistemology as social critical constructivism and qualitative research theory. Research design including the type of research, research framework (sustainable livelihoods approach) and data collection is included. For the data collection section, I outline a semi-structured interview that is applied for gathering primary data from the participants in this study Additionally, it includes how samples were selected and snowball techniques used. Connected to data analysis, I present a technique and tool for data analysis which are Software and coding. Finally, ethical issues and my research positionality are considered as a part of the chapter.

In the fourth chapter, I discuss findings from the fieldwork informed by the interviews of organisations in Vientiane and Xiengkhoaung province. I applied sustainable livelihoods framework to analyse perspectives from those interviewed are to look at the links between UXO as vulnerable context and processes and structures in that framework. This aims to respond the research question: what are the institutions and policies dealing with the impacts of UXO in Laos and how do they play out in Xiengkhouang province?. This chapter also synthesizes the qualitative findings and the literature review in order to address the two research questions which are: what are the major difficulties rural community members face for their livelihoods with UXO in terms of the agriculture sector and family labour, and how do people cope with those difficulties? In the sustainable livelihood framework, the chapter focuses on two main components which are household assets and livelihood strategies. Through this lens, the chapter details the difficulties people faced on their livelihood by UXO and the strategies used to cope with these difficulties. The chapter focuses closely on the two village case studies from two different districts in Xiengkhouang province, Yotphae and Nanu villages.

The final concluding chapter explains how the three main research questions have been answered. The chapter is a connection between chapters four and five. After that, I reflect on the implication of the development context by bringing the connections from the 
introduction chapter. At the end of the chapter, the recommendations drawn from literature and perspectives of informants from the fieldwork are included to answer the fourth research question: How are national policies around UXO addressing these difficulties and strengthening coping mechanisms?

\subsection{Conclusion}

This chapter has presented the links of impacts of UXO to rural communities' livelihoods. The chapter found that development is challenged by UXO in a way that it limits access to natural resources, farmable land in particular. The impact of UXO also suspends and delays development projects. Importantly, farming and development projects are major keys in development contribution both for national economic development and livelihoods of rural people. UXO limits access to agricultural land and this directly affects the national economy and also rural people's livelihoods. Xiengkhouang province as research location has strong links with the UXO issue as it was a heavily bombed province in the country. The province also has high agricultural potential, which is currently thwarted by UXO. The place and activities associated with UXO accidents are strongly connected with daily routine of local people. In this sense, people take risks every day for conducting daily activities such as farming to improve their living conditions. Exploring more detail in particular villages in Xiengkhouang province helps to understand the impacts of UXO on people's livelihood. 


\section{Chapter Two}

\section{Literature review}

\subsection{Introduction}

This chapter outlines the sustainable livelihood concept which includes the sustainable livelihood approach and framework. Furthermore, the chapter presents the impacts of UXO, structures, policies and institutions at a global scale and in Laos. For the international level, important statistics of injured and killed people are given and important conventions on UXO and mine action is detailed. This chapter introduces interesting case of UXO policies and institutions from different countries. Cambodia and Mozambique are two examples discussed showing the differences from and similarities to UXO management in Laos.

\subsection{Theoretical framework}

The theoretical framework applied in this research is The sustainable livelihoods concept. The concept is defined as is a way of thinking about the objectives, scope and priorities for development in order to enhance progress in poverty elimination (Johnson \& Christensen, 2008. p1). The sustainable livelihood approach (SLA) provides a comprehensive overview within which the complexities of living and surviving in poor communities can be assembled in such a manner as to contextualise relationships rather than just list data as measures of income, consumption and employment (Brocklesby \& Fisher, 2003). SLA can be applied with sustainable livelihood outcomes assessed at different levels such as from individual to household, to household clusters, to extended kin groupings, to villages, regions and so on (Lunsford \& Lunsford, 1995). Connected to this reason, it has been widely used in the development domain by various development agencies and organizations for several decades as a guideline for community poverty reduction.

In this study, I applied this approach because is a practical approach that fits with household livelihoods analysis of my particular case study. Together with sustainable livelihoods principles, the sustainable livelihoods approach I was able to focus on 
interesting aspects within the sustainable livelihood framework where it has been associated with UXO impact. The sustainable livelihood framework was applied as the conceptual framework to investigate the correlation between UXO impact on their livelihood and the livelihood strategies used by the inhabitants of a rural community in Xiengkhouang province in north east of Lao. Connected to the framework, UXO impact was taken into account as a vulnerable context happening after post conflict. Three main components of sustainable framework namely structures, livelihood assets and livelihood strategies were analysed through this framework lens. I applied the structures in the framework as they refer to organisations and strategies around the UXO sector. In the livelihood assets component, the framework was used for analysing how UXO shapes local people's assets such as land and labour on their livelihood tools. Similarly, the livelihood strategies component was utilised to analyse how local people in two case study villages, Nanu and Yotphae villages in Xiengkhouang province cope with their difficulties affected by UXO. The detail of outcomes of UXO impact on structures, livelihood assets and livelihood strategies analysed through the lens of sustainable livelihood framework will be presented in chapters four and five.

\subsection{Sustainable livelihood}

\subsubsection{The origination of sustainable livelihood}

The Sustainable livelihood (SL) approach is a systematic and adaptive approach that considers comprehensive aspects including poverty reduction, sustainability and empowerment processes such as gender empowerment and good governance. One of the ways to understand the SL system is to analyse the coping and adaptive strategies pursued by individuals and communities as a response to external shocks and stresses such as drought, civil conflicts and policy failure (Hoon, Singh, \& Wanmali, 1997). In order to be effective in achieving this aim it is necessary to develop both a clear understanding of what constitutes poverty and a practical implementation strategy for efforts to reduce it (Ashley et al., 1999b). These characteristics can be applied for wide range of development sites where the target is to understand the complexity of poverty and to seek appropriate 
interventions. Similarly, in mine affected areas where UXO impacts are causing poverty and development issues there are increased complexities. Bringing intervention programs requires a good understanding of the issues and good tools for analysing the issues. Based on these reasons, the SL concept was applied for this study. The Sustainable livelihood concept consists of two components: sustainable livelihood framework and sustainable livelihood approach. A framework is an analysis tool to help in understanding the complexities of poverty, while approach is a set of principles used as guiding action. This action is to address and overcome poverty in a way to improve understanding of the livelihoods of impoverished people and to draw on the main factors affecting these people's livelihoods and the typical relationships between these factors. Applying both, approach and framework, can help me to understand the complexity of difficulties issue affected by UXO and to understand the strategies used by affected people (Petersen, 2010).

Initial appearance of the sustainable livelihoods concept was presented in the Brundtland Commission report in 1987. This concept of sustainable livelihoods began with a focus on poverty elimination and low income (Brocklesby \& Fisher, 2003; Krantz, 2001). This narrow coverage of the idea led to policy makers, development practitioners and researchers to consider various factors including economic, ecological, social and healthcare aspects. In 1992, the UN Conference on Environment and Development developed the concept of sustainable livelihoods as a means of linking social economic and environmental issues (Brocklesby \& Fisher, 2003). In this sense, a livelihood in community is sustainable when it can cope and deal successfully with three main components of security of sustainable livelihoods which are security of ecology, efficient economy and equal society (Singh \& Hiremath, 2010). Security in ecology has a meaning of natural resources quality such as quality soil and water, forest preservation and air pollution. Efficiency of economy means a productivity of labour and marketable surplus. Equal society means land; assets and income are contributed equally among community members.

In 1992 a definition sustainable livelihood was proposed by Robert Chambers and Gordon Conway which would be acceptable to most people. They proposed a view that: "A livelihood comprises the capabilities, assets and activities required for securing a living; 
a livelihood is sustainable when it can cope with and recover from stress and shocks, maintain or enhance its capabilities and assets, and provide sustainable livelihood opportunities for the next generation; and also contributes benefits to other livelihoods at the local and global levels and in the short and long term" (Chambers \& Conway, 1992. p.6). This definition, more recently, has been applied by the Institute for Development Studies (IDS) and the British Department for International Development (DFID) (Krantz, 2001). In order to enhance the progress in poverty elimination, British Department for International Development (DFID) applied a meaning of sustainable livelihoods concept and its principles as a way of thinking about the objectives, scopes and priorities for development (Ashley, Carney, \& Britain, 1999a). Connected to this view, Ashley, Carney et al (1999a) emphasise sustainable livelihoods can assist the poor people to achieve lasting improvements against the indicators of poverty. In practical terms, sustainable livelihoods framework and sustainable livelihoods approach have to be applied together for effectiveness reason.

\subsubsection{Sustainable livelihood approaches}

The basic idea of SLA is putting the thinking around people rather than the technical inputs development, as this might provide an opportunity to the poor to improve poverty situation (Krantz, 2001). Practically, the sustainable livelihood approach helps to identify a variety of different options for supporting livelihoods for specific aspect rather than tackling all aspects of livelihoods (Carney, 1999). To support this view, a discussion of Ashley and Carney (1999a) in sustainable livelihoods work developed by the Institute of Development Studies show important principles associated with implementation of sustainable livelihood work which embraces a responsive and participatory methodology. The suggestion in this work is that in impoverished people themselves play an important role in identifying and addressing livelihood priorities. Ashley et al (1999b) also emphasise the need for outsiders to adopt a mode of engagement that enables them to listen and respond to the poor. In the work of DFID on sustainable livelihoods, the sustainable 
livelihood approach empowers the poor by seeing them not as victims, but as decisionmakers with their own sets of priorities.

The SLA essentially comprises six core principles and a conceptual framework. They are people centred, holistic, dynamic, building on strengths, macro-micro linkages and sustainability. People centre focuses on people's livelihood assets, how they change over time, and the specific vulnerabilities they face. Holistic refers to recognition that different factors and processes influencing the livelihood opportunities and choices of people, and that people have multiple livelihood strategies to achieve multiple livelihood outcomes. Dynamic principle is recognition of rapid change in poor people's livelihood strategies. Building on strengths focuses on an analysis of strengths rather than needs. Macro-micro linkages are a consideration of linking between the two levels to inform more supportive policies and institutions. Finally, sustainability takes into account a variety of economic, social, political, and ecological factors that impact a person's ability to sustain a livelihood. In practice, application of the sustainable livelihoods approach is flexible in different place to place depending on location situation, complexities of poverty, level of skills or knowledge, situation of access to education, sources of credit, and networks of social support and so on.

In this research, the sustainable livelihood approach helped me to understand and to analyse the assets that people have and their lack, the impact of external factors both positive and negative on their daily life, and how UXO affects communities' livelihoods in a holistic and systematic way. It also highlights the need to talk to people at community help to understand the basic need from them which would lead to intervention to improve their life and their coping strategies.

\subsubsection{The Sustainable livelihood framework tool}

Sustainable livelihood framework (SLF) is a tool for development work which focuses on how to understand, analyse and describe the main factors that affect the livelihoods of the poor people (Petersen, 2010). In sustainable livelihoods concept, SLF has strong connection to support SLA. In this sense, the understanding of the poverty issue 
analysed by the framework will be an input for intervention action designed by SLA. SFL can be used for planning new activities in development programs and for evaluating impact factors to sustainability of the livelihood in existing activities in development programs. There are various models of the sustainable livelihood framework developed by different development agencies focusing on different components, but all originate from the same principles. The Sustainable livelihood framework developed by DFID (UK) is the most widely recognised and popular. Figure 2.1 is DFID's sustainable livelihood framework which shows the core components of livelihood and its influencing factors. The framework has been flexibly designed, so the focus can be on any component of the framework by keeping the wider picture in view.

Figure 2.1: Sustainable livelihoods framework

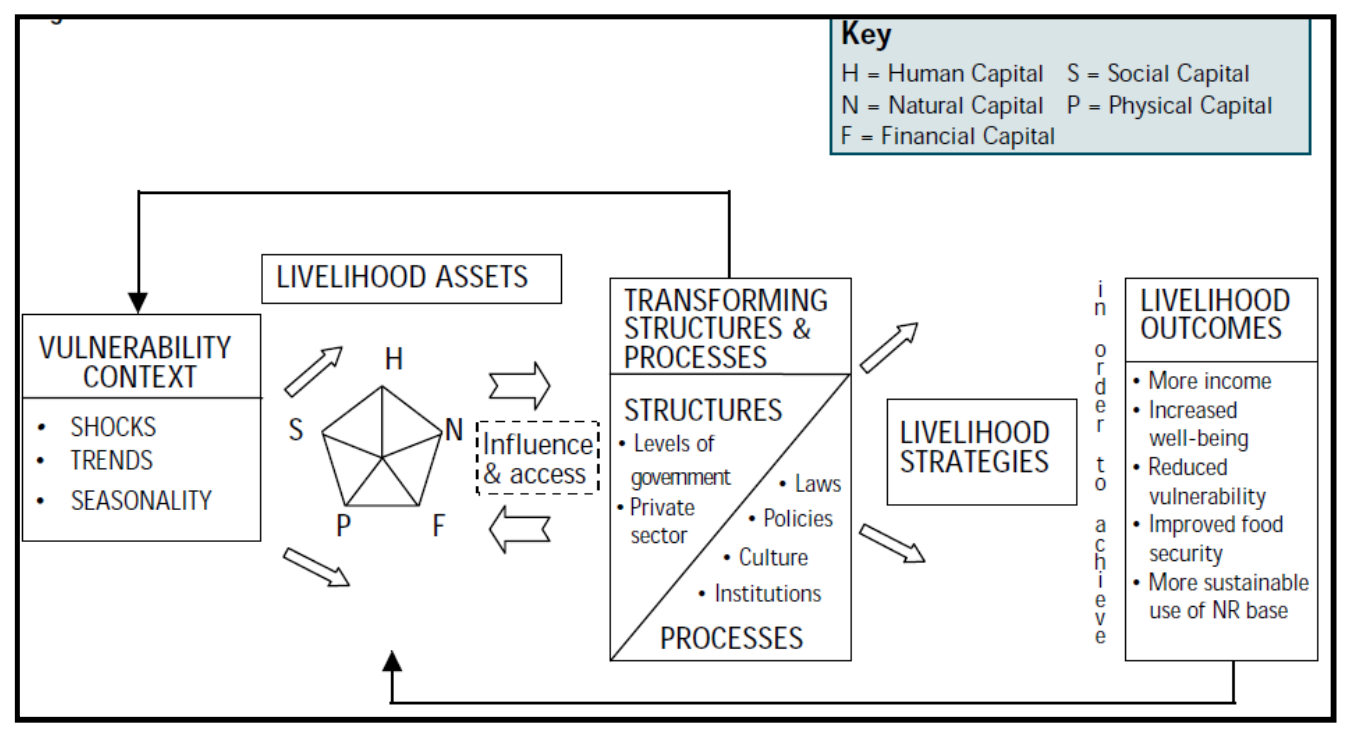

Source: Ashley et al. (1999a)

In the first box on the left, the vulnerability context represents the external environment and factors people live with. The vulnerability context comprises three main components: trends, shocks and seasonality. These components are critical factors and directly affect people's livelihood's assets. Trends include population trends, resource trends, national or international economic trends, trends in governance and technological trends. Shocks can be classified as human health shocks, natural shocks, economic shocks, 
and conflict, crop or livestock health shocks. In some cases, the shocks, such as floods, storm or civil conflict, may force people to leave their living place and land. Supporting this view Walsh and Walsh (2003) stated that post-war refugees are unable to return home because their land has been mined, and many of these people become permanent refugees. The final component is seasonality, concerning price, production, health and employment opportunities. Seasonality mainly links to economics in rural areas and is associated with poor people in urban areas (Carney, 1999).

The second box is livelihood assets which are the core of the livelihoods framework. In poverty elimination strategies, understanding of people's livelihood assets allows them to create appropriate coping strategies. Assets have also an interrelationship with transforming structures and processes through the influence of institutions and policies on access to the assets. However, different assets can create different outcomes varying on each case. Assets are classified as five cores or types of capital: human, natural, social, physical and financial capital (Carney, 1999).

Human capital refers to the skills, knowledge, ability, labour and good health of the people. Gaining of human capital can be in various ways such as educational sessions, schooling, access to medical services (Hoon et al., 1997). Social capital refers to the social resources that can be gain from networks and connectedness including both vertical and horizontal; membership of more formalised groups; and relationships of trust, reciprocity and exchanges. The third capital in livelihood assets is natural capital; it refers to natural resource available and services such as land, forests, water, air quality, erosion protection, storm protection. In the sustainable livelihood framework, the natural capital closely links to the vulnerability context. In some cases, many shocks that challenge the livelihoods of the poor are themselves natural processes destroying natural capital, for instance, wildfires destroy forests, floods and earthquakes destroy agricultural land (DFID, 1999).

Physical capital comprises basic infrastructure, tools, and equipment used for increasing productivity. Financial capital refers to the financial resources used for reaching 
the livelihood objectives of people. There are two main sources of financial capital, general labour-based income and available stocks. Available stocks refers to savings, regular inflows of money such as pensions, or other transfers from the state, and remittances (Carney, 1999).

The last three components of sustainable livelihood framework are the transforming structures and processes, livelihood strategies and livelihood outcomes. Firstly, the structures within the livelihoods framework refers to institutions, organisations organizations that establish and enforce legislation, provide the necessary requirements for acquiring and capitalizing upon assets, manage natural resources, and provide other services crucial for gaining access to assets, exchanging them, and benefiting from their use. Secondly, the processes are to determine the interactions between the structures and individuals such as policies, legislation, power relations, norms, market stability, and general rule of law (Kollmair \& Gamper, 2002). This operates at all levels, from the household to the international arena, and in all spheres, from the most private to the most public.

Secondly, the livelihoods strategies are activities that seek to support choice, opportunity and diversity. In practical terms, this means focusing on conditions that provide the widest diversity of choice and flexibility to maintain a livelihood. Specific choice and flexibility is applied for each individual household as each household is different. Some households have the capacity to successfully adapt and diversify their livelihood strategies, for instance through diversification of agricultural production, or through adopting a production system that can better maintain productivity or through seasonal migration. Others move out of an area in search for a better living in urban centres. Many remain where they are and struggle on a daily basis to make a living (Hagmann, Chuma, Murwira, $\&$ Connolly, 1999). In this sense, it requires to provide more access to capital assets and strengthen institutions and policies shaping livelihoods. 
The final box from the sustainable livelihood framework diagram is outcomes of livelihood. Basically, outcomes of livelihood denote the output of livelihood strategies. It could be a form of more income, increased well-being such as non-material goods, health status; reduced vulnerability; improved food security such as an increase in financial capital in order to buy food; and a more sustainable use of natural resources (Carney, 1999).

In this research the sustainable livelihoods framework developed by DFID is applied to explore the complexity of UXO impact on rural local communities' livelihoods in Xiengkhouang province in such a way that the UXO issue is considered as the vulnerable context as entry point in SLF. After that, three main components: transforming structures and processes, livelihood assets and livelihood strategies are utilized to analyse the impact of UXO in the communities. Results of the fieldwork analysed through the sustainable livelihood framework will be presented in detail in chapters four and five.

\subsection{Vulnerability after conflict}

In sustainable livelihoods framework, the vulnerability context often refers to trends, shocks and seasonality; these components are critical factors and directly affect people's livelihood's assets (Ellis, 2000). However, in the broad sense of vulnerability, it represents the physical, economic, political or social susceptibility or predisposition of a community to damage, often in the case a destabilizing phenomenon of natural or anthropogenic origin (Cardona, 2003 .p1). This makes livelihood activities extremely fragile for certain social group. Connected to mine/UXO affected areas, the vulnerability context may refer to its impact in a way that it hinders the local community to access their agricultural land, water source and forests. This has a wide range of economic impact at the national level, community or even household level. In Xiengkhouang province, the vulnerability context is in a form of the UXO impact which resulted from an anthropogenic phenomenon during the Second Indochina War, and it still has an impact on people .

The outcomes of the war have blocked people's access to their land, limited choice of income generation, and placed people in danger for physical impact caused by UXO accidents. UXO can also prolong and exacerbate the conditions of poverty. Based on the 
vulnerable context as the impacts of UXO as entry point in the sustainable livelihoods framework, this study aims to explore its impacts in three particular components: transforming structures and processes, livelihoods assets and livelihoods strategies. In transforming structures and processes component, the research seeks to understand what policies and institutions are doing in dealing with the impacts. For livelihood assets, the research aims to explore UXO impacts on villages' livelihoods, and final component: livelihood strategies, the research aims to understand the communities' strategies adopted to cope with difficulties.

\subsubsection{UXO impacts globally}

Conflicts have brought into use many types of explosive weapons, and many have remained in the conflict areas even though the dispute has long since ended. Unexploded ordnance and mines are one of the explosive remnants of war that have threaten people's lives in more than 80 countries around the globe (Benini, Moulton, \& Conley, 2002). Since 1960, an estimated approximately 110 million mines have remained unexploded(Walsh \& Walsh, 2003). These mines have caused many deaths and accidents which have significantly affected people's livelihoods. There are approximately 26000 people maimed or killed annually (WHO, 2000 p.4), and approximately 80 per cent of these casualties are civilians including children, women and elderly people (Walsh \& Walsh, 2003). For every 5000 mines cleared, one death and two injuries of demining workers are involved (Walsh \& Walsh, 2003). From table 2.1 it can be seen that a large number of de-miners would be killed or maimed in order to make land mine free world. 
Table 2.1: Countries with the most landmines in the world

\begin{tabular}{|l|l|l|}
\hline Country & Estimated in millions (no. of landmines) & Remark \\
\hline Egypt & 23 & \\
\hline Iran & 11 & \\
\hline Iraq & 10 & \\
\hline China & 10 & \\
\hline Angola & 10 & \\
\hline Afghanistan & 10 & \\
\hline Cambodia & 7 & \\
\hline Bosnia & 6 & \\
\hline Kuwait & 5 & Number of munitions \\
\hline Mozambique & 3 & \\
\hline Laos & 80 & \\
\hline
\end{tabular}

Source: Adapted from Walsh and Walsh (2003)

Clearing mines is quite expensive, and clearing one mine needs approximately 300 1000 USD (Walsh \& Walsh, 2003). From table 2.1, for Mozambique, the least mineaffected country, it would cost 900 million to Three billion USD to de-mine. This is around 20 percent of GDP of the country in 2012(WorldBank, 2012). The impacts of UXO and mines make these countries very concerned. The pervasive contamination of agricultural land is the main factor which limits national social and economic development and hinders poverty eradication in many communities in affected countries (Moyes et al., 2002). Limitation to secured land means limitation of access to land available for growing crops and herding livestock which is the main source of food. The work of Walsh and Walsh (2003) cited from Andersson, Palha da Sousa, and Paredes (1995) suggested that without mines, agricultural production could be increased by 88-200 percent, 11 percent, 13.5 percent, 3-6 percent in Afghanistan, Bosnia, Cambodia and Mozambique respectively.

At the individual level, mines and UXO affect people in psychological aspect as well as physical. People become scared to use the land for daily activities such as collecting food and fire wood from forests. Physically, mine or UXO can cause any or all of the following: multiple fragmentation wounds, amputation of one or more extremities, and loss of senses including vision, hearing and touch if people come into contact with them and they explode. Even after surviving initial injury, people might be faced with a loss of sense 
function, body disfiguration, chronic pain caused by the injury or the amputation and posttraumatic stress disorder (Walsh \& Walsh, 2003).

\subsubsection{UXO impacts in Laos}

Laos was a part of the Second Indo-Chinese War between 1964 and 1973. The war started from violation of the 1954 Geneva Convention on war to protect civilians and 1962 Geneva Agreements that prohibited the presence of foreign military personnel or advisors in neutral Laos. The bombing mission was undertaken by United States military with justification of countering of the illegal presence of North Vietnamese troops in Laos (Khamvongsa \& Russell, 2009; Shoemaker, 1994). The bombing focused on north-eastern and southern provinces. In the north eastern part, US military mission was to prevent the use of territory, particularly the Plain of Jars, by the communist Pathet Lao Forces and North Vietnamese forces as combat base. In the southern part, the mission intended to block Vietnamese supply lines, known as Ho Chi Minh Trail crossed the border in the east of Laos (Khamvongsa \& Russell, 2009; Shoemaker, 1994). The US military mission flew from their bases in Thailand, with the bombing rate every eight minutes and twenty four hours a day, for nine years, making up 580,000 bombing missions in total. During the nine years of the war, over two million tons of ordnance was released by the US army on to Lao territory which more bombs dropped by the US army than on all countries during the World War II (Khamvongsa \& Russell, 2009). The bombing in Laos made the country the most heavily bombed country per inhabitant in the world (Khamvongsa \& Russell, 2009). After the war ended, unexploded cluster bombs and other ordnance remained, posing a constant threat to Lao population until now.

As a result of the war, up to 30 percent of bombs, around 80 million sub-munitions were not detonated (UNDP, 2012). As a result, 17 provinces of the country and approximately 25 percent of the villages (approximately 2861 villages) are contaminated with UXO. Nine provinces were the most affected: Savannakhet, Xiengkhouang, Saravan, Khammouane and Sekon (Khamvongsa \& Russell, 2009). A third of the total area, around 87,000 square kilometres, covered by UXO contamination, and over 12 thousand civilians 
killed and maimed. This severely limits the expansion of agricultural production, which leads to scarcity of food supplies, and limits local people's ability to achieve sustainable livelihoods. Of this contaminated land, only around 270 square kilometres has been cleared. Accidents caused by the UXO has killed and injured over 50,000 people in the period 1964-2008 and more than 20 thousand people have been killed or injured 1974-2008 (NRA, 2010).

\section{Figure 2.2: Map of areas affected by UXO}

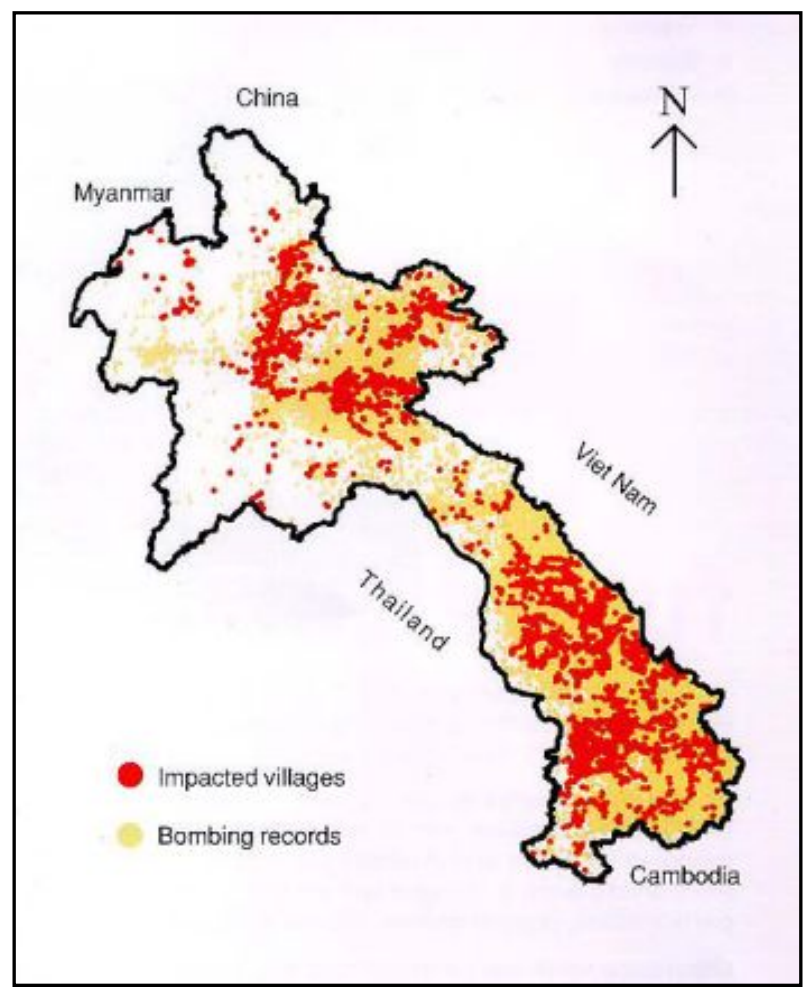

Source: Report from NRA (2010)

The impact of UXO has widely affected the lives of people and their national development in Lao. It constitutes a significant obstacle to the achievement of the Millennium Development Goals (MDGs), which wants to achieve the national goal by 2020 to lift the country out of the list of Least Developing Countries. In 2011 gross national income (GNI) per capital of Laos was USD 1,130; while Least Developing Countries GNI 
criteria adopted by World Banks are between USD 992 and USD 1,190 (World Bank Group, 2012). UXO contamination limits access to agricultural and forest-based activities. In addition, the cost of implementing development projects is increased in UXO contaminated areas when land needs to be cleared causing delays; and in some cases, suspends projects entirely (UXOLao, 2010). In the agricultural sector, UXO limits access to farmable land. This limitation shapes the agricultural products, which are very important as this sector contributes over 50 percent to national GDP. It also provides the main source of income for some 80 percent of the labour force (FAO, 2011).

Moreover, the UXO issue has been identified as a major cause of poverty. According to a report from World Vision Lao in 2007 high levels of poverty in rural communities often correlate with high levels of UXO contamination and lower economic and social well-being of people (WoldVision, 2007). Many affected areas are mainly poor communities, many people associated with collection of scrap metal for selling. Scrap metal has become a significant industry in Laos as the demand for recycled metals for infrastructure projects is increasing both in Laos and neighbouring countries. There are correlations between scrap metal price and number of accidents. One example was in 20042005, when the scrap metal price rose, the number of related casualties also increased (Flowerdew \& Martin, 2005; NRA, 2012b). Many people took up this activity knowing that it can make money, despite the risks involved. Sadly, the collectors are often children. Accidents from UXO have led to huge loss in family security and economy. Collecting food in the forest, farming activities and fire making contributed to the causes of accidents. This caused a loss of productive labour with the average age of people having UXO accidents 26 years, with the majority of casualties aged between five and 35 (NRA, 2012a). This loss of young, able bodied people has significant impacts on families who often rely on them for income generation, family care and food production. 


\subsection{Structures, policies and institutions concerning UXO}

\subsubsection{Global UXO policies and institutions}

At the global level, mine action is complex and composes five main core components: mine risk education (MRE); mine clearance, including survey, mapping, and marking; victim assistance; destruction of stockpiled anti-personnel landmines; and advocacy to stigmatise the use of landmines and support a total ban on anti-personnel landmines (United Nations Mine Action Service (UNMAS), 2004). Various actors are involved in mine action including the United Nations, International Organizations, NGOs, Commercial Operators, Donors, Coordination and Liaison Groups, Field Coordinators. In countries where the humanitarian emergencies and peacekeeping operations need to be urgently acted, the United Nations Mine Action Service (UNMAS) takes responsibility for mine action in this situation. Outside of this situation, such as long-term capacity building programmes, the United Nations Development Programme (UNDP) with support from United Nations Office for Project Services (UNOPS) takes leading roles in mine action in these countries. There are specific UN organisations taking responsibility for each core component of mine action. In this sense, the United Nations Children's Fund (UNICEF) takes leading role in mine risk education (MRE), and the World Health Organization (WHO) takes a leading role for victim assistance.

In each country, the UNDP service provides assistance in the development of sustainable programmes through provision of mine action about technical advice and capacity building support which includes advice on the legislative framework for national mine action initiatives, establishment and strengthening of the National Mine Action Authority (NMAA) and/or Mine Action Centres (MACs), development of national policies on mine action and associated work plans, particularly with regard to assessing and responding to the socio economic impact of landmine and UXO contamination within the framework of the UN policy on mine action and the Mine Ban Treaty (MBT). Another important player in mine action is donors who provide the funds through governments, international organizations, charities, foundations and companies. In several countries, 
mine action is funded through mechanisms of mobilising and channelling of donors which include the Voluntary Trust Fund for Assistance in Mine Action (VTF) managed by United Nations Mine Action Service(UNMAS); the country-specific trust funds, generally managed by UNDP; Management Services Agreement (MSA) signed by UNDP for execution by UNOPS; and the Adopt-a-Minefield programme of Better World Fund (United Nations Mine Action Service (UNMAS), 2004).

In Laos, the UNDP takes responsibility for mine action as the country is not in an urgent need for intervention, but it is in a period of long-term capacity building. UNDP focuses mainly on development partners to provide and support capacity building to NRA and UXO Lao, and also directly manages the UXO trust fund. These donors mainly support affected countries to strengthen international convention obligations. Currently, global mine action is influenced by two remarkable conventions: the Ottawa Treaty, the Anti-Personnel Mine Ban Convention and Convention on Cluster Munitions (CCM). The Ottawa Treaty, the Anti-Personnel Mine Ban Convention or often simply referred to as the Mine Ban Treaty (MBT), but officially known as the Convention on the Prohibition of the Use, Stockpiling, Production and Transfer of Anti-Personnel Mines and on their Destruction, and the Convention on Cluster Munitions (CCM). The Mine Ban Treaty was adopted on 18 September 1997 and entered into force in 1999 and has 161 States' Parties and 133 signatories' countries (Landmine Action, 2002). These States' Parties have obligations to destroy their stockpile of antipersonnel mines within four years of entry into force; make every effort to identify and clear mined areas under their jurisdiction or control as soon as possible, but not later than 10 years after becoming State Party; provide assistance to mine victims and support for mine risk education; and submit annual reports on Mine Ban Treaty implementation activities.

The Convention on Cluster Munitions was adopted on 30 May 2008 in Dublin and signed on in December 2008 in Oslo. Which Laos signed the convention and ratified it in March 2009. The Convention on Cluster Munitions entered into force in August 2010 with 112 signatories, and 83 State Parties. Countries that ratify the convention will be obliged not to "use cluster munitions; develop, produce, stockpile, retain or transfer to anyone, 
directly or indirectly, assist, encourage or induce anyone to engage in any activity prohibited to a State Party under this Convention" (Docherty, 2009).

Global policies and institutions have influenced the mine sector at the global level. Having specific UN organisations such as the UNDP and UNMAS taking responsibilities on specific situations can help affected countries for coping with the $\mathrm{UXO} / \mathrm{mine}$ issue. The policies and structures of the UN on mine action also become a tool to push national governments to more actively tackle with the issues and comply with the convention that they become state party.

\subsubsection{Lao UXO policies and institutions}

Mine action in Laos is managed by the National Regulatory Authority for the UXO/Mine Action Sector (NRA). The (NRA) was established in 2006 with the main responsibility for coordination, regulation, prioritizing and monitoring of all UXO sector activities, and reports directly to the government's office (UXOLao, 2010). NRA works closely with UNDP and UXO/mine operators such as the Mines Advisory Group (MAG) and UXO Lao. MAG, the second largest mine humanitarian operator and British NGO, began in 1992. MAG was the first humanitarian mine action operator in Laos working on UXO clearance (Durham, 2012) and provides support for UXO Lao in terms of capacity building. It works closely with UXO Lao, the largest operator in $\mathrm{UXO} /$ mine action sector in Laos. UXO Lao, the government operator established in 1996, focuses on mine risk education (MRE), surveying, marking and clearing in the nine most contaminated provinces. All activities of UXO Lao are reported directly to NRA. Additionally, other organisations such as Handicap International, World Education and Quality of Life for UXO survivors also work on UXO activities and mainly focus on victim assistance and community's awareness. These mine clearance operators are fully funded by international donors in form of bilateral funding or the UNDP trust fund.

At the international level, Lao PDR became the first country in Asia to sign and ratify the Convention on Cluster Munitions, and the UXO issue in Laos is one of many sensitive issues in Laos. It can be seen that the government realises this issue as a national 
development issue. Thus, to support mitigation, the Lao government announced a national Millennium Development Goal 9 (MDG 9) at the first States Party meeting for the Convention on Cluster Munitions in November 2010 in Vientiane. MDG 9 has the objective to reduce the impact of UXO in accordance to the National Strategic Plan for the UXO sector called "The Safe Path Forward II" (Durham, 2012). SPF II targets to ensure the complete clearance of UXO from priority/high value agricultural land by 2020; reduce substantially the number of casualties as a result of UXO incidents; ensure that the medical and rehabilitation needs of all UXO survivors are met in line with treaty obligations under the Convention on Cluster Munitions (NRA, 2012a).

$\mathrm{UXO} / \mathrm{mine}$ action in Laos is shaped by international and national policies. In this sense, international policies has influenced UXO mine action sector in Laos in a way the country must comply with its obligations on Convention on Cluster Munitions (CCM). This is positive side-effect benefiting the population. Another influence from the structures and strategies on UXO/mine action is the funding source. Involvement of the UNDP in funding management assisted Laos to gain creditability of transparency which leads to more opportunity for increased funds from international donors.

\subsubsection{Interesting cases of UXO policies and institutions from around the world}

Globally, there are more than 80 countries affected by mine and UXO. However, Cambodia and Mozambique are an interesting comparison. Mine action in Cambodia has a similar structure of management to Laos, but the role of army is a more important contributor to mine clearance. Another interesting case is informal de-mining conducted by village de-miners. Even though the safety concerns have been widely debated among professional operators, limited access to professional operators is the main factor pushing villagers being involved in risky tasks. The case of informal mine operators, does not exist in Laos, and the Lao army plays a minor role in clearance compared to Cambodia.

For the case of Mozambique, the new innovation in mine action is a striking feature to explore. Involving of rats, known as Mine Detection Rats (MDRs) has been launched to help the clearance operation since 2013; MDRs aim to save miner lives that take risky tasks 
every day. Whether the case of Mozambique would respond the UXO issue in Laos or not, it is new innovation to consider and study more for further action.

\subsubsection{Case of Cambodia}

Civil war in the 1970s resulted in numerous landmines being placed by different factions: the Khmer Rouge, the Heng Samrin and Hun Sen regimes. They were placed in the whole territory of the country to defend towns, villages, military positions and supply routes from attack by opposition forces (HALO TRUST, 2014b). Results of the civil conflict left around seven million mines on the territory, which made Cambodia become one of the most heavily contaminated countries in the world (Pascal, 2012). In rural districts the landmine problem continues to negatively affect much needed development by hindering access to land for agriculture and resettlement, infrastructure and basic social services, irrigation and safe drinking water. It also impacts land for cattle raising and foraging for forest products (HALO TRUST, 2014a). More than 60 000victims of landmines and Explosive Remnants of War (ERW), and over 25,000 amputees were recorded from 1979- 20210 (HALO TRUST, 2014b). There are positive signs that the number of victim casualties has decreased from a record 4,320 in 1996 into 243 in 2009 (Pascal, 2012). Largely contaminated land by mines and UXO has affected the main development goal of the Royal Government of Cambodia in order to reduce poverty. The Cambodia government has realized the importance of de-mining and UXO, so de-mining, UXO and victim assistance has become goal 9 of National Millennium Development Goals (MDGs) in a similar manner to that of Lao. However, achieving the target by the 2015 deadline under the global Convention on the Prohibition of the Use, Stockpiling,

Production and Transfer of Anti-Personnel Mines, cannot be possible because the contaminated area is greater than expected (Keane, Lemma, Kennan, Cali, \& Massa, 2010). This has led to the approval of an extension to 2019.

The mine action in Cambodia has been conducted by both informal and formal actors. All mine action is under the control of the Cambodian Mine Action and Victim Assistance Authority (CMAA). It is a public institution which was established in 2000. It is a unique 
institution working on policy guidelines and strategic plan development for mine actions and coordination of all operators in the country with their strong network with local government, international support, and operator agencies. In addition, there are four officially recognized mine clearance operators: (CMAC), governmental operator funded by UNDPO trust fund, the HALO Trust is NGO received the fund from NGO channel the same as the Mines Advisory Group (MAG), British NGO. The Royal Cambodian Armed Forces (RCAF) has implemented de-mining in Cambodia, funded by the government (Dammers, 2008). A total area of $595.5 \mathrm{~km}^{2}$ from 1992- mid 2010 was cleared by four demining operators. Among these cleared areas, $385 \mathrm{~km}^{2}$ were cleared by three humanitarian de-mining operators, (CMAC), the HALO Trust, and the Mines Advisory Group (MAG) (Pascal, 2012). These three operators have their own focused activities. CMAC has been working on de-mining since 1998 focusing on four core functions, mine risk education, information, clearance and training. HALO Trust began formal mine clearance operations in 1992 and has focused on the northwest provinces in the country. Its objectives are to return safe land to poor communities for agriculture and land for settlement and to decrease victims caused by mines and UXO.

Mines Advisory Group (MAG) began their operation in Cambodia in 1992 focusing on clearance, community liaison and mines risk education (Pascal, 2012). The Royal Cambodia Armed Force has played an important role in de-mining operation in the country. Their main roles are to provide urgent de-mining to support government prioritized projects and to support the United Nations peacekeeping operation. Interestingly, land cleared by the army has covered more than 50 per cent of the three other civilian operators' achievements, around $210.5 \mathrm{~km}^{2}$ between 1993 and mid 2010 (Pascal, 2012). Apart from the four main mine clearance operators, there are other Non-Governmental Organizations (NGOs) such as Handicap International and Norwegian People's Aid (NPA). These organizations provide victim assistance and risk education activities.

In Cambodia, a huge area of de mining operation has been conducted by informal mine operation called village de-mining which is not officially allowed. Even though the 
village de-miners realise the danger of the activities, the need for access to the land for agricultural as the main food source ensuring families security is the main factor (Dammers, 2008; Fleisher, 2005; Pascal, 2012). Another important factor that pushes villagers to become de-miners is limited access of official clearance from officially recognised operators due to slow progress and funding shortage of the government (Fleisher, 2005). Some village de-miners have generated income from the service; some make money, around 100 to 250 USD per hectare from the land owner (in 2002) (Fleisher, 2005; Pascal, 2012). Another interesting figure from village de-mining is the percentage of the land cleared by them. According to the Landmine Monitor Report from CMAC in 1999 has shown village de-miners had cleared an estimated around 80 per cent of the surfaces cleared by professional operators and decreased at 45 percent in 2000 (Pascal, 2012). Some mine action professionals proposed to provide technical support or equipment to them, but safety, risk and liability concerns have been raised among professional operators. It is interesting that, from a variety of sources such as research and reports, all mine action operators has realised this issue, however; the coping strategies cannot recently be concluded, it is still on-going debate issue.

In comparison to Laos, UXO between the two countries has similar structures, and shared the same NGO who are UXO operators such as HALO Trust, MAG. It is interesting that UXO and mine action in Cambodia, the role of army in clearance is increased, and the informal village de-miners have been heavily involved in terms of clearance. Whether the role of village de-miners is positive or negative, or even it is questionable so far on the safety concerns, it does not exist in Laos.

\subsubsection{Case of Mozambique}

Mozambique was considered one of the ten most mine affected countries in the world (Mollenhauer, 2014; TRUST, 2014). The civil war lasted for 16 years between 19771992, which was the conflict between government side, the Front for the Liberation of Mozambique (FRELIMO) and opposition side, Mozambican National Resistance (RENNAMO). Both groups used mines to defend provincial and district towns, roads, 
airstrips, key bridges, power supply infrastructure and military posts (Manning, 2014). The end of the civil war in 1992 left the country with three million mines in the territory covering 70 percent of the land in the country. It created difficulties for the country to develop social and economic aspects in all level and sectors. Landmines have impacted the use of farmable land resulting in stopping peasants from producing food. It has impacted infrastructures such as roads, schools, electrical lines, airports and factories. Wildlife is also threatened by mines with elephants in particular. Many elephants have been found maimed and killed by anti-personnel mines (Manning, 2014). In terms of social development, landmines affect life expectancy and contributes to it being a low of 46 years in Mozambique (Manning, 2014).

Mine action in Mozambique began in 1992 with three major demining operations. Belgian NGO Handicap International is only continuing operations through the support of the UN Development Programme (UNDP) (TRUST, 2014). HALO Trust US mine operator, largest humanitarian demining operator in Mozambique. APOPO, the Belgian $\mathrm{NGO}$, is smallest demining operator in the country. Mozambique is a State Party and gave a signatory of the Convention on the Prohibition of the Use, Stockpiling, Production and Transfer of Anti-Personnel Mines and on their Destruction or Ottawa Mine Ban Treaty (MBT) singed in1997 which came into effect in March 1999 (Manning, 2014). Under obligations of the treaty Mozambique must clear all mines from their land within 10 years from 1999. Due to the slow progress of mine clearance, Mozambique was granted a fiveyear extension of March 2009 deadline to remove all known anti-personnel mines and unexploded ordnance on its territory. To meet the new deadline by year 2014, the Republic of Mozambique and the international community has invested about 39 million USD, and is applying new innovation mine clearance methods such as the Mine detection Rats (MDRs).

Mine Detection Rats (MDRs) have been launched to help the clearance operation since 2013. The project has been implemented by Belgian NGO APOPO funded by multiple international donors of 4.5 million USD. Mine Detection Rats are faster than human de-miners 50 times with a capacity to clear land of 200 square meters within 30 minutes, while human need to spend around a day (Mollenhauer, 2014). Rats have been 
trained for nine months before deploying the mining detection operation. Once rats detect mine items, they will mark by scratching location of mine items in order to notify mine removal experts.

Mozambique has a similar structure to Laos and policies on $\mathrm{UXO} / \mathrm{mine}$ action sector in terms of institutional structures and progress of clearance. Under constraints of obligations from the Ottawa Mine Ban Treaty (MBT) for Mozambique and under Convention on Cluster Munitions (CCM) for Laos seems challenging to meet its obligation within time frame of ten years, while the annual rate of clearance is very slow. The case of using Mine detection Rats (MDRs) in demining operations in Mozambique is very new and a possible method for Laos. It is interesting to learn how they help the professional operators. Animal mine/UXO detector as rats might be optional for the clearance team to boost the speed of clearance.

These two interesting cases could respond to the issue of this research in a particular way. Lessons from the role of army in the Cambodia case could be considered to apply for particular conflict terms as "development" that is differently viewed from government and humanitarian operators. Applying the role of army for this particular issue of development views could be optional for sectors, government and humanitarian operators. The case of rats involvement in mine action as in Mozambique would respond to slow progress of clearance because its capacity is faster than human 50 times.

\subsection{Conclusion}

This chapter presented how the sustainable livelihood concept was applied. Sustainable framework developed by DFID is used for analysing and framing the research. The concept consists of the sustainable livelihood approach and sustainable livelihood approach, both are inseparable in practical. While the framework is used to identify the issue, the approach is considered for intervention addressing to those issues. In this research, three main components sustainable livelihood framework are applied to analyse the UXO impacts, which are transforming structures and processes, livelihood assets concepts and livelihood strategies. The most importantly, UXO issue is inserted into the 
framework as the vulnerable context that still continues to threaten civilian after post conflict. In transforming structures and processes component, it allows seeing the relationship between the impacts and policies and UXO operators. Furthermore, livelihood assets and livelihood strategies adopted by communities to cope with impacts helps seeing the clear connection of impacts to their assets and connection between impacts and response used. More details on how this framework will be applied will be present in the chapters four and five. Additionally, this chapter has provided two interesting case studies: Cambodia and Mozambique mine action. It is important to recognise for mine action in Laos that these particular actions exist in mine action, they could be a possibility for Lao. The involvement of rats addressing mine action in Mozambique is also interesting to consider for mine action in Laos as the capacity of rats are faster than humans several time and save de-miners lives as well. 


\section{Chapter Three \\ Research methodology}

\subsection{Introduction}

This chapter provides a description of the methodology and research methods used with a focus on how they were selected for this research. This includes a description about the tools and techniques for data collection, sampling selection, data analysis and ethical issues. Firstly the chapter introduces my epistemological approach to this research. This is followed by a discussion of qualitative research theory, with a social critical constructivism, which seeks the meaning from experience and perceptions on particular issues. The chapter then presents the theoretical framework and research design including type of research and data collection. Following this section is a description of the tools used for data analysis. The software used and coding methods designed is presented. Finally, the chapter includes ethical issues concerning the participants and my research positionality.

\subsection{Research epistemology}

Epistemology, known as theory of knowledge, means knowledge, understanding and study. It is the branch of philosophy concerned with the nature and scope of knowledge (Hofer, 2001). It often questions" what knowledge is and how it can be acquired, and the extent to which knowledge pertinent to any given subject or entity can be acquired focusing on the philosophical analysis of the nature of knowledge and how it relates to connected notions such as truth, belief, and justification" (Hofer, 2001). Different epistemologies use the term knowledge in different ways. There are several epistemologies such as historical, empiricism, rationalism and constructivism. This study was based on a constructivism approach meaning a type of learning theory that explains human learning as an active attempt to construct meaning about the world. To be more specific, this research study applied social critical constructivism theory which means the "researcher seeks to establish the meaning of phenomenon from the view of participants" (Creswell, 2009,p.16). 
The theory was applied in this study as a way of bringing my experience and understanding to the interpretation of my field experience. I connected the theory with how local people construct knowledge about their world, specifically about the impact of UXO on their livelihoods. Through analysis of the responses from participants on the impact of $\mathrm{UXO}$, and perspectives on potential of UXO policy improvement from both villagers, Nanu and Yotphae villages, and people involved in national policy and strategies and UXO activities sector from relevant organisations namely UXO Lao, NRA, UNDP, AusAid, World Education, QLA, MAG, COPE were analysed to build the outcomes of this research project.

\subsection{Research design}

\subsubsection{Qualitative methods}

Qualitative research has played an important role in achieving the status and visibility of the social sciences for over twenty years (Merriam, 2002). Qualitative research defines as an enquiry useful for exploring and understanding a central phenomenon (Johnson \& Christensen, 2008), and as "situated activity locating the observer in the world which has a set of interpretive, material practices that make the world visible, where these practices change the world into series of representations, including field notes, interviews, conversations, photographs, and recordings" (Denzin \& Lincoln, 2011,p.3).To learn about any phenomenon they are interested in, the researcher questions broadly and collect detailed information and then analyses the information for themes. From the data, the researcher interprets the meaning of the information by also drawing on personal reflection and past literature (Johnson \& Christensen, 2008; Creswell, 2005). According to Creswell (2008; 2005) qualitative data is useful within the research setting as participants can freely express their thoughts, perceptions and experiences in more detail in relation to the research topic. Thus the research usually involves fieldwork where the researcher has to physically visit the selected site and the research participants in order to conduct the interviews in their natural settings (Johnson \& Christensen, 2000; Creswell, 2008). 
In my research study, I visited two research sites, Yotphae and Nanu villages in Xiengkhouang province, and conducted individual interviews in the form of open-ended questions with 15 research participants, I encouraged these participants to express and share their personal perspectives on situations related to UXO in their own style of conversation. Additional questions where relevant were asked, especially if mentioned by participants. Applying a qualitative approach allowed me to gain understanding and allowed me to analyse how people confront the UXO impact and how people use strategies to overcome the issues in Xiengkhouang province.

\subsubsection{Individual semi-structured interviews}

In qualitative research, interviews are commonly used for data collection. Interviews are the process of both interchange between interviewer and interviewee allowing the interviewer to gain information from the interviewee by asking questions (Longhurst, 2003). Different types of interviews are utilised for different research approaches. In qualitative research, a semi-structured interview is one of familiar types of qualitative interviews for gaining information from research participants. It is a set of predetermined open-ended questions using an interview guide to help interviewer to focus on the topics at hand without constraining participants to a particular format. During the interviews, the interviewer has a list of key themes, issues and questions to be explored, but the order of questions can be changed depending on the direction of the interview. It is often that additional questions can be asked as dialogue between interviewer and interviewees and the interviewer can ask in different ways for different participants with some questions that have not been anticipated in the beginning of the interview (DiCiccoBloom \& Crabtree, 2006). Importantly, semi-structured interviews allow participants to describe their experiences and their lives in their own words or own style of conversation rather than yes or no type answer (Flowerdew \& Martin, 2005).

In this study, I conducted the fieldwork for three months and used semi-structured interviews as the first data collection method in to allow participants to freely express 
themselves, which allowed me to extract more hidden information from the interviews. The interviews were conducted in a form of individual interviews, lasted for an hour. I divided the research participants into two groups: villages and organisations. At village level, in total I interviewed 15 participants from two villages, seven participants including two women in Nanu village and 8 people including 3 women in Yotphae village in Xiengkhouang province. Approaching these participants in villages was assisted by UXO Xienngkhouang staff who played a coordination and guiding role for me for the interviews in the villages. All participants were interviewed in a comfortable place for them. Some interviews were set in the participant's house, and some interviews were conducted in a village office.

When I first arrived 29th May 2013, I organised a meeting with the head of the village to introduce the research project and conducted a participant selection process with assistance from the head of villages combined with the use of the snowball technique to fine hidden participants. At the organisations level, I interviewed 9 participants, all men from different organisations namely UXO/Mine Action Sector in the Lao PDR (NRA), National Unexploded Ordnance programme (UXO Lao), UXO Lao in Xiengkhouang, Cooperative Orthotic and Prosthetic Enterprise (COPE), Mines Advisory Group (MAG), United Nations for Development Program in Lao (UNDP Lao), AUS AID, World Education and Quality of Life Association Xiengkhouang (QLA). I approached participants in this level was made by myself, and appointments were made via email and telephone with an attachment of an information sheet of the research project and official letter from Victoria University of Wellington.

\subsubsection{Sampling and research participants selection}

Sampling is the process of defining a representative subpopulation to study (Lunsford \& Lunsford, 1995). The snowball technique is common used to locate hard-to-reach populations as a way of sampling. Snowballing, also known as chain referral sampling, is an effective tool to gain access to the hard-to-reach population(Noy, 2008), and it can 
reduce sampling bias, maintain confidentiality, and increase the validity of findings (Penrod, Preston, Cain, \& Starks, 2003). The snowball technique allows researchers to tap into a wider social network which might not otherwise be seen by researchers.

I utilised the snowball technique in this research project to avoid the power relationships influencing the process of the selection participants. I realised that a hierarchy system was in all levels of society from the national political system to the village or even family levels. In this sense, decision making of all matters could be made from people in higher positions who have the power. In order to reduce the power and bias, I consulted with the head of the villages to select participants for this research and then I took an opportunity during interviews with the participants selected by village chef to locate other participants. In Nanu village, I located one more participant referred by other participants, and two in Yotphae village. My chosen criteria for the sample population at village level are people who are farmers, men, women and young people who have experience of UXO indirect or direct impact and can/want to provide information.For organisations I selected staff of each representative of government, non-governmental organisations and private organisations conducting activities related to UXO activities. In this fieldwork, United National for Development Program in Lao (UNDP Lao) was selected as it plays an important role in UXO trust fund management; AUS AID was selected as donor role. Furthermore, UXO/Mine Action Sector in the Lao PDR (NRA) was chosen as it is a public institution of the Lao government, this institution takes responsibility for the regulation and coordination of all operators in Laos working on the unexploded ordnance, artillery shells, and grenades. Additionally, National Unexploded Ordnance programme (UXO Lao) was also selected as a governmental operator that reports and works in parallel with NRA. Importantly, the research project has selected Cooperative Orthotic and Prosthetic Enterprise (COPE) because it plays an important role for victim assistance; and QLA and World Education were selected because they are victim assistance operators in Xiengkhouang province. Finally, Mines Advisory Group (MAG), which is NonGovernmental Organisation, MAG was selected because it is UXO operator who has many years of experience on mine clearance and mine risk education in Laos. However, selection 
of staff who was the organisation representative for the interview was made within their organisations.

\subsubsection{Negotiation for access to the field}

In conducting research, it is important for the researcher to think about gaining access. Gaining access is about a consideration on how to convince selected participants for providing information for the research (Johl \& Renganathan, 2009). In particular, in doing qualitative research gaining access is one of the problems facing researcher, therefore a huge amount of time is spent on this task (Okumus, Altinay, \& Roper, 2007).

Similarly, in this research, most of the fieldwork time was spent on coordination with relevant organizations and involved people. There were three main procedures for the field work in this research in terms of access to the participants. Firstly, I gained an official letter from Victoria University to certify that they are the organisation I am studying with. This letter was presented to organisations conducting UXO activities. Secondly, it needed to have permission from relevant institutions in Laos. It is very important to know that the field of the researcher is under various institutions' responsibilities. This research is about exploring the impact of UXO; therefore, I also obtained a permission letter from the National Regulatory Authority for the UXO/Mine Action Sector in the Lao PDR (NRA). The letter from NRA allowed me to coordinate with UXO Lao office in Vientiane in order to gain permission from UXO Lao to work with UXO Lao in Xiengkhouang province office. The final step was about working at the provincial and village level. After gaining the permission from NRA, and having permission from UXO Lao in Vientiane, is was easier to work comfortably with provincial and village levels. At the same time, UXO Lao in Xiengkhouang province selected the villages, coordinated with villagers and guided me to villages as well. This process of having an official letter from institutions allowed me greater access in the fieldwork. 


\subsection{Data analysis and writing process}

Analysing information involves examining it in ways that reveal the relationships, patterns and trends, etc. that can be found within it (Luna-Reyes \& Andersen, 2003). There are several methods and tools for data analysis. I applied a coding method by using software for data analysis in qualitative research called Weft Qualitative Data Analysis. Coding is one of the important steps for data analysis, as it helps the researcher to organise and make textual data meaningful (Basit, 2003). The central idea of coding is to move from raw text to research concerns in small steps, each step building on the previous step that allows the researchers to be able to see further and take the step after that step (Auerbach \& Silverstein, 2003). The raw text in form of script was coded by Weft Qualitative Data Analysis (Weft QDA). Weft QDA is qualitative software to explore documents and search for patterns and themes that emerge from the text and it is used to link, explore, and this allows the researcher to ask questions in order to determine relationships and establish hierarchies within the data (Sarai \& Sithole, 2012).

I transcribed interview notes and voice recordings from the fieldwork. The transcription was made in the form of electronic documents, Excel format, and translated from Lao language to English day by day. Another important stage for data analysis was a creation of familiarity with qualitative data analysis software. By assistance from my supervisor, one session was organised for this software application in university campus. In the final stage of data analysis, I transformed the Excel documents into word documents that were able to be imported into the software. One word document was for one interviewee response. There were 24 documents, one and half pages of each document, imported and coded

Additionally, it is important to realise that this thesis was written by non-native English speaker. The process of writing is conducted by chapter by chapter, but it does not follow in order according to the structure of thesis chapters. I started by research methodology chapter and follow by literature reviews chapter. After that, I wrote the 
findings chapters. Finally, I finished writing introduction chapter before starting concluding chapter. Once I finished each chapter, it is checked by supervisor and I edited after supervisor comments. Proofreading for each chapter is conducted, when supervisor told that it is ready.

\subsection{Ethical considerations}

The ethical issues of a study provide precedence to participant safety and protection and aim to protect researchers as well (Williman and Buckler, 2008). In this research, the participants were given enough information on research project as I described it in a project information sheet both in English and in Lao languages. I also gave an opportunity to research participants to ask or to clarify any concerns about the research project during interviews. Before the investigation has started, I prepared the ethical proposal complying with Human Ethics Committee Guidelines (2007) of Victoria University of Wellington (HEC). The approval was granted by Human Ethics Committee of Victoria University of Wellington (VUW) in12th April 2013 ( reference number: 19705).

In terms of informed consent in this study, all participants were voluntary For the participants who were not confident with writing or reading skills, oral consent by audio recorded was applied. I read the informed consent form for all participants in village level. For the participants at the organisation level, the informed consent form was attached together with information sheet by email. Importantly, the participants in this research had the right to accept or decline their participation in any stage of the research process.

I also realised the importance of confidentiality in this research project; as Wiles, Crow, Heath, and Charles (2008) maintain that there are a variety of ways in which they protected the confidentiality of their participants in the dissemination of their research. These included including omitting data and changing the key characteristics of participants. Therefore, in terms of confidentiality, all material collected including all written material, questionnaires and interview notes for this research project was kept confidential. This material was also kept in locked file and access was restricted to myself and my supervisor. 
For electronic information, I kept it in a password-protected file and only I can access to it. Destruction of all material such as interview notes, questionnaires will be preceded in two years after conclusion of the research completed. I applied pseudonyms when required to ensure that participant names were not used anywhere in the research. More importantly, there were not opinions that were attributed to participants in any way that can identify participants in published results.

\subsection{Positionality}

In doing research, it is important that researchers think about both the similarities and differences between themselves and the researched (Hopkins, 2007). In this regard, ChiseriStarter (1996) emphasises the way that researchers present themselves to their informants and the way of how researchers think their informants perceive them would shape the research(Chiseri-Strater, 1996). This requires researchers to recognise our own

positionalities; how various identities may influence and shape our research activities(Chiseri-Strater, 1996).

Connected to my research, my positionality was shown as I grew up in a rural area in Laos and that made me feel like an 'insider' when I have conducted my work within local rural communities, because I could share similar life style during my childhood story. I am also associated with development organizations and worked as a junior practitioner for a few years with non-profit association (NPA) which allowed me to gain familiarity with the research area. My field work experiences in this research area assisted me to interact smoothly with communities. Some local people might associate me with the government or see me as development organisation officer as I travelled with government officials who helped with the coordination for my research project. In this case, participants may view me as an outsider. I am also educated in an overseas manner. This affected the research in terms of the power relationship amongst us. In this sense, the perception of me from participants at village levels was associated with fund donors, especially when I talked about my scholarship provider organisation. To reduce these views from participants, I applied a strategy of relationship and trust building between me and participants by 
spending some time to greet and talk to the local people at the first arrival. The presence of government officials had in this case, both advantages and disadvantages. The positive side was that local government officer helped me to clarify that I have a role as student researcher rather than funding involvement. On the other hand, their presence impacted on my conversation as I intended to make informal conversation which allowed the villagers to freely express their ideas by their own style of conversation. This made me concerned that it would impact the information provided by the participants. In this case, using language in an appropriate level was the key for me to reduce the power relations among us. I talked to my participants by using similar level of their language, not too formal and not too informal. At organisational level, it was positive of me as these organisations work with international donors which was associated with my previous work background.

\subsection{Conclusion}

This chapter has outlined how this research study was conducted. The fieldwork for this research took for three months starting in beginning of April until the end of June 2013. The research study relied on qualitative research with a strong focus on social critical constructivism theory. Semi-structured interviews by open-ended questions were selected for data collection for both, national and village levels. The interviews lasted for around an hour. Research participants came from different organisations, public institutions including the central government, local government, local and international civil society, development partners, fund donors and heads of villages and villagers. These interviewed organisations also played an important role in providing secondary data sources that proved to be useful for the project. Data analysis applied qualitative data analysis software to code and to categorise the field notes and responses from participants, there were 24 documents with one and half pages of each document were coded. These coded responses were prepared for the next chapter. Ethical considerations and researcher positionality were briefly mentioned in this chapter. In the next chapter, it will talk more specifically about discussion on UXO issue from data analysis. 


\section{Chapter Four \\ Relationship between structures, processes and people livelihood}

\subsection{Introduction}

In the literature review chapter, I presented the concept of sustainable livelihoods which includes the sustainable livelihoods approach and the sustainable livelihoods framework that are now applied in this chapter to analyze the data from the fieldwork. The chapter aims to respond to the first research question: What are the institutions and policies dealing with the impacts of UXO in Laos and how do they play out in Xiengkhouang province?. This chapter synthesizes the results of the fieldwork through applying the sustainable livelihoods concept to analyze the impact of UXO. The outcomes of this analysis are formed by the views and perspectives on UXO from interviewed organisations in Vientiane and in Xiengkhouang province combined with the interviewed villagers where relevant. The discussion in this chapter looks at the relationship between clearance and victim assistance pillars and livelihoods of local people. Finally, it looks at particular terms in the UXO strategies affecting and shaping UXO institutions.

\subsection{Structures and processes of UXO/mine action program in Laos}

As explained in the literature review, the term 'structures in the sustainable livelihoods framework refers to organizations, both in the public and private sectors which establish and implement policies, legislation, deliver services, trade and perform all manner of other functions that shape livelihoods (DFID, 1999). Where are processes that determine the interactions between the structures and individuals such as policies, legislation, power relations, norms, market stability, and the general rule of law (Kollmair \& Gamper, 2002). This component appears at various levels, which does not only focus on local level that is relevant to livelihoods but it is from the multi-national to the very local. Based on this views, the structures of UXO/mine action context in Laos, as shown in figure 4.1, include the NRA; humanitarian clearance/MRE operators victim assistance operators; commercial operators and donors. Processes include the UXO national strategic plan (SPF II)consisting 
of clearance, victim assistance, MRE pillars along with the $7^{\text {th }}$ Five Year National SocioEconomic Development Plan 2011-2015. These institutions and strategies will elaborate in the next section.

Figure 4.1: UXO Structures (institutions) and Processes (policies/strategies) in the Sustainable Livelihood Framework

\begin{tabular}{|c|c|c|c|}
\hline $\begin{array}{l}\text { Vulnerability } \\
\text { Context }\end{array}$ & \multicolumn{2}{|c|}{$\begin{array}{c}\text { Transforming Structures and } \\
\text { Processes }\end{array}$} & \\
\hline $\begin{array}{l}\text { UXO } \\
\text { IssuesFigure }\end{array}$ & $\frac{\downarrow}{\text { Structures }}$ & & rocesses \\
\hline $\begin{array}{l}\text { Policy and Strategies } \\
\text { Maker } \\
\text { - } \\
\text { National Regulatory } \\
\text { Authority for } \\
\text { UXO/Mine Action } \\
\text { Sector (NRA) } \\
\text { Donors } \\
\text { UNDP } \\
\text { Humanitarian Clearance/ } \\
\text { MRE Operators } \\
\text { - Handicap } \\
\text { International(HI) } \\
\text { - Japan Mine Action } \\
\text { Service (JMAS) } \\
\text { - Lao National } \\
\text { Unexploded Ordnance } \\
\text { Programme(UXO Lao) } \\
\text { - Mines Advisory Group } \\
\text { (MAG) } \\
\text { - Norwegian People's } \\
\text { Aid (NPA) } \\
\text { Solidarity Service } \\
\text { International (SODI) } \\
\text { - The HALO Trust }\end{array}$ & $\begin{array}{ll} & \frac{\text { Victim Assistance }}{\text { Operators }} \\
\text { - } & \text { Association for Aid } \\
& \text { and Relief (AAR) } \\
\text { - } & \text { Catholic Relief } \\
& \text { Services (CRS) } \\
\text { - } & \text { Cooperative } \\
& \text { Prosthetic and } \\
& \text { Orthotic } \\
\text { - } & \text { Enterprise (COPE) } \\
\text { - } & \text { Quality of Life } \\
\text { - Association (QLA) } \\
\text { World Education } \\
\text { (WE) }\end{array}$ & $\begin{array}{ll}\text { Commercial Clearance } \\
\text { Operators } \\
\text { - } & \text { ASA Power } \\
\text { Engineering Co., Ltd } \\
\text { (ASA) } \\
\text { - } \text { Bactec Lao Ltd } \\
\text { (BACTEC) } \\
\text { - } \text { Lao BSL } \\
\text { Unexploded } \\
\text { Ordnance Disposal } \\
\text { (Lao BSL) } \\
\text { - LXML MMG } \\
\text { (MMG) } \\
\text { - Milsearch Lao EOD } \\
\text { Sole Company } \\
\text { Limited } \\
\text { - Phonhsackda (PSD) } \\
\text { - Sibounhueang UXO } \\
\text { Clearance Co (SBH) }\end{array}$ & $\begin{array}{l}\frac{\text { UXO National }}{\text { Strategic Plan(Safe }} \\
\frac{\text { Path Forward }}{\underline{\text { I }(\mathbf{2 0 1 1 - 2 0 2 0}))}} \\
\text { - Clearance pillar } \\
\text { - MER pillar } \\
\text { - Victim } \\
\quad \text { assistance pillar } \\
\underline{7^{\text {th }} \text { Five Year }} \\
\underline{\text { National Socio- }} \\
\underline{\text { Economic }} \\
\text { Development Plan }\end{array}$ \\
\hline
\end{tabular}


In this framework, in the first block, the vulnerability context in form of UXO issue aims to show the connection to other component of the framework because vulnerability context ( UXO issue) is the entry point for the whole framework.

\subsubsection{The interrelatedness between UXO clearance strategies and the livelihood of people in Xiengkhouang province}

In the framework, NRA, a national governmentinstitution is a special institution as a big umbrella acting as a strategies maker. It is a leading institution for UXO and the Mine Action Sector.The institution was founded in 2004, fully operational in 2006, and has been funded through the UXO trust fund administered by the UNDP and funded by bilateral aid. The funding sources includes as the Armor Group North America, Government of Australia, Swiss Foundation of Mine Action, Mines Advisory Group, Government of New Zealand, Government of Switzerland, UNDP, UNICEF, and the Government of the United States of America. The NRA works under the guidance of the NRA Board, which includes the Minister of National Defence, Vice Minister of Labour and Social Welfare, and representatives from the Ministry of Foreign Affairs, Ministry of Security, Ministry of Education, Ministry of Information and Culture, Health Member, Agriculture and Forestry Member, Planning and Investment Member (NRA, 2007, 2012b). The NRA plays a crucial role in providing policy direction and accreditation for mine operators based on strategies and standards, and for managing, monitoring and coordinating national and international operators in the UXO/Mine Action sector to ensure that these operators meetstandards of practice. Since its establishment, the NRA has developed two national strategic plans: the Safe Path Forward I and II (UNDP, 2012).

SPF II is a new strategic plan with a time frame of 2013-2020 to be completed. It has been edited from SPF I ( 2003-2013) to review and reflect the progress to adapt to changing situations in the country and further needs for defining and prioritizing contaminated areas in 2010. Safe Path Forward II is in line with priorities established in the $7^{\text {th }}$ National Social- 
Economic Development Plan between 2011-2015 (NSEDP), the National Growth and Poverty Eradication Strategy (NGPES) and the MDGs (Lao, 2004; Ministry of Planning and Investment (MoPI), 2011) and is led by the board of National Mine Action Authority. This strategic plan aims to achieve the ultimate goal as "people from the most highly impacted communities to live free from the impacts of landmines and UXO” (NRA, 2007 p.67). It has identified 46 priority districts in 9 Provinces as the most affected namely, Attapeu, Champassak, Huapahn, Khammuane, Luangprabang,Savannakhet, Saravane, Sekong, and Xiengkhuang(NRA, 2007, 2012b). There are three main pillars of the strategy: mine risk education (MRE), clearance and victim assistance.

Now, I will move to discuss the relationship between the clearance and victim assistance pillar in SFP II and communities' livelihoods in Xiengkhoaung province. Additionally, I will present the opinions of UXO clearance operators and victim assistance operators that I interviewed in the fieldwork.

Clearance is the main pillar of UXO and the mine action sector in Laos. It is bounded by the Convention on Cluster Munitions (CCM) under Article 4 that "State Party has to clear and destroy, or ensure the clearance and destruction of cluster munitions remnants located in contaminated areas not later than ten years after the entry into force of the Convention" (NRA, 2012a. p5). Aligned with this obligation, in the national strategic plan 2011-2020 known as SPFII, clearance sector targets are to release priority land and clear UXO in accordance with National Standards and treaty, focusing on all agricultural areas identified as high priority as well as other areas identified as medium priority. To support this target, the clearance pillar issues four main actions. Firstly, it targets to identify priority land identified based on clear criteria and take into account existing village, district, provincial and national development plans. Secondly, it targets to release priority land through a risk management approach applying data analysis and then general survey followed by technical survey, roving response and/or, finally, full clearance. Thirdly, it conducts clearance monitoring and land handover programmes in terms of impact and cost. Finally, it ensures that all operations are in accordance with national standards. The 
Prioritized land for clearance has three main categories: high, medium and low. High (Priority I) consists of agricultural tasks; roving services; public service utilities; and educational facilities. Medium (Priority II) land is grazing land and forested areas; communal facilities; government facilities and offices. Low (Priority III) is public infrastructure work; communal "profit-making" areas; tourism sites; and commercial/private business sites (GICHD, 2007). In the SPFII, it estimates more than 200,000 hectares of contaminated needs to be cleared by 2020. Currently, clearance rates in Laos range between 4,000 - 5,000 hectares/year combined by all agencies (HALO TRUST, 2014c).

The main UXO operators in Laos are National Unexploded Ordnance Programme (UXO Lao), Handicap International (HI), Japan Mine Action Service (JMAS), Mines Advisory group (MAG), Norwegian People's Aid (NPA), Solidarity Service International (SODI), The HALO Trust and other commercial operators. Each organisation is funded differently; some agencies are funded through the UNDP Trust Fund in form of NGO channel or UXO Trust Fund or bilateral fund. Among these operators, UXO Lao, the governmental operator, is the biggest operators for clearance sector, and MAG, British NGO is second biggest. UXO Lao is a national government agency, the biggest humanitarian UXO/mine action operator in Laos; it was established in 1996 with support from UNDP, UNICEF, and other stakeholders. It is funded by UNDP Trust Fund and bilateral funding from donors. The main organizations have as their mandate to clear land for agriculture and to supporting development agencies' projects such as irrigation systems, school construction, hospitals, health centres, clean water projects and roads.From 19962012, UXO Lao received financial support of approximately 70 million USD for bilateral fund and 14 million USD for UXO Trust Fund, and 11 million USD for bilateral fund and 9 million for bilateral fund from 2013 -2016. UXO Lao currently operates in 9 nine provinces of the most heavily impacted in the country. UXO has more than 1100 employees in nine operational provinces; with 85 percent in field operators. UXO Lao significantly contributed to UXO sector in Laos. In 2012, 3,199 hectares of cleared land were released benefiting 516,410 people and 49,189 UXO items were destroyed (NRA, 
2007, 2012b). In Xiengkhouang province UXO Lao has cleared 5,462 hectares since its beginning until 2013 (UXO Lao Xiengkhouang, 2013).

MAG is the 2nd biggest humanitarian operator that began its mission in Laos since 1994 providing clearance for communities affected by UXO. It has currently two operations in the provinces, Khammouane and Xiengkhouang. MAG also supports national sustainable workforce by employing and training staff from local people. Its total employees MAG are around 400 staff with 12 clearance teams, six teams in Xiengkhouang province and six teams in Khammouane province. Each team has 20 members including 12 technicians. Additionally, there is one roving team in each province. MAG works with communities through community liaison teams using participatory rural appraisal techniques in order to facilitate the identification and prioritisation of clearance tasks. Through village assistance clearance methodology, MAG hires community members to remove vegetation from task sites and other support tasks before clearance in order to provide local opportunity for income generation. Village assistance clearance is trained in the appropriate methods of vegetation removal prior to recruitment. Experience of MAG on clearance processes has made significant contribution to UXO clearance and mine risk education for Laos. Between 2004 and 2012, over 38.7 square kilometres of suspect land in Lao PDR were cleared, 161,802 items of UXO destroyed and 450,894people gained access to safe land. Additionally, in 2012, MAG contributed grants for small development projects implemented by agencies such as World Education and Health Poverty Action, and district authorities in Xiengkhouang and Khamouane Provinces (NRA, 2007, 2012b). 
MAG and UXO Lao have contributed significantly in the UXO clearance pillar for several years in the most affected provinces including Xiengkhounag province. In practical terms, within the context of clearance strategies there is the gap how it shapes people's livelihoodin the operational provinces, Xinegkhoung province in particular. Interviews from senior staff of UXO Lao in the Vientiane office elaborated more on how land is selected as a priority:

Our provincial UXO Lao office will select priority of land for clearing in affected communities. The applicants will propose their land to our organisation (UXO Lao) first and then we will consider based on the importance of land use. Importance means that will the applicants will really use that land, and combined with the conditions of access to the land and its distance of the location, because before the clearing the UXO Lao team have to go the field for survey. If it is too far and poor accessibility condition, it will be not selected yet.

Interview location: Vientiane, Date: $9^{\text {th }}$ may 2013

This shows that people who live in remote areas with poor conditions for access are disadvantaged. In Xiengkhoaung province most of the affected people are in remote areas where infrastructure and road access is very poor and combined with the characteristic of the province as mountainous the area is difficult to access. It seems that the opportunity of the people to have more secured land for cultivating crops for living condition improvement is more limited.

When connected to the sustainable livelihoods concept, emphasising sustainable livelihoods strategies is about focusing on what people have, in terms of existing assets rather than focusing on or demanding what people are lacking to adapt to the specific conditions to boost their income. 
In some areas, the clearance task is providing significant benefits to villagers. In this case, the clearance gives more opportunity for people to access to safe land. But, it does not necessarily influence their economic aspect. As a MAG senior staff said:

We, MAG, conducted post clearance evaluation in our responsible districts in Xiengkhouang province; we found that there are two groups of people associated with clearance. First group used cleared land for planning additional crops such as nuts and maize a part from main crops as rice. Second group, the land use between post and pre-clearance showed no difference, because this group of people is associated with other factor as labour and money for investment.

Interview location; Vientiane, Date: $17^{\text {th }}$ May 2013

This shows that UXO clearance does not guarantee that to help people to boost their living condition improvement through crops production. It still requires integrated cooperation with other sectors. Nanu villagers gave more opinions about this:

I plant rice as main crops after that my family plant maize for consumption, I want to grow maize for selling to Vietnam but it requires huge amount of money for investment, more land, labour and I also need the seed as well. Importantly, I do not know how to contact the traders in the market.

Farmer from Nanu, Date: $29^{\text {th }}$ May 2013

Interestingly, the UXO clearance for households who have poor economic conditions only provides the benefits on safety issues as more secured land is available rather than income generation. On the other hand, UXO clearance for the households who have good economic levels the recipients have gained more benefits from the clearance through 
agricultural production from secured land. The good example of this benefit occurred in Yotphae village from one interviewed villager.

Two years ago, UXO Lao cleared my land which allowed me to have more secured land for planting crops. I plant rice and maize together as I am confident to use the land. My children help me to grow these crops that can solve labour shortage for my family. I gained many benefits from this land as I have more maize sell in the Phonesavanh market that makes me to have more income to buy equipment such as tractor and for buying school clothes and other educational tools for my children.

Farmer from Yotphae, Date: $30^{\text {th }}$ May 2013

Besides, UXO clearance strategies, there are other constraints and conditions on land use that shapes people livelihoods. In the $7^{\text {th }}$ Five-Year National Socio-Economic Development Plan 2011-2015, the government has a target to stop shifting cultivation completely by 2015 to protect the remaining forests and reforest degraded areas (Ministry of Planning and Investment (MoPI), 2011).This policy will limit the opportunity for people to extend into more farmable land combined with UXO contamination that blocks the full use of cultivated land. This makes it more difficult to boost communities' living conditions. In particular a place such as Xiengkhoaung which is a mountainous area, where the majority of people rely on shifting cultivations this is very limiting for them. A senior villager in Nanu village provided -his view on how this constraint condition affects his villagers' livelihoods:

There are 20 households heavily relying on shifting cultivation in our village. This agricultural system gives less production yield; therefore, these people need more land for cultivating. However, extending new farmable land is not possible in our village due to the land policy. This affects these families on food production to 
feed the family members. Compare to others households in the village, they are poorer.

Senior farmer from Nanu, Date: $29^{\text {th }}$ may 2013

In this case, UXO clearance plays a key factor in allowing them to fully utilise the existing cultivated land and with applying new techniques to increase crops yield. In practice, this requires farmers to integrate with other relevant sectors such as the agricultural department as stated by the sustainability principle in the sustainable livelihoods approach meaning that policy makers, development practitioners and researchers have to consider various factors including economic, ecological, social and healthcare aspects (Singh \& Hiremath, 2010). In fact, the concept in $7^{\text {th }}$ Five-Year National Socio-Economic Development Plan fits in the concept of sustainable livelihoods in the sense of security in ecology which means that natural resources quality such as soil and water quality, forest preservation and air pollution is important. Looking at other aspects of sustainable livelihood concepts especially about the efficiency of economy meaning that a productivity of labour and marketable surplus (Singh \& Hiremath, 2010). The land use policy and UXO contamination seems to be negative impact on rural people livelihood, because it decreases their agricultural production. In practical, keeping the balance between ecological and economic aspects is challenging, which requires to consider and have integrated approach to intervene the situation.

In some cases, in Xiengkhouang province, the lack of identification of UXO contaminated areas including the village, district, provincial and national levels and accurate data survey affects both clearance operators and the livelihood of people. Interviews with MAG senior staff provides a greater connection:

We (MAG) had an experience clearing a huge area of land in Xiengkhouang province, but we did not find any UXO item. We want government to give better ideas on how many items are left and where exactly the UXO items are. This kind of information is 
very useful for us and for our donors as well in terms of clearance tasks.

Interview location; Vientiane, Date: $17^{\text {th }}$ May 2013

The accuracy of data and land use planning can help operators to save the costs and clear more land in the same amount of money. It is important to realise that there are many disadvantaged people from the clearance task in Xiengkhouang province. While some operators are still clearing the empty land where there is not any UXO item, disadvantaged people are still waiting for the benefits from the clearance team.

\subsection{Impact from strategies to UXO operators and livelihood}

\subsubsection{Impact from funding allocation in strategies}

\subsubsection{Source of funding}

The UXO sector in Laos is totally supported by international donor funding. There is some amount contributed by the Lao government, but officially this contribution figure is unavailable. The government is planning to scale up their support for UXO sector. The international funding for the UXO program in Laos started in 1995 in the form of a Trust Fund under UNDP. There are two channels of funding in UXO sector in Laos: UXO trust fund and bilateral funding. UXO Trust Fund is administered by UNDP, the funding is Trust Fund has become the major source of funding for UXO program in Laos; multiple donors support the funding form of earmark and non-earmark. The fund is allocated in the form of bilateral aid and through NGO channels(UNDP, 2012). The Trust Fund, which currently serves primarily as a mechanism for support to the NRA and UXO Lao, is operated under the framework of the national UXO strategy and UXO policies approved by the NRA Board. Its Steering Committee is chaired by the Government and co-chaired by UNDP, in close consultation with the UXO Sector Working Group. The major donors of Trust Fund for UXO sector are come from multiple international donors (see table 4.1). 
Table 4.1: Major donors for UXO and mine action sector in Laos

\begin{tabular}{|l|}
\hline Donors for UXO Trust Fund \\
\hline Australian Agency for International Development (Aus Aid) \\
\hline Canada \\
\hline France \\
\hline Ireland \\
\hline Luxembourg, \\
\hline New Zealand \\
\hline Switzerland \\
\hline Belgium, \\
\hline Denmark \\
\hline Norway \\
\hline EU \\
\hline Germany \\
\hline Netherlands \\
\hline
\end{tabular}

Source: (UN (2003); UNDP, 2012)

Another form of funding is bilateral funding; this includes the support directly to Lao government and directly to NGOs. Some are administered by UNDP some direct to NGOs. The main donors in this kind of funds are the USA, EU, UK, Japan, South Korea, Italy and Finland.

In the current situation, budget demands from the international aid sector for UXO in Laos is 50 million USD annually for the next five years in order to meet CCM obligations. UXO/mine action sector in Laos have not received enough international aid, so their target are still far from that requirement. An UNDP senior advisor staff who was interviewed provided his views on this issue that: 
The current situation of UXO sector in Laos combined with CCM obligations, Lao government will easily receive international aid around 10 million annually, but this amount is still far from the needs to meet the obligations. To meet the amount government and partners have to work hard and depending on several factors

Interview location: Vientiane, Date: $9^{\text {th }}$ May 2013

Concerning the funding, it is still questionable about the funding through NGOs, as a high proportion of the income is spent on overhead costs. NRA staff elaborated more about this:

We (NRA) have proposed several times on the reduction of direct aid through NGOs, because the overhead of NGOs is very high. Therefore, beneficiary will receive less. The reduced amount fund could be funded through UXO trust fund in order to extend UXO Lao team clearance speeding up.

Interview location: Vientiane, Date: $10^{\text {th }}$ May 2013

This is interesting concept; it could be spent to employ local people involving on the clearance tasks. In fact, international staff head costs are higher than national staff around 4 or 5 times in the same position.

\subsubsection{Impact from funding allocation}

In the strategic plan SPF II, funding allocation is not specified into each UXO victim assistance and provincial operators. This impact affects both UXO operators and UXO victims who benefit from these organizations. The victim assistance sector for UXO has not covered comprehensive aspects, it responds only to medical care in practical. Victim assistance operators in $\mathrm{UXO} /$ mine action sector in Laos compose of the Cooperative Orthotic and Prosthetic Enterprise (COPE), Xiengkhouang Quality of Life association (QLA) and World Education Laos. 
Cooperative Orthotic and Prosthetic Enterprise (COPE) was established in 1997 by agreement between the Ministry of Health of Lao PDR and a group of non-government organizations including POWER, World Vision and Cambodian School of Prosthetics and Orthotics. COPE currently works with the Centre of Medical Rehabilitation (CMR) under the Ministry of Health providing prosthetic, orthotic and rehabilitation physiotherapy, occupational therapy and paediatric services to UXO victim and to other people with disabilities in Laos. The majority of COPE's funds (around 85 percent) come from large donor organizations 85 percent and 15 percent come from private donations through its website and product sales through the COPE Visitor Centre. Major donors of COPE are multiple (see table 4.2).

At provincial level, COPE has four operational bases in provincial rehabilitation centres, Xiengkhouang, Champhasak, LuangPrabang, and Savannakhet provinces. In 2008, COPE established visitor centres to show an exhibition providing education and information on UXO in Laos. In the UXO victim assistance pillar, COPE takes responsibility for expenses for UXO victims and other people with disabilities and for those cannot afford to pay. These expenses include the costs of prosthetic and orthotic devices, surgery and treatment, transport to and from people's homes to the rehabilitation centres and a daily allowance for patients and their care givers. COPE also strengthens the capacity building to national government staff in the fields of prosthetics and orthotics, physiotherapy and occupational therapy through on the job training, support skills development, and upgrade clinical processes (NRA, 2007, 2012b). 
Table 4.2: Majors donors of COPE

\begin{tabular}{|l|}
\hline \multicolumn{1}{|c|}{ Donors } \\
\hline Association for Aid and Relief (AAR Japan) \\
\hline the Australian Agency for International Development (Aus AID) \\
\hline Christian Blind Mission (CBM) International \\
\hline Deseret International Charities (DIC) \\
\hline Government of Norway \\
\hline Government of Luxembourg \\
\hline International Committee of the Red Cross \\
\hline Special Fund for the Disabled (ICRC-SFD) \\
\hline Netherlands Leprosy Relief \\
\hline Margaret J. Hunter Donor Advised Fund \\
\hline The Philanthropic Collaborative \\
\hline Power International \\
\hline
\end{tabular}

\section{Source: Adapted from COPE (2014)}

The impact from funding source allocation affects UXO victim in a way that it cannot cover variety of factors that leads to living condition improvement. High level staff from COPE expressed his views on this point that:

The impact of UXO in affected area including in Xiengkhouang province are wide range. I think that victim survivor assistance should not focus only on the emergency medical care. It should focus on comprehensive aspects for livelihood improvement such as professional training and job seeking assistance. In some cases, it should specify type of assistance such as compensation for those who cannot generate income for family at all. In some case, in Xiengkhouang province, children lost their limb which affected their school attendance because the school is located very far from 
the village; the children have to walk to school. This kind of situation should be given specific assistance. Additionally, assistance should respond to each type of victim such as permanent disability.

Interview location: Vientiane, Date: $3^{\text {rd }}$ May 2013

In the theoretical context of sustainability of the livelihoods concept, it also recommends considering other aspects apart from healthcare, including social and economic wellbeing. In this sense, the aid for this particular type of disability needs to be included such as pension. It is a hard life for people in Xiengkhouang province, because they rely on agriculture production as the main source of food and income. Loss of important organs decreases their ability to work and support family. Moreover, transport is limited and some children have to walk long distances to school. Apart from UXO operator??,Aus AID senior staff as donor also commented that:

I do not see the clear definition for victim in the UXO strategies, response to victim assistance needs to classify the types of victim in detail and separate budget for each type by considering surrounded factors.

Interview location: Vientiane, Date: $19^{\text {th }}$ June 2013

In many cases in Xiengkhouang province, UXO victims have associated psychological problems. Working in this area, there is only The Xiengkhouang Quality of Life Association (QLA) who has started working to support victim to cope with this issue since 2011

QLA is supported by the McKnight Foundation and it was the founder of QLA in 2011. QLA is only one Lao Non-Profit Civil Society Organisation serving people with disabilities and unexploded ordnance (UXO) survivors in particular in Xiengkhouang Province. This local civil society provides services on advocacy for people with disabilities and UXO survivors, victim assistance to UXO survivors through livelihood training, medical and psychosocial support. The services have been supported by World Education 
Laos, and through funding from the US State Department, the McKnight Foundation, MAG, the Schmitz Foundation, the German Embassy, German Development Services (DED) and private contributions. The projects conducted by QLA are animal husbandry, handicraft production and psychological support for children. Livestock feeding and handicraft workshops have benefited more than 200 people. Participants were trained on animal husbandry and received some funding from QLA for buying animal to feed. Production of handicraft was about silk weaving, sewing and traditional art. For psychological support a project was to bring children ages 7 to 18 from Xiengkhouang province to conduct activities in order to express their experiences with UXO through art. QLA also ran workshop on UXO impacted communities to help children and their families in order to work and learn together for improving their skills. These activities help UXO survivors to develop better self-esteem and confidence through family income contribution (NRA, 2007, 2012b). For QLA the limited budget affected both QLA itself and the victim's living conditions as well. QLA staff elaborated more about this:

Limited budget hinders the organization to employ the trainer of training for working on psychosocial projects to support UXO victim survivors, because the trainers of training for this sector are not available for Lao national. Employing from international staff is high cost overhead cost, which is challenging for small organization as QLA. We cannot hire qualified people also affected on effectiveness of projects implementation.

Interview location: Xiengkhouang Province, Date: $28^{\text {th }}$ May 2013

This shows that the impact from the limited budget in victim assistance pillar has impacted both QLA and victim. In the report of QLA, there are around 50 victim of UXO every year in Xiengkhouang province. For these people, assistance is very important for continue their 
lives in terms of encouragement. In an extreme case, the assistance saved the life of a UXO survivor, QLA explained more on how assistance importance is related to the victim life.

I visited the UXO victim in one village in remote area, I found one case that the victim felt discouraged his life and wanted to suicide. I asked him the reason why he wanted to suicide. The victim replied that I could not help family as before. I did not want to be a problem of family anymore. This victim started by reducing his numbers of meal day by day from three meals until one meal. Finally, with an assistance of our organisation (QLA) by providing him artificial arms and some fund for animal husbandry. Therefore, he continued his life again.

Interview location: Xiengkhouang province, Date: $28^{\text {th }}$ may 2013

Many cases that victims are disappointed with their life which resulted in discouragement for livelihood improvement. The case in Xiengkhouang province could illustrate that coping with the issues are required comprehensive approach. In some village, there was a project that brought religion to get involved addressing the psychological impact. However, different belief in different culture and religion are challenging for coping with the issues. It is a good start that the victim assistance operators trying to integrate several aspects such as cultural and traditional and belief of the people.

Connected to the sustainable livelihood framework, it can be seen that organisations, policies, strategies influenced to livelihood assets of people and the assets link to their coping strategies. In this sense, it shows that victim assistance funding shape livelihood in form of human capital such as mental and physical health. This links to livelihood improvement in a way that people makes decreased ability to work for support family. 
Currently, victim assistance pillar is allocated small amount of funding focusing on providing professional training and animal husbandry to UXO victim. One of the main organisations working on these kinds of activities is World Education Laos.

World Education Laos (also known as World Education/Consortium in the Lao PDR) is a non-profit organization based in Boston, Massachusetts, USA. World Education has begun its mission in Laos since 1992, under agreements with the Lao Ministry of Foreign Affairs, Ministry of Labour and Social Welfare, Ministry of Education, Ministry of Agriculture and Forestry, Ministry of Finance and the Ministry of Health. World Education Laos works with rural communities in nine provinces, classified as heavily impacted by $\mathrm{UXO}$, focusing on the domain of health, education, income generation and microfinance. World Education helps communities to minimize the impact of UXO through improving the quality of health care services, increasing access to education, and promoting sustainable livelihoods for accident survivors. The main funding source supported by USAID, the McKnight Foundation, and other private foundations and contributions. In UXO sector, World Education Laos provides onemergency and continuing medical care, livelihoods development and UXO risk education. Emergency and continuing medical care project builds a capacity for health providers through training. In 2012, there were 172 people in Sekong province, and 202 people in Xiengkhouang province benefiting from the training in emergency care and first aid training including district and village levels. Additionally, 44 staff participated to training of trainers' activities. For UXO victim survivors, World Education Laos provides direct funding of UXO survivor treatment in seven provinces through the War Victims Medical Fund. In UXO risk education tasks World Education Laos and government partners provides training of trainers approach, develops capacity of partners at central, provincial, district and school levels. At school level, the program organizes training in the in-school curriculum at the primary school level, it also has been developing modules for pre-service teacher training program at eight teacher training colleges(NRA, 2007, 2012b). 
In the project of support animal husbandry and professional training, it is not widespread enough for UXO survivor. Interviewed staff from World Education Laos elaborated more about this:

We support the training for victim assistance with full responsibility during their training including expenses on transport, accommodation and food cost. We supported training for them based on their characteristic of disabilities and their needs. After training, victim has to go back to their home. It is hard for them to get job related to their training in their home place. There are few people finding jobs in the town related to their training. Husbandry training can only help them for a short period. In this case, we provide training and animal such as pigs, chickens for them. I do not know yet what kind of assistance will work for them. This needs to be debated together with relevant sectors.

Interview location: Vientiane, Date: $18^{\text {th }}$ June 2013

Interestingly, connected to this issue, development cooperation strategy between 2009 and 2015 between Australia and Laos has focused on particular attention to victim survivors, as they can observe that a current assistance for survivor of UXO accidents is limiting and it is still far from demand (AusAID, 2012). Assistance focuses mainly on medical care and physical rehabilitation and livelihood improvement. This new development cooperation strategy also includes the provision of socio-economic reintegration services to UXO survivors as well as people injured and disabled from UXO accidents (AusAID, 2012). Moreover, in the rural livelihood program between Laos Australia addressing to UXO issue, 15 percent of their budget that goes through NGO channel will be allocated in to victim assistance pillar (Lao, 2004). This new direction of development in UXO sector could bring new positive to Xiengkhouang people life.

Besides, victim assistance pillar funding limited, no specific provincial funding also affect the UXO operators on human resource and equipment update. In UXO Lao, clearance operator, this affects the organization terms of loss of skilled staff to other 
organizations. Addressing to this problem, Aus AID takes consideration about increased wage in the new document of development cooperation human resource sector particularly (Lao, 2004).

Moreover, limited budget cannot keep equipment such as computers and GIS software is up-to date. This results in long processing time and inefficiency (GICHD, 2007). Similarity, UXO Lao in Xiengkhouang province has problem of out of dated equipment and limited number of equipment compare to number of staff. These challenges affected its operation in the field, effective time particularly. Senior staff from UXO Lao in Xiengkhouang province expressed perspective on this views that:

The budget could not respond to the need for the local office, especially for the equipment updating. Requesting budget from main office in Vientiane has been successful sometimes, but it does not respond on time. In particularity, one UXO items detector that we have at the moment is shared almost ten people in the field, it will make the tasks slow. Additionally, vehicles were very old; they were more than 15 years which were used by MAG before. More importantly, the vegetation removal and cutting trees still has been done by hands. Compare to other country as Cambodia, clearing forest or vegetation are used machines which is faster and can hand over to the villagers immediately.

Interview location: Xiengkhouang Province: Date: $28^{\text {th }}$ May 2013

This is clear connection on how equipment updating benefits affected people in Xiengkhouang province and how it is related to their living condition improvement.

\subsubsection{Impact from key terms in strategic plan}

\subsubsection{Impact of the term "development"}

In Laos, the prioritization of development sector are guided by two policy documents the National Growth and Poverty Eradication Strategy (NGPES), and National 
Socio-Economic Development Plan (NSEDP) (Lao, 2004; Ministry of Planning and Investment (MoPI), 2011). Both strategic documents are proposed by government and approved by national assembly. NSEDP is five years plan which aims to achieve socioeconomic development and periodically managing the government's economy through policy, regulation, plan of action, and project detailed work plan, to achieve the highest goal. The NGPES began in 1996 to define the long-term development objective to graduate from the status of least-developed country (LDC) by 2020 (Lao, 2004).

In particular, strategic documents of UXO and mine action sector in Laos are also guided by 6th NSEDP (2006-2010) and 7th NSEDP (2011-2015), all activities in UXO and mine action has been designed to support NSEDP. The term "development" as a concept is contested both theoretically and politically with no single agreed definition (Sumner \& Tribe, 2008). Therefore, in practical, the terms and context of development between government and humanitarian UXO operators has been seen differently. A different view between them has shaped the UXO operators. For humanitarian UXO operators, common understanding of the terms "development" is important. In this sense, Goslin (2003) and Horwood (2003) emphasis on linkage between mine action and development that it requires a re-focusing on the way where mine action inputs are prioritized and leading to a greater focus on developing task identification and prioritization systems. Connected to this point, a common definition of particular terms allows UXO operators in Laos work smoothly with their donors, because UXO and mine action operators in Laos are fully funded by international donors. Therefore, implementation of their funded projects have to be followed the donors strategies. In terms of clearance, the donors assumes that once land is demined, land will be returned to productive economic use to improve livelihoods focusing on where the most socio-economic benefits will be achieved, and framing its work within the livelihoods approach (AusAID, 2006; DFID, 2010). In this sense, for donors, any target of UXO clearance that is out of this boundary is defined as it is not development purposes. For UXO operator as MAG, it also follows the donors' strategies to implement their projects. Interview the senior officer of MAG provide more detail on this views: 
MAG is humanitarian operator focusing on clearance for productive work such as irrigation system, schools, markets for community, farming and health care centers. These kinds of service, we consider as development purpose. However, for Lao government, development purpose is understood as economic zone, resettlement location, tourist site for instance. For us, MAG, these are not development issues. The good example is happening now is football stadium clearance in Xiengkhoung province, which is top priority of provincial governor. For MAG, they cannot spend donor money to clear this stadium that is not development issue for MAG. Moreover, in NSEDP does not specify enough for development especially development for UXO humanitarian sector.

Interview location: Vientiane, Date: $17^{\text {th }}$ May 2013

Practically, in sustainable livelihood framework, the influence does not only happen between policies, strategies and livelihood assets, but it also happens within the structures themselves (between governmental institutions (policy makers) and other operator such as NGOs). In this sense, the governmental institutions as policy makers influence NGOs or other UXO operators to follow their own definition of particular terms. This can also reflect how the power relation between government and development partners affect each other.

Interestingly, in some countries, Cambodia in particular, the army plays an important role in clearance for specific government project by spending their own funding. Increased role of army would be optional for Lao government for clearance the specific projects. Generally, Lao army provides UXO commercial service and government specific projects; therefore, in some cases, the government could use army service for the projects that humanitarian operators cannot do. 


\subsubsection{Impact prioritizing land for clearance}

In the past decades, the Lao government focused on clearing areas in order to reduce the risk, these areas perceived to be important to the development of the country such as schoolyards, hospitals, and other infrastructure projects. However, it is important to recognise that Laos is agricultural nation, as the country relies on agriculture, representing 53 per cent of GDP and 80 per cent of the labour force (GICHD, 2007). The shift to increasing focal area to agriculture land from government is good idea. However, the approach of prioritisation of all agricultural land needs to be more specific. In strategic plan, the priority land to clear classified as high, medium and low. Unclear priority land to be cleared seems to be questionable for clearance operators. For operators, they need government to consider more relation of suspect land to be cleared and other factor prior to prioritising. However, some international communities and government has focused too much on seeing the size of land cleared grow, rather than ensuring that land cleared could be used by communities to improve their lives and tackle poverty. In strategies that look high priority to the clearance of agricultural land. This criterion is not specific enough to assist in task selection. It should specify more which has combination of parameters, such as high contamination, but low population and low agricultural potential. In some case, it should specify the method of addressing the land priority such as fencing for low population and low agricultural potential land (GICHD, 2007). For UXO humanitarian operators' perspectives, the priority of the land and land use planning should be combined. The information of how much land will be used for productive agriculture after clearance is required for them. Interview the MAG senior officer, he elaborated that:

In some cases, unclear land use planning and priority of land combined with inaccuracy data survey has challenged the UXO operators. The senior officer of MAG added that MAG used to clear huge area of the land without finding any UXO items. There is not clear definition of land prioritized affect donors funding and it cannot focus on other development issues. Money will focus on UXO clearance. 
Interview location: Vientiane, Date: $17^{\text {th }}$ May 2013

There is no land prioritized directly affect the timeframe of clearance, at the same time it affects the donors as they need to spend money on other development areas rather than focusing on UXO clearance for unlimited time.

\subsection{Conclusion}

The chapter has outline the structures (institutions) and processes( policies/strtegies, legislations) of UXO and mine action in Laos composts of NRA, UXO operators and donors, while processes (policies, legislations) include ten years national strategic plan on UXO and mine action sector. In this chapter, it found that, in some area, clearance does not respond to economic benefits, because living condition improvement is also associated with other factors such as investment money for crops and family labour conditions. Another important issue raised in this chapter was the concerns of funding through NGO channel which majority of amount contributed to overhead costs. In this point, NRA has argued that with the same amount of funding spent on overhead costs could extend several teams for national UXO operators. Furthermore, limitation of funding affects provincial UXO operator to update equipment facilitating clearance such a vehicles and UXO items detectors. More importantly, the national development plan that restricted to swidden cultivation has created more constraint for living conditions improvement. In overall, applying the sustainable livelihood approach to unpack the context of UXO impact very useful in some regard but at the same time it has limited to explore the full extent of institutions policies and interventions with regards to UXO in Laos. 


\section{Chapter Five}

\section{Local perspectives on UXO impacts on livelihood}

\subsection{Introduction}

This chapter presents the results of fieldwork and responds to the two research questions which are: What are the major difficulties rural community members face for their livelihoods with UXO in terms of the agriculture sector and family labour? and how do people cope with those difficulties? The background context to the villages is explained further and the impact of UXO in both villages, Yotphae and Nanu is presented.. The key findings from interviews with villagers and local organisations working UXO in Xiengkhouang province are discussed. The findings are divided into two main areas: Firstly, the impact of UXO on villagers' livelihoods which are: the fear caused by UXO leading to lower agricultural production, impact on labour, education, policy constraints and loss of opportunity to generate income. Secondly, the coping strategies which people use are discussed, including different forms of social networks and productive diversification, casual work and seasonal cropping.

\subsection{Village case studies, Xiengkhouang province}

When I arrived in Xiengkhouang province on $28^{\text {th }}$ of May 2013, I met the provincial UXO Lao officer to consult about the villages' selection for my study. I began with introducing myself, with an explanation of the research project and my criteria for selection. I gave them a definition of differences between victim of UXO accidents and people affected by UXO, because UXO can be associated only with victims. In this study, UXO a victim is person who has had an accident from UXO, while people affected by UXO are people who suffer from UXO including economic, mental and physical aspects. I also gave them my selection criteria for the villages that have suffered by UXO in terms of economic, social, educational mental and physical effects. By the end, we had two selected villages, Nanu and Yotphae villages in different districts with the plan to visit each village 
for one day. Both villages have a history of UXO and during the war both areas were battlegrounds for conflict.

\subsubsection{Village overview}

\subsubsection{Nanu village}

Nanu is located in Paek district, which is far from the provincial capital, Phonsavanh, around two hours by car. The village has a population of 373 people in total, (194 women) including two ethnic groups, the Monk and Lao Loum. The village is divided into 80 households, two clusters including 20 households of Monk in one cluster and 60 households of Lao Loum in another cluster. Each cluster is located around three kilometres apart from each other. The main occupation of the villagers is farmers. The Lifestyle of each cluster is different. The Monk group relies on shifting cultivation and the other hand Lao Loum relies on sedentary farming. The Monk cluster is far from the national electricity grid, so not all households are connected to the grid. UXO issue has a long history for the village as it was heavily bombed as one of many villages in the province during the Second Indochina War (1964-1974), because it was one of the Communist's bases. Currently, live UXO items still threatens the livelihood of villagers. With areas of paddy field around 47 hectares, only 31 hectares has been cleared. Shifting cultivation area covers 25 ha and gardening 12 ha; those areas are not yet cleared. There were 12 victims of UXO between 1976 and 2002. The number of victims and accidents has decreased since and UXO Lao has launched mine risk education in the village which increases the awareness of the UXO risk. During the difficult time (UXO accidents and affected the family victims in terms of labour shortage) villagers help each other for planting and cultivating the crops.

\subsubsection{Yotphae village}

Yotphae village is located in Phoukout district, around $60 \mathrm{~km}$ from Phonesavanh, the capital of Xiengkhouang province. The Yotphae village area has been involved in a former

ground battle and was heavily bombed during the Second Indochina War. The village 
spreads over an area of around 160 hectares, which includes 93 hectares of paddy field, 36 hectares of shifting cultivation and 6 hectares of gardening. The village has 956 people; of which, 47 percent are women. People are divided into 159 households with an average of six people per household. More than 80 percent are farmers, while there are only 12 people recruited as government staff, such as soldiers and teachers. There are two main ethic groups in the village; Lao Loum and five households of Monk ethnic groups, both ethnic groups practice sedentary farming. The living conditions of villagers rely heavily on agriculture and natural resources. Rice crops are the main source of food, and seasonal crops namely, peanut and corn, are secondary crops and also a main source of income. These agricultural products are sold in Phonsavanh which is the main market in Xiengkhouang province. Furthermore, evergreen forests are also good source of secondary income where people find wild food such as mushroom and non-timber products to sell them in the market. In Yotphae village, people are related by kinship; therefore families have strong a social network that effectively supports them in times of food shortage.

\subsubsection{UXO impact on villages livelihoods}

Impact of UXO shapes people livelihood in different ways, specifically in Xiengkhoaung province where people become associated with the UXO items in many forms, such as scrap mental trade, farming activities, playing with UXO items and dismantling the mines. In the village case studies, after I coded all transcripts, the key themes that merged were fear caused by UXO leading to lower agricultural production, loss of labour capacity, diminished child education and constraining national policies. These types of impact affect livelihood differently.

\subsubsection{Key finding number 1: Fear caused by UXO leading to lower agricultural production}

An understandably high amount of fear has been created through the experience of villagers from what they have seen with UXO accidents happening with their family members or in the village. This fear has mainly affected people when they conduct land preparation and crop harvesting 
activities. In Yotphae and Nanu villages, land preparation was involved in slashing bush, forest clearance and land digging. These activities were prepared for cultivating rice, maize and peanut crops. Slashing bush, forest clearance and digging allowed villagers to see UXO items and made them fearful of the consequences of accidents. In Yotphae village, when digging by using hoe the farmers go very slowly with acute carefulness because they were afraid that they will hit UXO items. Some villagers used tractor for soil preparation. When using the tractor they are afraid the heavy mental wheels of the tractor will hit the munitions bombs. As an effect of this fear, soil preparation goes very slowly and requires many labourers to help. Talking to a senior villager who is a farmer, he mentioned that:

When I go to my land for slashing forest and bush for maize plantation, I have seen dozens of UXO items every day. Once I saw them, I imagine the accidents happening in the village; this connection makes me feel scared. Even though the feeling is temporary or for a short time, it makes my work slow progress. Someday, I can do only a few square meters, because I have to do with carefulness.

Mr Touy, Famer 62 years-old, Nanu village, Interview date: 29th May 2013

Some cases in the different villages in Xiengkhouang province, the fear prevents people from conducting farming activities in the place where accidents happen. Sadly, this affects their livelihood as they have to face more constraints apart from limited land availability. From interviews with people in charge of the victim assistance in Xiengkhouang province in World Education Laos organisation, he revealed that:

I conducted UXO victim assistance project in Xiengkouang province, and I had the opportunity to talk to victim's family. Majority of people had UXO accidents; they did not go to do 
farming in their land again. They will assign other family members going to that place. These victims will do farming in different places.

World Education Laos staff interview, Vientiane, date: $18^{\text {th }}$ June 2013.

The stories of both villages and other cases in Xiengkhouang province shows that the fear is associated with the background of bad experience happening that surrounded them. Sadly, this could cause a double difficulty for them in trying improve living conditions were contaminated by UXO is prevalent.

\subsubsection{Key finding number 2: Loss of labour force}

In Nanu and Yotphae villages, the majority of the population are farmers; therefore, physical labour is the key factor for their living condition improvement. Accidents caused by UXO often affect other family members. Victims of UXO accidents are associated with the loss of important organs such as limbs and eyes. This has caused decreasing capacity for an active and capable labour force and resulting in family constraints. The majority of the accidents often end up causing increased responsibilities for other members in roles of taking care of family and other aspects. In Nanu village, there were 12 victims, (and?) 10 deaths caused by UXO accidents between 1976-2002, these families have been adversely shaped as elaborated by an interviewed farmer:

My father died when I was around 13 years old, so I had to help my mother to find food and conducting farming activities. Rice production was not enough for consuming throughout a year. I have two younger brothers to take care of. During that time, life was difficult, I had to go to the river when I had free time for catching fish for family, and I also went to the forest for finding food such as mushroom and bamboo shout. Relatives provided 
some assistance from time to time, but I was still the key man for the family.

Interviewed Mr. Ki, Farmer 55 year-old in Nanu, Date: $29^{\text {th }}$ May 2013

In the case of Yotphae village, there are four families being involved in UXO accidents. The accidents led to the loss of two productive young people and three children were injured. For two young productive families, the accidents affected their crop production such as rice in terms of family labour support. Importantly, for children, two of them quit school, because their legs were affected and they could not walk the long distance due to the school location being far from the village.

\subsubsection{Key finding number 3: Emotional and psychological impacts}

In both villages, accidents are caused from playing with UXO by children, dismantling for scrap mental and farming activities for adults. Another important feature affected by UXO accident is feelings of despair and discouragement happening directly to UXO victim families. The majority of victim families felt upset with their lives in the sense that UXO accidents diminished the victim's capacity of working as some loss of important bodily functions. This made them feel different from others. This emotional impact shaped the way of life for of next generation, their children in particular. Once they were discouraged, they did not want to be active in farming activities. As a result, there is less land tenure for their children. Talking to a village committee member of Nanu village, he elaborated that:

Among 12 families, some of them do not want to create economy and do not want to think of future, they just wanted to continue their lives day after day. They the lack motivation for life continuation. So, their economic level is lower than other families than other households in the village. They also do not have enough rice to consume for whole year. They have to find other source of 
income to support their living. Another important barrier for these families is the annual expenses for ceremony for the death according to the custom. These households have to borrow money from others; sometimes they can give it back. But, sometimes, it is hard to give it back to another neighbour.

Interviewed date: $29^{\text {th }}$ May 2013

This shows that psychological impacts affects not only individuals but it also affects families and communities in areas of UXO affected communities. I would add a bit more here about the psychological effects - needs a bit more elaboration. Can you do this?

\subsubsection{Key finding number 4: Diminished child education}

Child education and UXO impact are heavily related to each other, which was another key finding. Child education is often associated with the shortage of the family labour resulting in the need of more labour support from family members. The option for villagers to respond to this issue is for kids to drop out of school to support family labour and interviewed farmers gave more details on how UXO affects the education of children.

My father had UXO accident and affected his arms and legs; I was around14 years old at that time. My family confronted difficulties as my father was the a head of my family who played a role in for taking care of family to ensure that we have enough rice to eat whole year. After accident, he could not work as full capacity. I had to leave school as I was eldest son to help my mother doing farming in order to prevent other members dropping out of school.

Interview of young villager in Yotphae 24 year-old, date: $30^{\text {th }}$ May 2013 
My family has six people, four children, two still study. During harvesting and cultivating seasons, there are not enough people to help. We plant rice and seasonal crops, peanut and maize. During cultivation season, it is better because it is school summer for my children then they can help. Yet, during the harvesting season, we have less people. Some weeks two children do not go to school for helping me. In particular, peanut harvesting takes slow because we have to do with carefulness due to the fear of UXO items.

Mrs Sy, Farmer 40 year-old, Yotphae village, Interview date: 30 May 2013.

In the villages studied, it is clear that the shortage of productive labour, income generation and education are knock on effects which are heavily connected to each other. Labour affects directly household income in a way labour as input and crop production as output. The more labour that household have, the more chance to have more production resulting in income. Therefore, families with higher income can support their children to get higher education. In Yotphae village, households that have more labour and land have more maize and peanut production to sell in Phonsavanh market as provincial market. Some families supports their child to go to university in Vientiane province or some support their child to study in vocational school within the province.

\subsubsection{Key finding number 5: Constraining national policies}

Living condition improvement of affected village is not only adversely affected by the UXO contamination; it is also affected from outside factors such as national policies. In the study villages, Nanu in particular, the villagers are shaped by the $7^{\text {th }}$ Five Year national Socio-Economic Development Plan 2011-2015 (SEDP). This plan has a target to cease all shifting cultivation by 2015 in order to protect the forests(Ministry of Planning and Investment (MoPI), 2011).In Nanu village, the plan has affected all families in the long 
term and has immediately affected 20 households of Monk ethnic group, because these households have relied on shifting cultivation for a long time. Another factor is that swidden cultivation requires huge area of land as it gives less crop yield compared to sedentary farming system.. One informant gave elaboration about this:

I do not have much land, extension cannot be done due to government prohibits to slash-and-burnt and combined with fear from UXO items. Shifting cultivation gave less production than sedentary farming. My parents left very little piece of land for planting. I have not enough rice to eat for whole year, I have to have causal work and go to forests for finding extra food for sell and eating.

Interviewed Mr Noy, Farmer 47 year-old, Nanu village, date: $29^{\text {th }}$ May 2013

According to the $7^{\text {th }}$ Five Year national Socio-Economic Development Plan (SEDP), people cannot extend any more land for cultivation. This plan doubles the difficulty for villagers as their land available now cannot be used fully due to UXO contamination and slow progress of UXO clearance tasks, as well as government policy. Moreover, characteristic of Monk ethnic group people, they are only familiar with planting primary agriculture crop as rice, they do not grow much seasonal crops such as maize or vegetable or even livestock feeding. Ned a final sentence here to conclude the effects of policy

\subsubsection{Key finding number 6: Limited potential full use of land available}

In UXO contaminated areas, extension of farmable land is very limited. This also limits the opportunity of villagers to increase their crop production as the source of their income. Land that is available cannot be used fully. As a result, it makes them lose opportunity to increase family income. In this case, I take Yotphae village for analysing this potential loss for income generation, because this village grows crops for the market. 
I applied a calculation based on total land available in the village without consideration of other factor such as drought to show how much the potential crops production for villagers. Taking data from the field through analysis, it could be seen that total village area has 129 hectares (93 ha of paddy field and 36 hectares of shifting cultivation) for rice growing. Rice production yield in Xiengkhouang province is three tons /hectare in average and rate of consumption in average around $170 \mathrm{Kg}$ per person in a year (Schiller J.M, Chanphengxay M.B, Linquist B, and, \& Appa Rao, 2006). Assuming that with the land available without UXO contamination the village could produce around 387 tons and 1.8 tons of rice per house hold in average in a year (see figure 5.1). With an average of six people per household in Yotphae village; one household will consume annually one ton approximately. People will have around 0.8 ton to sell in a year.

\section{Figure 5.1: Potential of rice production with assumption that land without}

\section{UXO contamination}

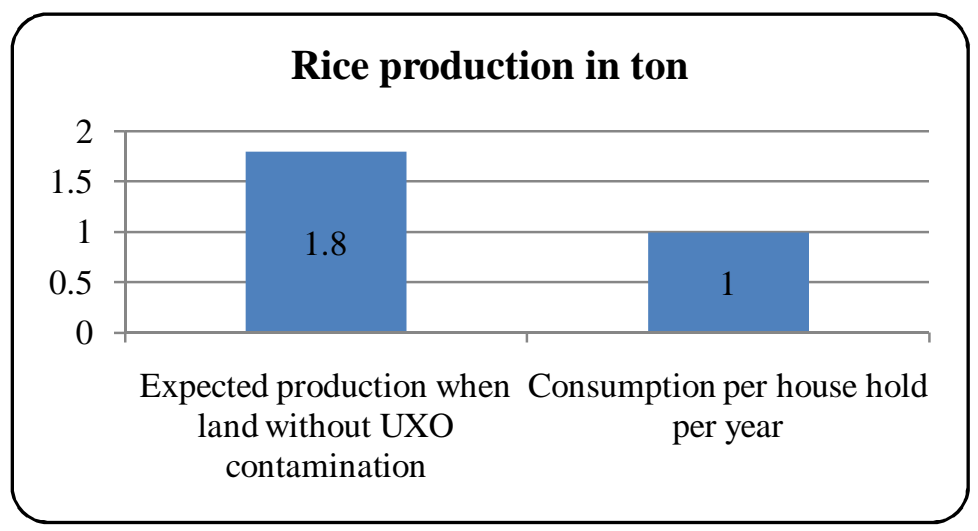




\section{Figure 5.2: Potential of maize production with assumption that land without UXO contamination}

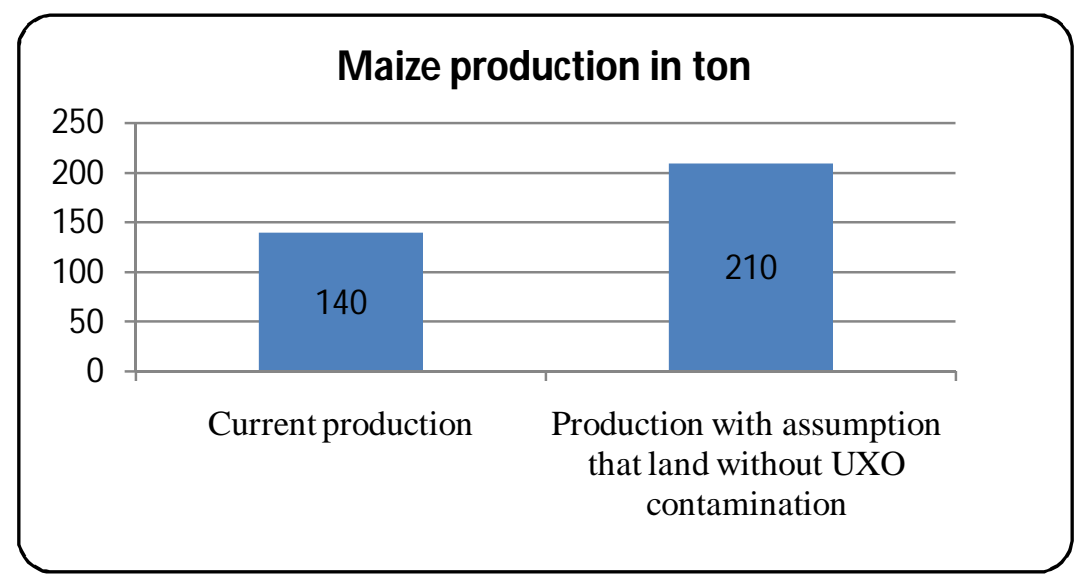

On the other hand, capacity of maize production area is 42 hectares, taking full capacity of maize will make around 210 tons per year with maize yield around five tons/hectare (Keophosay, Viau, Jobard, \& Castella, 2011). With current production, the village has produced only 140 tons per year (see figure 5.2). The difference of maize production could be 70 tons per year in the case of assumption that the current cultivated land is not affected by UXO.

This income could assist villagers to mitigate the issues and could be spent on their children's education. This assumption is considered only the UXO contamination which in practice, the farming production might rely on other factors such as environmental constraint such as drought or flooding.

\subsubsection{Relationship between Impact of UXO and sustainable livelihoods framework}

The impact of UXO in study area, Xiengkhouang province had a wide range such as limited access to land, education and household income. However, when these impacts are applied to the sustainable livelihood framework; it shows, in general terms, that three main 
livelihood assets are affected in the form of knock on effects: financial, natural and human capitals, as shown in figure 5.3.

Figure 5.3: Connection between UXO impact in the villages and sustainable livelihood framework

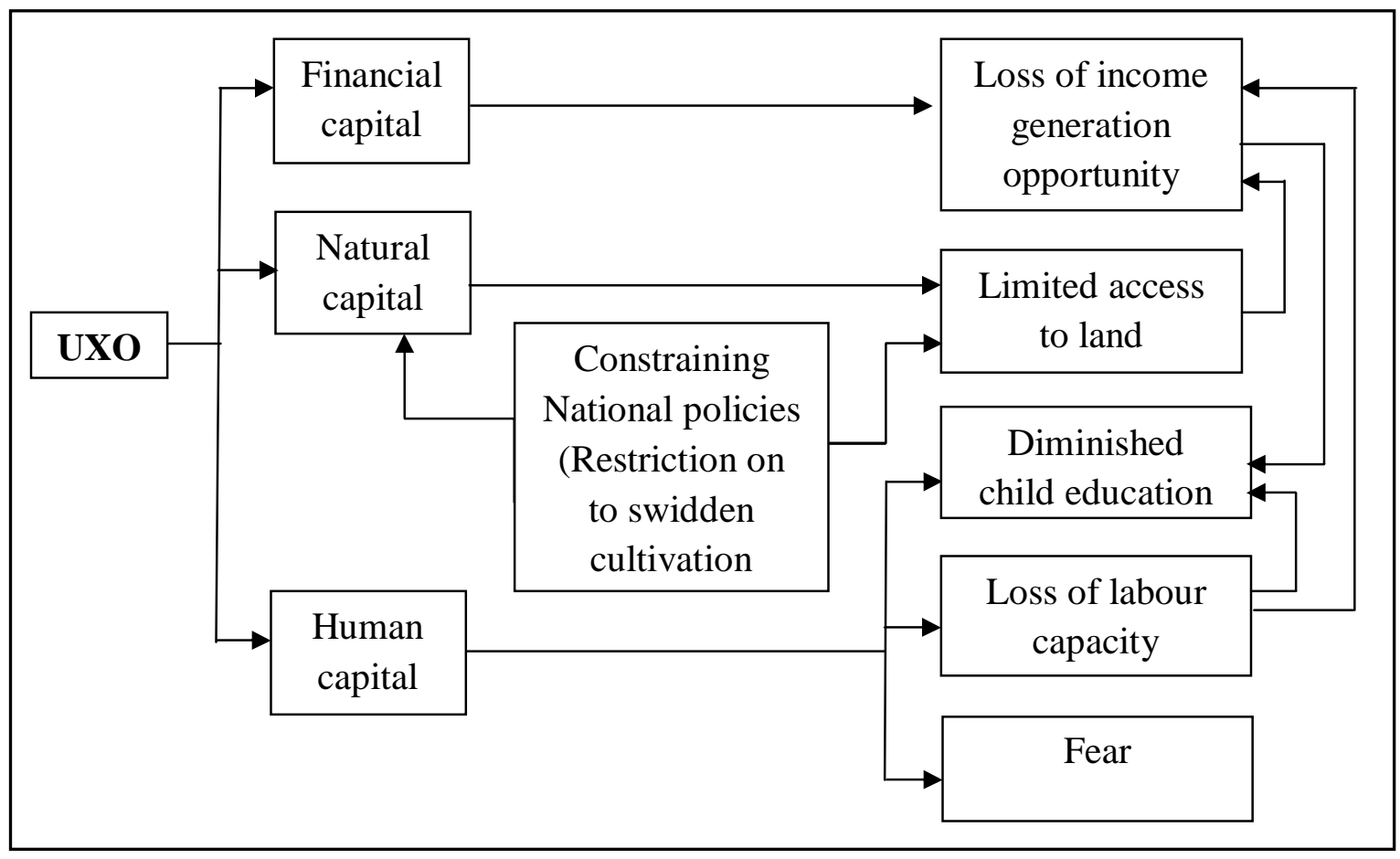

Opportunity lost for income generation is the main consequence in financial capital, which is strongly affected by natural and human capitals. The impact of UXO causes limited access to the land and is a direct impact to household income when people do not have land as a tool for their income through agricultural production. Human and financial capital that has been affected by human capital in the form of physical health caused by UXO is mainly the decreased capacity of the work force which reduces income. Additionally, in human capital; UXO also affected the mental health of villagers in the form of fear. Importantly, there is a connection between the education of children and 
household income. In the case study villages, families with low income have a reduced capacity to support their children for education. In some cases, suspension of education is selected to support the family labour shortage. I This confirms the country report of Understanding of Children's Work Programme which indicates that household income plays a role in decisions about children's work and their education attendance with households with higher income having more children attend school than low income families (UCW, 2014). Children's earnings or productivity can play an important role in household survival strategies among low-income families (Jatta, 2013). In natural capital, the outside factor of villagers' land use is affected by the national development plan issued by government that targets to suspend completely swidden cultivation in 2015 . This directly affects Monk villagers in Nanu village as they rely on as shifting cultivation system. According to the aim of this plan, they cannot extend more land.

In practice, applying the sustainable livelihoods framework allowed me to see the complexity of the issues and the linkages to other components within the framework. This information is important as guiding future input for intervention action in response to specific issues. However, it is still questionable for livelihood sustainability as Singh and Hiremath (2010) state that a livelihood in community is sustainable when it can cope and deal successfully with three main components of security of sustainable livelihoods which are security of ecology, efficient economy and equal society. In particular of the two components, the first is efficiency of economy meaning a productive labour and marketable surplus. In this sense, it does not fit with the village studied because many households still have labour shortage and access to the market is still limited for their production. The second component is equal society, which means that land, assets and income are contributed equally. The study shows that this does not happen in villages studied, as there are several households, Monk ethnic groups in particular, who have less land tenure and still have financial burdens. 


\subsection{Coping strategies used to overcomes the issues}

The villager interviewed for this project applied various strategies to cope with the difficulties caused by UXO. Livelihood assets such as social capital in form of social collaboration are applied to respond the shortage of labour. Family members help each other out. Diversification production including noodle production, seasonal agricultural crops and casual work in urban areas are also applied to handle the difficulties. The strategies used by villagers are useful for their livelihood improvement, but in practical terms there is the raising point about how it fits with sustainable context focusing on three components: security of ecology, efficient economy and equal society.

\subsubsection{Social collaboration}

Social collaboration is one strategy that villagers in the two case studies applied to cope with UXO issue during difficult time. There are two types of cooperation used by villagers: assistance from relatives and other villagers and knowledge transfer through training.

It is a normal characteristic of rural people when other families have difficult times, they will help each other. In Nanu and Yotphae, villagers volunteer to help households that have more difficult circumstances. Assistance is mainly in the form of help for cultivating and harvesting season, rice crops in particular. In some case, their relatives assist for specific tasks such as roof repairing or providing some rice. One of the participants added more detail about this:

My father had UXO accident and affected his arms and legs; he could not repair the roof by himself. I was still a little boy during that time. One day when the rain came, the drop of rain went through the roof hole and floor all got wet. Next day, by assistance of my uncle, the roof was fixed. I was so happy and could sleep for whole night. My uncle often helped us when we had difficult time. 
Interview of young villager in Yotphae 24 year-old, date: $30^{\text {th }}$ May 2013

In Yotphae and Nanu villages, the family with a high capacity of payment provided some tasks to troubled families with payment such as house building. Social collaboration is quite a powerful tool for the villagers to overcome the issues of labour shortage in short term, and also for emergency cases such UXO accidents. Villagers took care of the victim and sent him/her to hospital.

Another collaboration among villagers themselves is knowledge transfer through training. The training is about agriculture and husbandry. In Nanu village, the training benefited the Monk ethnic group households because their agricultural system is different, and gave less production comparing to others households. The training was organised by the village committee which took place in the village office. In agricultural training, the targets to boost the production which focuses on vegetable plantation and corn. Animal husbandry training focused on pig and chickens to ensure that villagers had some food stock during difficult time. Sometimes, the training was organised by district agricultural office proposed by the villagers. This training extends the villagers' capacity in areas of technical and theory to do with farming which is mainly provided by district experts outside the community.

\subsubsection{Productive diversification}

Villages that are affected by UXO find that it hinders their capacity to improve their living conditions. Different sources of income generation are the many ways that many people apply to cope with their difficulties. In the past, traditionally people planted only rice and found food from the forest for consumption. Now, different income activities are involved in general commerce from which they can make more extra money. In Nanu village, people group together for making noodles for provincial market. Yotphae village is involved in seasonal crops as maize and peanuts for income generation. Non-timber forest products are shared by both villages. 


\section{Example 1: Noodle production}

Responding to difficulties affected by UXO, villagers have sought to find a variety of income activities to mitigate the issues. One of the options is noodle making. This production occurs in Nanu village, within the village itself, but the noodle making does not cover all households. Nanu village is divided into two clusters, Lao Loum ethnic group 60 households and Monk ethnic group 20 households. Both clusters have different living styles and their economic level is also different. In the past, the Monk ethnic group has been invited to join the others for producing noodle, but investment money is a concern, combined with a lack of familiarity with this kind of production results, so often they decline the request. Therefore, noodle production occurs only among the Lao Loumcluster, which covers 56 households divided into 4 groups each, included 14 households. Each cluster has several group divisions. These depend on the structural organisation of the village which in this case, has four groups and each group manages and controls themselves. In terms of the financial investment, group members contribute their own money to the group for buying the raw material, but labour is shared together. After selling the noodles, an investment fund is organised and the remaining profit is distributed to individual households in the group.

Noodle making cannot cover the whole month period for each household member; because they were concerned the price dropping if they produced too much. Therefore, they controlled the price by keeping the appropriate amount of noodle produced every day. In four groups, each group takes turn once week, which means that one household, can generate income for seven days per month. This strategy is to keep the price in the market due to others villages in Xiengkhouang province also being able to produce noodles. This shows that villagers apply clever strategies for keeping the price for their production in the small market. The main market for their production is Phonsavanh market, the provincial market. According to the interviews, Nanu village produces 1.5 tons of noodle per day, 
which they sell 5,000kip/kg (around 6.5USD). One household can make a profit around 70,000-80,000 kip per day (9-10 USD). In total one household has a monthly income of approximately 490,000-560,000 kip (63-70 USD).

The income for noodle production is not high compared to Laos' Gross Domestic Product (GDP) per capital of Lao people, which is around 1,417 USD per capital (World Bank, 2012). The noodle production income is around half of that GDP;. This money is not included in food production such as rice; and some food collected from the forests, and vegetable and animal husbandry in their backyard. Therefore, this money can be spent on necessary expenses such as education, health care and other agriculture equipment.

\section{Example 2: Seasonal agricultural production}

In the studied villages, apart from main crops such as rice, additional crops are maize and peanut planted as extra sources of income. In Nanu village, maize is only planted for consumption rather than for trading. In Yotphae village, maize and peanuts are grown for selling to the provincial market, Phonsavanh market. The income from these crops became the main source of income for villagers, as the primary rice crop is only for consumption. According to the villagers in Yotphae, the village produced 140 tons of corn and 40 tons of peanuts annually. The price of maize is $1,000 \mathrm{kip} / \mathrm{Kg}(0.15 \mathrm{USD})$ and 6,000 $\mathrm{kip} / \mathrm{Kg}$ (0.7 USD) for peanut. In total, every year the village made around 140 million kip from maize or 21,000 USD and around 240 million kip or around 28,000 USD. On average, every household generates an annual income of approximately 2.4 million kip or around 300 USD. However, each household did not have a similar scale of income; some households made more income depending on how much they plant maize and peanut. The families also relied on investment money, land available and labour. Villagers do not have to spend much money on food as the majority of villagers have enough rice to eat for a whole year. Income from crop selling is accumulated for buying agricultural materials such as motorcycles, agricultural equipment such as tractors and educational materials for children. 
Villagers have additional income sources from forests such as mushroom and nontimber forest products. The products from the forest become food rather than goods for selling. The income from forest food is a very little amount of money, but, during rainy season, the forest plays an important role in providing a food source to the villagers, especially bamboo shoots and mushrooms. In difficult times, for instance the beginning of the end of the Second Indochina War, the forest became a source of cassava and kumara which people consumed instead of rice at that time. Even though forest produce cannot return much income in terms of cash, it can save villagers revenue in terms of buying firewood and other wooden building including house in the villages.

\section{Example 3: Casual work in urban area}

A casual job is one option that people do for generating more for their income. It is normal that in a rural life style after crops production people will have some free time until the new season. People will take this off-season time to go to other places for earning money and send back to their family. For Monk people in Nanau village, every day they go to the nearby town centre, Phonsavanh to find casual jobs. These jobs are mainly about moving goods from transport trucks to warehouses and construction shops or moving goods from warehouses to transport trucks. This kind of job uses a lot of physical force so the workers are mainly young people.

This type of job is not regular and many people coming from others villages do the same so there is high competition among them. There is often no employment contract between traders and workers and agreement is made day by day immediately when the trucks arrive. Additionally, this job is for a temporary period and it does not guarantee the regularly monthly income. In some months, the workers do not get any job, and for other months only around a few days a month of work is available. This type of job can pay the workers 300,000-400,000 kip (37.5-50 USD) for the day. I had a chance to talk to a young worker in Nanu village and he described that:

I go to the town even when I do not have job in my village; when the truck arrives, I get in the truck immediately and make 
negotiation with the owner of the goods. Many workers from different villages in same truck, someday I am successful for negotiating and get job. But majority of the day is not good day for me. I make money around 200,000 (25 USD) kip per day. There are too many days in a month that I do not get a job. In particular, during rainy season, this kind of job is almost absolutely unavailable. So, rainy season, I go to the forest instead to find wild food for consumption or selling.

Young productive people, 39 year-old, Nanu village, date: $29^{\text {th }}$ may 2013.

Sometimes, there are some casual jobs provided for the villagers in the village. The job is usually house building or roof building. In this case, it is rare to hire villagers within the village, because this kind of job requires high skills. Villagers in Nanu village are mainly hired as assistants rather than the main house or roof builder.

\subsubsection{Connection between coping strategies and sustainable livelihoods framework}

When I study these coping strategies from the villagers in both villages and analyse them against the sustainable livelihood framework. It can be seen that there are three types

of strategies, as figure 5.4 shows that people applied to cope with UXO impact: increasing social and human capital and diversification of income sources. 
Figure 5.4: Connection between coping strategies in the villages and sustainable livelihood framework

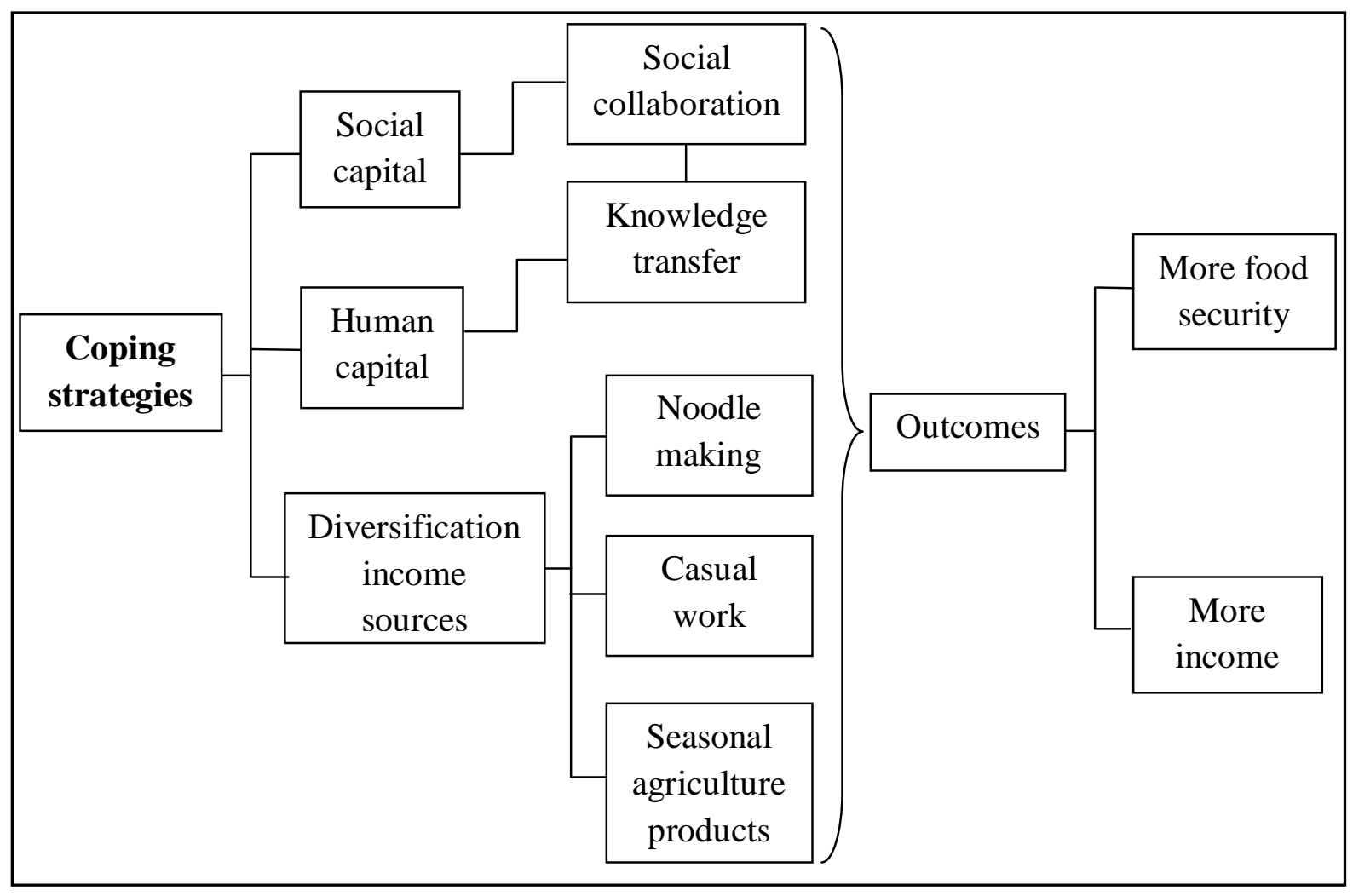

Both villages have well done in using strategies for boosting their income. Ellis (1998, 2000) defined "livelihood diversification as the process by which rural families construct a diverse portfolio of activities and social support capabilities in order to survive and to improve their standards of living. This can take place through both agricultural diversification and non-agricultural livelihood diversification in form of casual labour or migration" (Asmah, 2011; Khatun \& Roy, 2012). In this sense, both villages used very 
diverse sources of income. Noodle making and casual work in urban areas are main sources of income for Nanu village and non-timber products from the forest are a secondary source of income for both villages. All strategies used by the villagers is to secure more food and extra income for buying agricultural equipment and educational materials.

The strategies used by the villagers fits with the context of coping strategies which are useful for short term periods. It is still questionable for the sustainable context which is defined as security of ecology, efficient economy and equal society where security in ecology has a meaning of natural resources quality such as quality soil and water, forest preservation and air pollution. Efficient of economy means that a productivity of labour and marketable surplus. Equal society means that land, assets and income are contributed equally (Singh \& Hiremath, 2010). In this sense, casual work and noodle making does not respond to long term period because noodle making still has the gap of market that need to have intervention action to ensure that villagers can increase their productions and cover whole village members. As there are around 25 percent of households that are not benefitting from this kind of products. It is not the best long term solution. Added to this casual work covers only a few days per month and only in the dry season.

\subsection{Conclusion}

The chapter responded to the focal points of research which is the difficulties that local communities faced by UXO and the ways that local people handle with the situation. By using the sustainable livelihood approach and framework, I clearly saw the complexity of impact of UXO and the relationship within the livelihoods assets of the villagers in the form of knock on effects. Following this, it was clear to see what intervention actions were applied by the villagers to cope with UXO issue. Analysis through sustainable livelihoods frame work illustrated that there was a clear connection between loss of income generation opportunity and child education. Importantly, an outside factor which was the national development plan affected natural capital by restricting extension of the land. By using the sustainable livelihoods approach and framework in issues analysis could reflect a fitting and gap of intervention action used by villagers. This allowed me to see how people us 
existing assets to respond the issues. In this sense, the case study villages applied social collaboration in the form of assistance to respond to labour shortage and knowledge transfer as training to increase crops production. Importantly, the villagers' applied different ways of income generation to improve living conditions such as noodle making, casual work in urban area and seasonal crops. On the other hand, in the village case studies, the context of sustainability and their strategies used although effective, do not respond to long term solutions for the villagers. 


\section{Chapter Six}

\section{Conclusions and recommendations}

\subsection{Introduction}

The study sets out to explore the impacts of UXO on rural communities' livelihoods and strategies adopted to cope with these difficulties. This chapter summarizes keys elements of the first part of this thesis such as the background to this study, the literature on this topic and the research methodology I used. The second part of this thesis has presented the key findings and arguments made in chapter four(links between structures, processes and people livelihood) and chapter five (local perspectives on UXO impacts on livelihood)in order to answer the research questions:

- What are the institutions and policies dealing with the impacts of UXO in Laos and how do they play out in Xiengkhouang province?

- What are the major difficulties rural community members face for their livelihoods with UXO in terms of agriculture sector and family labour?

- How do rural communities cope with these difficulties?

Finally, in the third section of this concluding chapter, I discuss the strengths and limitations of this research and provide suggestions for future research. At the end of this chapter, I provide recommendations aiming to answer the last research question:

- How are national policies around UXO addressing these difficulties and strengthening coping mechanisms?

\subsection{Summary of the study}

\subsubsection{Research background}

The impact of UXO on rural communities' livelihoods was chosen as my research topic because development in Laos relies heavily on natural resources and international support in form of aid. These activities support economic development and livelihood 
improvement in rural areas challenged by UXO contamination. Access to natural resources as farmable land is limited by UXO impact, and development projects funded by international development partners and government are also affected. As the agricultural sector provides a large proportion, around 50 percent of the GDP of Lao in 2010 (World Health Organisation (WHO), 2014), it is a significant area of concern that much of this sector is hindered from growth by UXO. Furthermore, over 80 percent of the total population are rural and are engaged in the agricultural sector (Regional Office for Asia Pacific of FAO, 2013). I found that in order to boost the economy, Lao needs to have more land available for farming and development projects. This research project set out to understand how UXO's impact on local people's livelihoods is significantly important for any intervention activities.

Xiengkhouang province was chosen to explore the impact of UXO on rural communities' livelihoods, because it was one of the most heavily bombed province in the country with a current rate of UXO accidents around 30-50 UXO victim accidents per year It made up 12percent of total UXO accident across the nation. With an estimated 300,000 tons of explosives dropped in this province, this come to around two tons per person compared to the general population (Madhavi, 2008). UXO presence also prevents safe access to agricultural land meaning that improvement of livelihood of people is affected by UXO.

\subsubsection{Important ideas and concerns from the literature review}

The theoretical framework which was adopted for this research was the sustainable livelihoods approach. Sustainable livelihoods framework is a useful tool to help me to identify complicated issues and see its connection within the sustainable livelihood framework. I applied the sustainable livelihood framework to identify impacts of UXO affecting household livelihoods. This allowed me to understand the interconnectedness from one capital linking to another capital in the wider picture rather the single elements affected. 
While reviewing the literature I also discussed mine action in Cambodia and Mozambique. Mine action in both countries has similar structure to UXO in Laos as they have government institutes to take responsibilities for policy making and to collaborate with other operators. Furthermore, Laos, Cambodia and Mozambique are bonded by international convention to eliminate this issue. While Cambodia and Mozambique signed and are state parties for the Mine Ban Treaty that Laos has also signed and is state party to the Cluster Munitions Convention. In Cambodian mine action the army has more involvement in terms of clearance compared to Laos. In Cambodia, informal de-miners conduct the clearance in large areas of land, while this does not exist in Laos. In the case of Mozambique, using Mine detection Rats (MDRs) in the demining operation in Mozambique is a very new innovation method and could be useful for Laos. Animal mine/UXO detector as rats might be an optional method for clearance teams to boost the speed of clearance. UXO clearance in Laos has made slow progress and consideration of using mine detection rats might increase the capacity of UXO clearance as its capacity is faster than human. Furthermore, there is a conflict between UXO clearance operators and government in using role of army in UXO clearance responds to conflict term. Needs a final sentence here to conclude the paragraph

\subsubsection{Research methodology}

In this research, my epistemology paradigm shaped my research outcomes. Social critical constructivism, understood as an approach in which the "researcher seeks to establish the meaning of phenomenon from the view of participants" (Creswell, 2009,p.16), suited this study due to its concern with the views and perspectives of the participants. I conducted 23 interviews, representing governmental agencies, NGOs, international donors and villagers of two villages in Xiengkhouang province.

For selecting my participants I used the snowball technique to help to reduce sampling bias, maintain confidentiality, and increase the validity of findings (Penrod et al., 2003). I approached participants for interviews based on the information among previously 
interviewed participants. This helped lessen power relations when the process of participant's selection was conducted by the villages head for communities' participants. When I conducted interviews with villagers, I took this opportunity to ask information to locate other participants.

\subsection{Main findings with regard to research questions}

\subsubsection{What are the institutions and policies dealing with the impacts of UXO in Laos and how do they play out in Xiengkhouang province?}

UXO and mine action in Laos are influenced by a national strategic plan 2011-2020 known as Safe Path Forward II developed by NRA. The strategy includes three main pillars: clearance, mine risk education and victim assistance. Clearance is the main component of UXO and mine action sector in Laos and bounded by the Convention on Cluster Munitions (CCM) under Article 4 that State Party has to clear and destroy, or ensure the clearance and destruction of cluster munitions remnants located in contaminated areas not later than ten years after the entry into force of the Convention (NRA, 2012a. p5).

There are many development issues in terms of clearance that affect the mine action operators. The prioritizing of land for clearance is not well defined, combined with a lack of land use from community's level to national levels. This kind of issue hinders the clearance activities for humanitarian operators. Outcomes of clearance progress are slow due to limited funding and effects from inaccurate UXO data from surveying. This is the big challenge for development in Laos, which is aiming to be off the list of the least developed countries by 2020. The slow progress of clearance seems to delay the target for clearance by 2020 by Custer Munitions Conventions.

Another important issue in mine action in Laos is the way of understanding the specific key terms from government and international donors, the term "development" for instance. In this sense, humanitarian UXO and mine action operators cannot clear the land where it is not defined as useful for development purposes based on their donors' strategies. 
, This kind of issue reflected that the collaboration among development partners needs to be revised. They could set up the same definition for development term and follow the same direction. In some case, the national policies such as the restriction to swidden cultivation seems to be hindering living conditions of rural people rather than benefitting them. The idea of balancing the ecology by this national plan is good concept; however, it should show more consideration for sustainable intervention that could make rural people keep their livelihoods.

\subsubsection{What are the major difficulties rural community members face for their livelihoods with UXO in terms of the agriculture sector and family labour?}

The study found that the impacts of UXO on livelihoods can be classified as: fear leading to lower agriculture production, loss of labour force, diminished child education and constraining national policies. These are the key impacts that affect livelihoods differently.

\section{- Fear caused by UXO leading to lower agricultural production}

Fear has been created through the experience of villagers in a way that they have seen UXO accidents happening with their family member or in the village. The fear has mainly affected people when they conduct land preparation and crop harvesting activities, such as slashing bush, forest clearance and land digging. Agriculture production is affected by fear because farmers do not want to extend their crops, and they also have to be careful with harvesting and cultivating activities. As a result, it takes a far longer time for people to plant small amounts of crops.

\section{- Loss of labour force}

Labour force is affected by UXO through the accidents which are associated with the loss of loss of important organs such as limbs and eyes. This loss causes the victims to have a reduced capacity for labour resulting in family constraint. The majority of the 
accidents often end up with increased responsibilities for other members in roles such as taking care of family and other pressure on living ??UXO accidents also affect children, as in the study, two of them had quit school, because their legs were affected. If children are maimed they find it difficult to walk for long distances to go to school if it is located far from the village.

\section{- Diminished child education}

Child education is affected by UXO in a way that UXO accidents which lead to loss of productive people. As a result, victims loose important organs which reduce their workforce capacity. Due to family farming has strong relation with family labour force which is main factors to improve family livelihood. Less family pressure other family members in terms of family responsibility, so they want more labour to support family. Therefore, responding to labour shortage, out of school of family members is often selected.

\section{- Constraining national policies}

Restriction for swidden cultivation from national development plan doubles difficulties for villagers to boost their livelihoods. This is another benefit from applying sustainable livelihoods framework that allows seeing a bigger picture, including the outside factors affecting communities. In Nanu village, this national development plan has affected 20 households of Monk ethnic group, because these households have relied on shifting cultivation for long time ago. Another factor is that swidden cultivation requires a huge area of land as it gives less crops yield compared to a sedentary farming system.

\section{- Limited potential full use of land available}

UXO limits access to farmable land and limits opportunity of villagers to increase their crops production as the source of their income. Land available for villagers that they currently have cannot be used fully due to UXO contamination. This limitation causes a loss of opportunity to increase family income. 
The study also shows that the loss of opportunity of income generation, labour shortage and child education had a strong relationship. Labour shortage increased opportunity for family members out of school to help their family doing farming activities. However, farming activities required huge demand for labour, less labour was associated with less income. Less income affected the support for education in the family.

\subsubsection{How do rural communities cope with these difficulties?}

The study shows that people use social capital in form of social collaboration, and productive production which are noodle production, seasonal agricultural production and casual work in urban area to improve their livelihoods affected by UXO.

\section{- Social collaboration}

In Nanu and Yotphae villagers use social collaboration in form of assistance to help affected people This mitigates the labour shortage issue in affected families. This assistance

focuses on the harvesting and cultivating season because it requires a high amount of labour. Some families receive help from relatives for specific tasks such as roof fixing. In general case, villagers provide the assistance to these affected families. Furthermore, another form of social collaboration happens in Nanu village, by way of agricultural and animal husbandry training organized by the villagers themselves. This aims to help the Monk ethnic group to boost their crop yields.

\section{- Noodle production}

Noodle production is implemented as a group of income generation in Nanu village. However, in order to keep the price stable in the market, the amount of noodle production is controlled. As a result, every group takes turn one week per month. Therefore, very household has only seven days of income per month. According to interviews, one household can earn around 63-70 USD per month. However, this product revenue is not cover every house hold in the village, there are only 56 out of 80 households and 20 
households of Monk ethnic group are not included due to financial burden for investment and unfamiliar with this kind of production.

\section{- Seasonal agricultural production}

Seasonal agricultural crops are maize and peanut. In Yotphae village, these crops are grown for selling to provincial market, Phonsavanh market. The income from these crops selling became the main income source for villagers, the primary crops as rice is only for consumption. On average, every household in Yotphae village generates annual income of approximately2.4 million kip or around 300 USD. However, in Nanu, maize is cultivated for consummation purpose due to lack of investment money, land available. Income from crop selling is accumulated for buying agricultural for materials such as motorcycles, agricultural equipment such as tractors and educational materials for children.

\section{- Casual work in urban area}

This kind of job happens with villagers in Nanu village, in particular for the Monk people. After the harvesting season, they have free time and they go to the provincial market (Phonsavanh market) to find the job. The majority of jobs are about gods transportation which requires a lot of physical force; therefore, the workers are mainly young people. Even though villagers can earn quite high around 300,000-400,000 kip (37.5-50 USD) per day, some months they have only a few days or some months they do not have job at all. Therefore it does not guarantee the regularly monthly income. Sometimes, a casual job is provided by villagers themselves in the village such as house building and roof building.

\subsection{Research limitations and further research possibilities}

There are some limitations to this study. Firstly, the representation of research participants are a small proportion comparing to the affected communities in the research location, Xiengkhouang province. Within this proportion, there are a group of people that is not included- those with a different life style. Diversity of the participants is quite low. Not only at community level, as there are quite a number of interesting organisation that are 
not included in the interviews, because of the time constraint for the research. If I could, I would do differently the selection process by considering different groups of living style and culture. I would have carried out a pre-feasibility study for field selection by consulting with a variety of organisations.

This study only reveals the impact of UXO on rural community livelihoods in the agricultural sector and family labour. However, there are some unanswered questions possible for further investigation which could focus on:

- A comparison between UXO victim families and non-victim families in terms of education and economy

- How does UXO affect gender roles in family responsibilities?

- How does social and cultural perception on UXO victims affect their living style?

\subsection{Recommendations}

\subsubsection{Specific fund allocation into victim assistance}

In the national strategies around UXO, funding did not allocate to each pillar of mine action and UXO sector, in particular there was not specific funding for victim assistance pillar. Some people argued that once more land was cleared, UXO victims will decrease. They should not forget that during the clearance, another problem, victim assistance especially, occurs in parallel. Limited access to the funding affected the implementation of the projects of operators. Therefore, they should allocate the fund into each pillar by percentage. In some donors, this method was conducted, AusAid started to allocate the funding and victim assistance from 2014. The fund from AusAid will be allocated 15 percent of funding providing to trust fund of UNDP for UXO sector. However, other donors have not specified their funding yet. This is a good start model for other donors. It would be also good to have specific strategies for victim assistance funding from SPFII. 


\subsubsection{Response to land clearance resulting from unspecified term "development"}

All relevant organizations who work on UXO sector coming from government and NGO and donors should have a common understanding of important key terms. In the case that government and humanitarian operators have different views of the development definition of a particular aspect, they could specify which operator can do the specific clearance in this particular aspect. For instance, in Cambodia, the army plays an important role in mine clearance. Taking consideration of this role, it should be an option for UXO clearance where there is not common agreement between donors and government especially where both has different views of development definition.

\subsubsection{Community funding for communities in affected areas}

Providing the fund in the form of community funding by which villagers can spend this funding on boosting the income generation activities. The income generation activities could be animal husbandry, handicraft products etc. In particular, it could be spent for vulnerable people who are excluded in the cycle of community group for income generation due to the financial burden.

\subsection{Conclusions}

The research focused on the impact of UXO on livelihood of rural communities in particular location, Xiengkhouang province by using the sustainable livelihood framework as conceptual tools for analysing the fieldwork. However, what I found was that these impacts might not be coped with by single strategies or specific institutions of UXO. While particular context of UXO strategies affected UXO operator, it requires more collaboration form other national policies. Economic development and dealing with UXO issues be cannot separate because UXO has become a part of development issues. This being the case, boosting economic development through the agricultural sector cannot focus only on UXO issues. It needs to reflect others relevant policies in particular any policies related to the land in areas affected by UXO. 


\section{References}

Andersson, N., Palha da Sousa, C., \& Paredes, S. (1995). Social cost of land mines in four countries: Afghanistan, Bosnia, Cambodia, and Mozambique. BMJ, 311(7007), 718-721.

Ashley, C., Carney, D., \& Britain, G. (1999a). Sustainable livelihoods: Lessons from early experience (Vol. 94): Department for International Development London.

Ashley, C., Carney, D., \& Britain, G. (1999b). Sustainable livelihoods: Lessons from early experience (Vol. 7): Department for International Development London.

Asmah, E. (2011). Rural Livelihood Diversification and Agricultural Sector Reforms in Ghana. Paper presented at the Centre for the Studies of African Economies Annual Conference on Economic Development in Africa, Oxford, UK, March. www. csae. ox. ac. uk/conferences/2011-EDiA/papers/510-Asmah. pdf.

Auerbach, C. F., \& Silverstein, L. B. (2003). Qualitative data: An introduction to coding and analysis: NYU press.

AusAID. (2012). Laos - Australia Rural Livelihoods Program 2012-2016: Program Design Document. AusAID Retrieved from http://aid.dfat.gov.au/countries/eastasia/laos/Documents/larlp-pdd.pdf.

Basit, T. (2003). Manual or electronic? The role of coding in qualitative data analysis. Educational Research, 45(2), 143-154. doi: 10.1080/0013188032000133548

Benini, A. A., Moulton, L. H., \& Conley, C. E. (2002). Landmines and local community adaptation. Journal of Contingencies and Crisis Management, 10(2), 82-194.

Brocklesby, M. A., \& Fisher, E. (2003). Community development in sustainable livelihoods approaches-an introduction. Community Development Journal, 38(3), 185-198.

Burchett, W. G. (1970). The Second Indochina War: Cambodia and Laos: International Publishers. 
Cardona, O. D. (2003). The need for rethinking the concepts of vulnerability and risk from a holistic perspective: a necessary review and criticism for effective risk management. Mapping vulnerability: Disasters, development and people, 17.

Carney, D. (1999). Approaches to sustainable livelihoods for the rural poor.

Chambers, R., \& Conway, G. (1992). Sustainable rural livelihoods: practical concepts for the 21st century: Institute of Development Studies (UK).

Chiseri-Strater, E. (1996). Turning in upon ourselves: Positionality, subjectivity, and reflexivity in case study and ethnographic research. Ethics and representation in qualitative studies of literacy, 115-133.

COPE. (2014). COPE Supporters. Retrieved 20 May, 2014, from http://www.copelaos.org/supporters.php

Creswell, J. W. (2009,p.16). Research design: Qualitative, quantitative, and mixed methods approaches: Sage.

Dammers, C. (2008). Participatory Monitoring and Evaluation of Humanitarian Mine Action in Cambodia. Retrieved November, 23, 2010.

Denzin, N. K., \& Lincoln, Y. S. (2011,p.3). The SAGE handbook of qualitative research: Sage.

DFID, U. (1999). Sustainable livelihoods guidance sheets. London: DFID.

DiCicco-Bloom, B., \& Crabtree, B. F. (2006). The qualitative research interview. Medical education, 40(4), 314-321.

Docherty, B. (2009). Breaking New Ground: The Convention on Cluster Munitions and the Evolution of International Humanitarian Law. Human Rights Quarterly, 31(4), 934963.

Durham, M. J. (2012). Examining who benefits, in what ways, and in what contexts from Mine Action in the Lao People's Democratic Republic and Kurdish Iraq.

Ellis, F. (2000). Rural livelihoods and diversity in developing countries: Oxford University Press.

EU. (2011). Specific Terms of Reference, Formulation of EU intervention in Unexploded Ornance (UXO) Sector, Lao PDR: Humanitarian Aid, Crisis Management and PostCrisis Assistance (pp. 9). 
FAO. (2011). Lao PDR and FAO Achievements and Success Stories (pp. 21). Vientiane.

Fleisher, M. L. (2005). Informal Village Demining in Cambodia An Operational Study. Handicap International, Phnom Penh.

Flowerdew, R., \& Martin, D. (2005). Methods in human geography: a guide for students doing a research project: Pearson Education.

Frameworks, M.-T. E. (2001). SUSTAINABLE LIVELIHOODS GUIDANCE SHEETS.

GICHD. (2007). Lao PDR Risk Management and Mitigation Model.

Goslin, B. (2003). Making analytical tools operational: task impact assessment. Third World Quarterly, 24(5), 923-938.

Hagmann, J., Chuma, E., Murwira, K., \& Connolly, M. (1999). Putting process into practice: operationalising participatory extension: ODI Agricultural Research \& Extension Network.

HALO TRUST. (2014a). History of Minelaying Retrieved 13 May, 2014, from http://www.halotrust.org/where-we-work/cambodia

HALO TRUST. (2014b). History of Minelaying in Cambodia. Retrieved 12 May, 2014, from http://www.halotrust.org/where-we-work/cambodia

HALO TRUST. (2014c). History of the conflict. Retrieved 15 May, 2014, from http://www.halotrust.org/where-we-work/laos

Hofer, B. K. (2001). Personal epistemology research: Implications for learning and teaching. Educational Psychology Review, 13(4), 353-383.

Hoon, P., Singh, N., \& Wanmali, S. S. (1997). Sustainable livelihoods: Concepts, principles and approaches to indicator development. UNDP, New York.

Hopkins, P. (2007). Positionalities and knowledge: negotiating ethics in practice. ACME: An International E-Journal for Critical Geographies, 6(3), 386-394.

Horwood, C. (2003). Ideological and analytical foundations of mine action: human rights and community impact. Third World Quarterly, 24(5), 939-954.

Jatta, S. (2013). Labour Market Activities of Rural Households in developing countries.

Johl, S. K., \& Renganathan, S. (2009). Strategies for Gaining Access in Doing Fieldwork: Reflection of two Researchers. Electronic Journal of Business Research Methods, $8(1), 37-46$. 
Johnson, B., \& Christensen, L. (2008). Educational research: Quantitative, qualitative, and mixed approaches: Sage.

Keane, J., Lemma, A., Kennan, J., Cali, M., \& Massa, I. (2010). Case Study for the MDG Gap Task Force Report Draft.

Keophosay, A., Viau, J., Jobard, E., \& Castella, J. (2011). Impact of maize expansion on household economy and production systems in northern Lao PDR.

Khamvongsa, C., \& Russell, E. (2009). Legacies of war: cluster bombs in Laos. Critical Asian Studies, 41(2), 281-306.

Khatun, D., \& Roy, B. (2012). Rural Livelihood Diversification in West Bengal: Determinants and Constraints. Agricultural Economics Research Review, 25(1).

Kollmair, M., \& Gamper, S. (2002). The sustainable livelihoods approach. Input Paper for the Integrated Training Course of NCCR North-South Aeschiried, 9-20.

Krantz, L. (2001). The sustainable livelihood approach to poverty reduction. An Introduction. SIDA.

Landmine Action. (2002). Explosive Remnants of War: unexploded ordnance and postconflict communities. London, Landmine Action.

Lao, P. (2004). National growth and poverty eradication strategy. Vientiane, June.

Longhurst, R. (2003). Semi-structured interviews and focus groups. Key methods in geography, 117-132.

Luna-Reyes, L. F., \& Andersen, D. L. (2003). Collecting and analyzing qualitative data for system dynamics: methods and models. System Dynamics Review, 19(4), 271-296.

Lunsford, T. R., \& Lunsford, B. R. (1995). The research sample, part I: sampling. JPO: Journal of Prosthetics and Orthotics, 7(3), 17A.

Madhavi, J. (2008). Agricultural Land Use Debacles in Laos. Land Use: Reflection On Spatial Informatics Agriculture And Development, 148.

Manning, D. (2014). The Last Landmine in Maputo: Working Toward a Landmine-Impact Free Mozambique $\quad$ Retrieved 12 May, 2014, from http://blogs.state.gov/stories/2014/04/30/last-landmine-maputo-working-towardlandmine-impact-free-mozambique 
Merriam, S. B. (2002). Introduction to qualitative research. Qualitative research in practice: Examples for discussion and analysis, 3-17.

Ministry of Planning and Investment (MoPI). (2011). The Seventh Five-year National Socio-Economic Development Plan 2011-2015. Vientiane: MoPI Retrieved from http://www.undp.org/content/dam/laopdr/docs/Reportspercent20andpercent20public ations/LA_7thpercent20NSEDP_Eng.pdf.

Mishra, R. (2011). 'Merchants of Death'The Problem of Landmines in Cambodia, Laos and Vietnam.

Mollenhauer, C. (2014). Landmine-Detecting Rats Help Mozambique Achieve Mine-Free Status in 2014. Retrieved 12 May, 2014, from http://innovatedevelopment.org/2014/03/20/landmine-detecting-rats-helpmozambique-achieve-mine-free-status-in-2014/

Moyes, R., Lloyd, R., McGrath, R., \& Action, L. (2002). Explosive remnants of war: Unexploded ordnance and post-conflict communities: Landmine Action London.

Noy, C. (2008). Sampling knowledge: The hermeneutics of snowball sampling in qualitative research. International Journal of social research methodology, 11(4), 327-344.

NRA. (2007). National Regulatory Authority Uxo/Mine Action Sector in Lao PDR, UXO Sector Annual Report 2007 (pp. 83). Vientiane: NRA.

NRA. (2010). The unexploded ordnance (UXO) problem and operational progress in the Lao PDR: official figures. Vientiane: National Regulatory Authority for UXO/ Mine Action sector in lao PDR.

NRA. (2012a). National Strategic Plan for the UXO Sector in the Lao People's Democratic Republic 2011 - 2020. “The Safe Path Forward II”.

NRA. (2012b). UXO Sector Annual Report 2012 (pp. 88). Vientiane.

Okumus, F., Altinay, L., \& Roper, A. (2007). Gaining access for research: reflections from experience. Annals of Tourism Research, 34(1), 7-26.

Pascal, S. (2012). Transitioning Mine Action

Programmes to National Ownership 
Cambodia. Geneva: The Geneva International Centre for Humanitarian Demining (GICHD)

Penrod, J., Preston, D. B., Cain, R. E., \& Starks, M. T. (2003). A discussion of chain referral as a method of sampling hard-to-reach populations. Journal of Transcultural Nursing, 14(2), 100-107.

Petersen, E. K. (2010). The Sustainable Livelihoods Approach: From a psychological perspective. Approaches to Development.

Quang, T. G. (2010). INGOs and healing the wounds of war: the case of explosive remnants in Indochina.

Regional Office for Asia Pacific of FAO. (2013). Eucalyptus and Rural Development in Lao PDR - An NGO Perspective - Khankeo Oupravanh (CIDSE) and Charlie Pahlman (CUSO), Lao (supplemented by the report of the Japan International Volunteer Center (JVC), Lao) (Vol. II).

Reporters, T. (2013, 18 March 2013). DFDL Laos helps UXO survivors to build new lives, Vientiane Times. Retrieved from http://www.dfdl.com/images/stories/Articles/News/DFDL_Laos_helps_UXO_survi vors_to_build_new_lives_180313_Vientiane_times.pdf

Sarai, N., \& Sithole, G. (2012). Analysis of the process and outcomes of eportfolio development to recognise formal learning in Zimbabwe. Computer and Information Science, 5(3), p56.

Schiller J.M, Chanphengxay M.B, Linquist B, and, \& Appa Rao. (2006). Rice in Laos. Los Baños (Philippines): International Rice Research Institute: International Rice Research Institute.

Shoemaker, B. (1994). Legacy of the Secret War. Mennonite Central Committee, March. Available from: http://www. mcc. org/cluster bomb/secret_war [Accessed 7 October 2009].

Sibylle, C., \& Julie, V. D. B. (2009). A guide to Xinegkhouang (B. Soulivanonh Ed. first edition ed.). 
Singh, P. K., \& Hiremath, B. (2010). Sustainable livelihood security index in a developing country: A tool for development planning. Ecological Indicators, 10(2), 442-451.

Sumner, A., \& Tribe, M. A. (2008). International development studies: theories and methods in research and practice: Sage.

TRUST, H. (2014). History of Minelaying in Mozambique. Retrieved 12 May, 2014, from http://www.halotrust.org/where-we-work/Mozambique

UCW. (2014). Contry Report: Understanding children's work and youth employment outcomes in Laos (pp. 87). Rome.

UN. (2003). International Mine Action Standards. New York: UN Mine Action Service (UNMAS).

UNDP. (2012). Beyond the Horizon - Reducing UXO Impact for Poverty Reduction in Lao PDR

from

http://www.undp.org/content/dam/laopdr/docs/Reportspercent20andpercent20public ations/UNDP_LA_Beyondpercent20thepercent20Horizon.pdf

United Nations Mine Action Service (UNMAS). (2004). A Handbook for: Mine Action Programming United Nations. New York: United Nations Mine Action Service (UNMAS).

UXOLao. (2010). Living with UXO, Final Report. National Survey on the Socio-Economic Impact of UXO. Lao PDR.

UXOLAO. (2013). UXO Victims and Survivors (UXO Lao data). Retrieved 03 Apr, 2014, from http://uxolao.org/index.php/en/the-uxo-problem/uxo-victims

Walsh, N. E., \& Walsh, W. S. (2003). Rehabilitation of landmine victims: the ultimate challenge. Bulletin of the World Health Organization, 81(9), 665-670.

WHO, W. H. O. (2000). Guidance for surveillance of injuries due to landmines and unexploded ordnance.

Wiles, R., Crow, G., Heath, S., \& Charles, V. (2008). The management of confidentiality and anonymity in social research. International Journal of social research methodology, 11(5), 417-428. 
WoldVision. (2007). Macro Level Assessment: Lao PDR (pp. 1-45). Vientiane: World Vision.

World Bank Group. (2012). World Development Indicators 2012: World Bank Publications.

World Health Organisation (WHO). (2014). Lao People's Democratic Republic Statistics. Retrieved 23 May, 2014, from http://www.who.int/countries/lao/en/

WorldBank. (2012). World Bank Development Indictors, Mozambique. 


\title{
Appendix I
}

\section{Information Sheet for the research project \\ Impact of UXO on communities' livelihoods in Xiengkhuang Province, Lao PDR}

\author{
Sopha Soulineyadeth \\ Master in Development Studies \\ School of Geography, Environment and Earth Sciences
}

Victoria University of Wellington

I am a master student in Development Studies at Victoria University of Wellington, New Zealand. I am doing research, as part of my degree, on the impact of UXO on rural communities in Xiengkhuang province, Lao PDR. I am going to give you information and invite you to be part of this research.

This project aims to explore impact of UXO on livelihood in your community. In order to understand the impact, I want to find out major difficulties facing community with UXO and how you cope with these difficulties. I believe that your experience that you face and the way that you cope with the issues can help to better understand the impact of UXO. These kinds of information might also contribute to help policy makers/ development practitioners to develop more suitable projects/policy on these issues.

Your participation in this research is entirely voluntary. It is your choice whether to participate or not. If you agree to participate to this project, you can withdraw from it any time/ stage during the interview if you feel uncomfortable with the research. If you want to withdraw your participation after interview, you still can do that before data analysed (before 1st July 2013).

In this consent form, there may be some words that you may not understand. Please ask me to stop as I go through the information and I will take time to explain. If you have any question later, you can ask me any time.

The research project will involve your participation in an individual interview that will take about one and half hours. Conducting interview will be hold in comfortable location and time which is decided between us. I will take notes and audio record the 
interview with your permission. Interviews will be later analysed. At any point during the interview, you are free not to answer one or more questions if you choose to, and to mention issues you prefer not to discuss.

Responses collected will form the basis of my research project as a thesis student and will be put into a written report on confidential basis using pseudonyms. It will not be possible for you to be identified personally.

All material collected will be kept confidential and only myself and my supervisor will have access to it. The thesis will be submitted for marking to the School of Geography, Environment and Earth Sciences, Victoria University of Wellington and deposited in the University Library. It is intended that one or more articles will be submitted for publication in scholarly journals. Interview note taking and audio recording will be destroyed two years after the end of the project.

This project has been approved by VUW Human Ethics Committee.

If you have any questions or would like to receive further information about the project, please contact:

Sopha Soulineyadeth

Email address: soulinsoph@myvuw.ac.nz

Phone number in New Zealand +64 221744500

Phone number in Laos +856 21219486 


\title{
Appendix II
}

\section{ฉัมููโถรงางมถิ้มถิ้อ (Information sheet for research project)

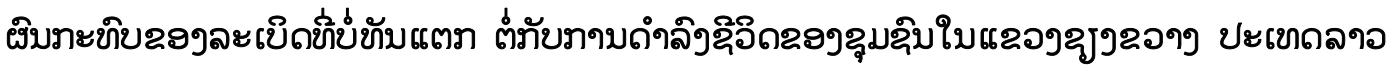

(Impact of UXO on rural communities' livelihoods in Xiengkhaung province, Lao PDR)

\author{
ข่าบ โสขๆ สุล็บยะเดถ \\ ปะลิบยาโขสาฉาภาบสิรสาล้าบขัดขะบๆ

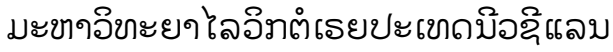

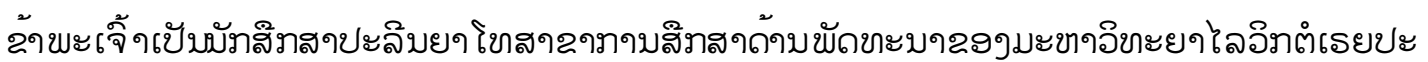

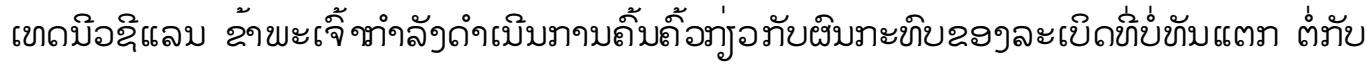

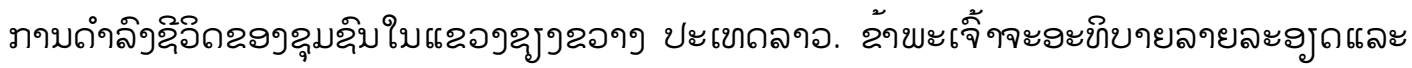

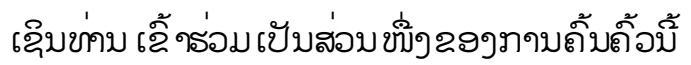

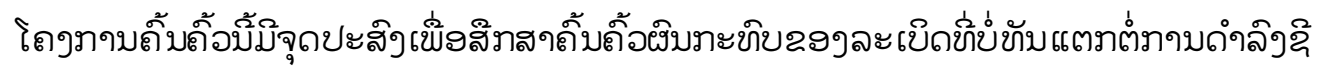

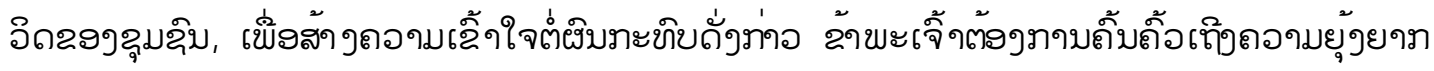

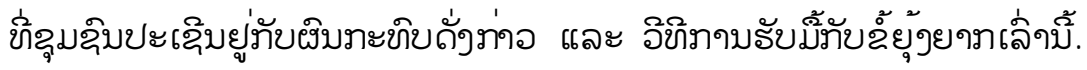

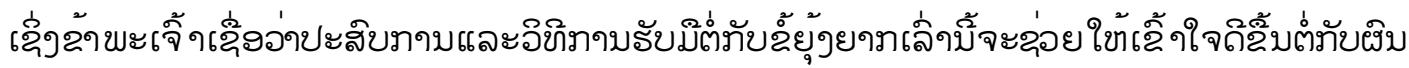

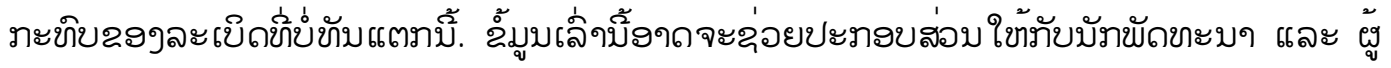

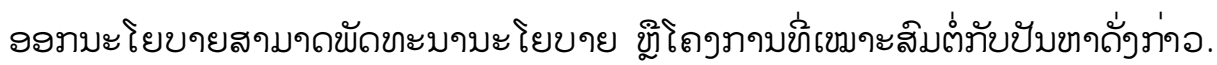

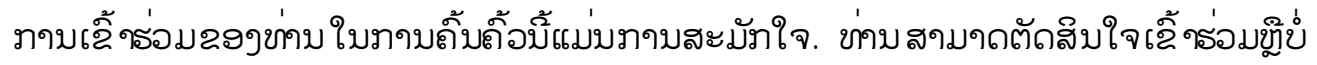

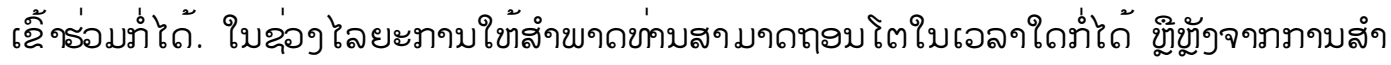

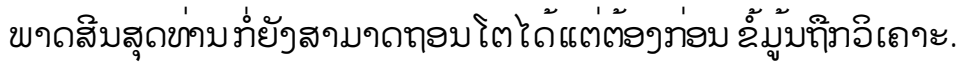




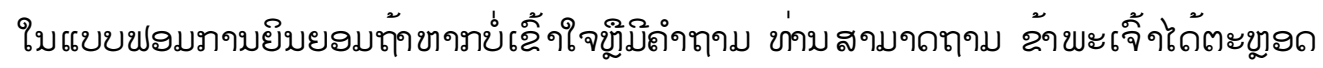
เอลๆ

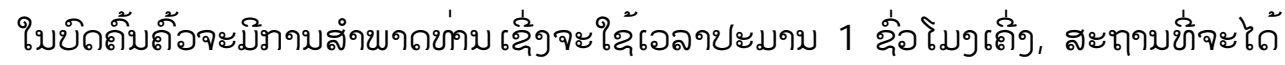

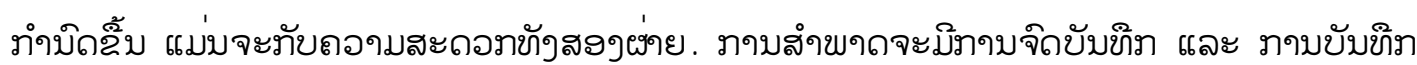

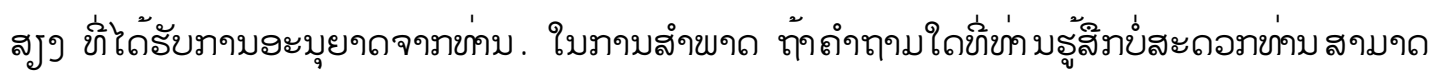
เลิ้อรฑั่จะบ่่ตอบท่่ใด้.

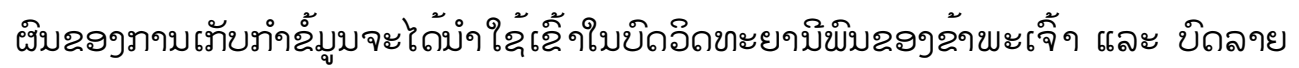

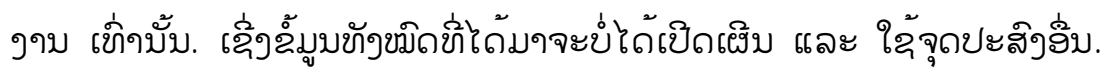

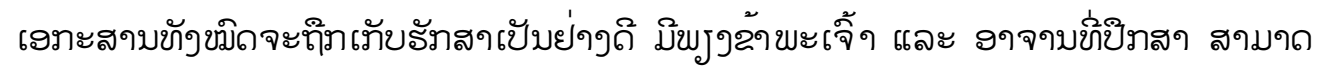

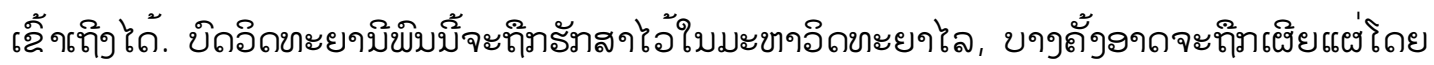

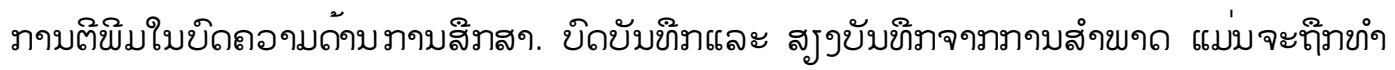

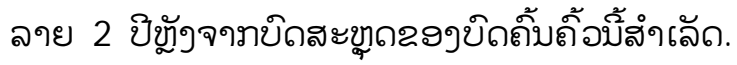

โถราาบถิ้บถิ้อบิ้แม่บฤ๊าธับธงจโดย:

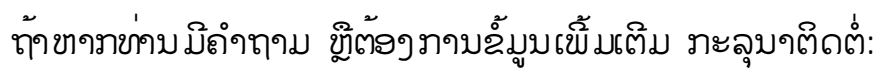

ข่าบ โสขๆ สุล์ยะเดถ

โขละสับลออ +85621214896

โขละสับบิอฉిเลบ +64221744500

อ๊เมอ sopha_sd@yahoo.com 


\title{
Consent Form
}

\author{
Sopha Soulineyadeth \\ Master in Development Studies \\ School of Geography, Environment and Earth Sciences, \\ Victoria University of Wellington
}

I have been given and have understood an explanation of this research project. I have had an opportunity to ask questions and have them answered to my satisfaction.

I volunteer to participate in this research project conducted by Mr. Sopha Soulineyadeth from Victoria University of Wellington. I understand that the project is designed to gather information for academic work.

I understand that any information I provide will be kept confidential, the published results will not use my name, and that no opinions will be attributed to me in any way that can identify me unless I choose otherwise and state so in this form.

I understand that I still can withdraw my participation after interview completed before data analysed (before 1st July 2013).

I understand that the results of this project will be published as student thesis and deposited university library and possibly as academic papers or presentations. I can be given a copy of conclusion of the project and summary of the outcomes if I request it. I understand that the interview notes taking and audio recording will be destroyed two years after the end of the project.

I understand that the information I provide will not be used for any other purpose or released to others without my written consent.

I understand that I can give recorded oral consent if I choose instead of written consent. It will include my answers to the questions below.

$\square$ I agree to take part in this research

$\square$ I would like my identity to be disclosed and my opinions to be attributed to me in the research report and any further publications (DO NOT TICK IF YOU WISH YOUR IDENTITY TO REMAIN CONFIDENTIAL)

$\square$ I would like to receive a summary of the results of this research when it is completed

Signed: 
Name of participant:

Date:

Contact details in case you have requested a summary of results

Email address or postal address: 


\section{Appendix IV}

\section{แบขขอมทาบย์บยฮม}

\section{(Consent form)}

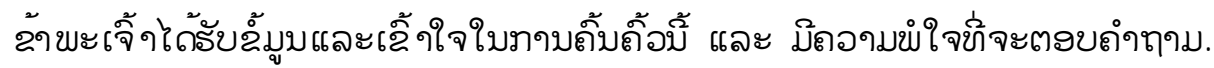

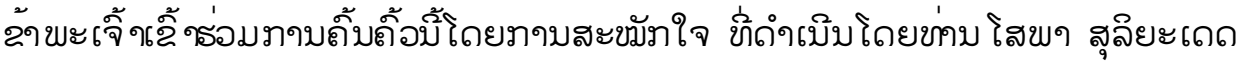

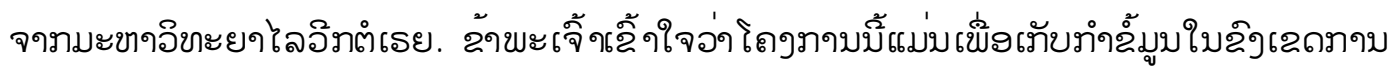
สิาสา.

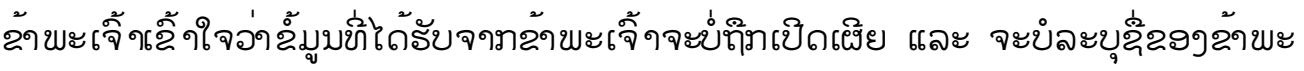
เจิ้ๆ.

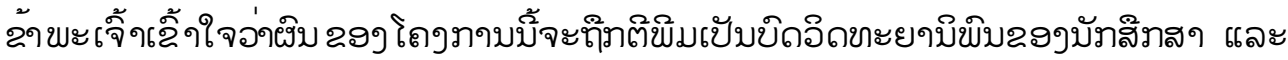
จะทึกจัดองๆไอ้ใบขสะมุถะองมะขาคอิถขะยาไล.

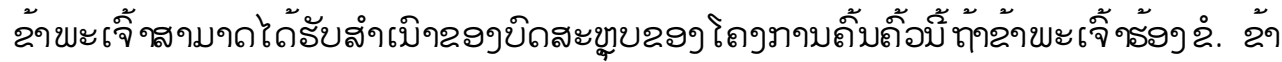

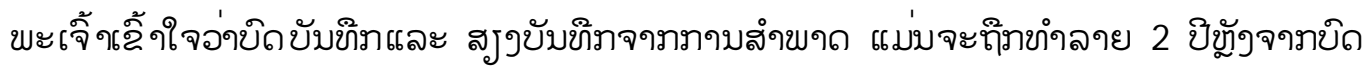
สะขุดฉองข์ลถิ้มถิ้อบิ้สำเลัด.

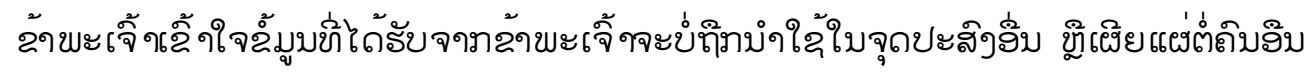

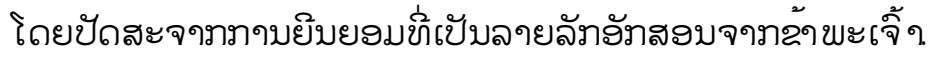

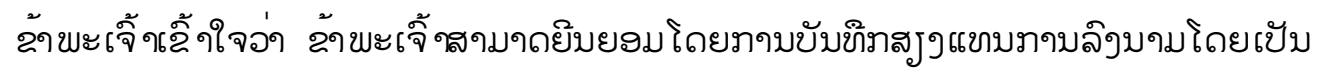
ลายลักอักสอบ. 


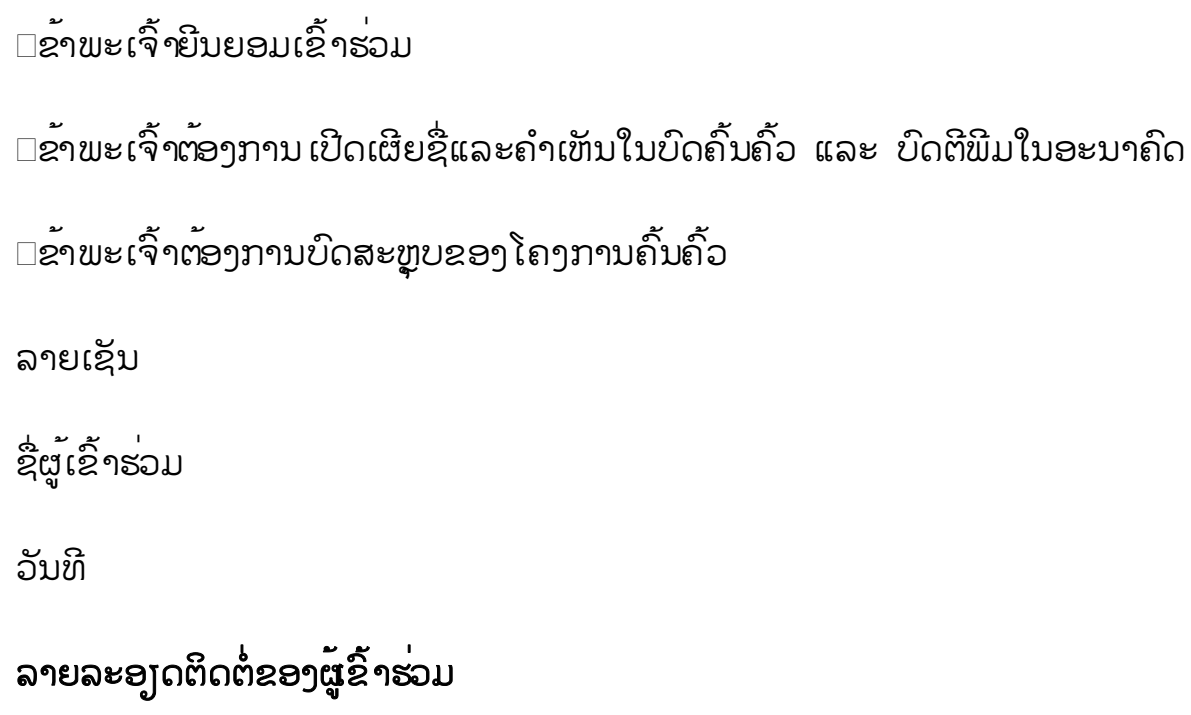




\section{Appendix V}

\section{Head of village interview questions}

District name:

Village name

Interviewee name
Date

Interviewer name:

Sex:

1. General information of the village

-Number of household

-Population

-Female number:

2. What is the main occupation of villagers?

3. What is the main income source of the village?

4. What are the main agricultural products?

4.1 Is the crop for sale or consumption?

- If for consummation: Is it enough for consuming?

If not: why....?

5. How do UXO impact the community?

6. Has there been any UXO accidents in the village? If yes, when?

6.1. What do people do when an accident happens?

6.2. What is the assistance from government or organization?

6.3. Is the assistance suitable? Why? Why not?

7. How do the villagers cope with difficulties in lives?

8. In your opinion, what kind of support would that be the most appreciate after UXO accident ( E.g. The support might be from government or NGO, local organisations, village etc) 


\section{Individual Interview Questions}

District name:

Date

Village name

Interviewer name:

Interviewee name Sex:

1. General information of the family

-number of family member:

- -Female number:

2. What is your occupation?

3. What is the main income source of your family?

If from agricultural product

4. What are the main agricultural products?

4.1 Is the crop for sale or consumption?

- If for consumption: Is it enough for consumption?

If not: why....?

5. How do UXO impact your family?

6. Has there been any UXO accidents in your family? If yes, when?

6.1. What do you do when accident happens?

6.2. What is the assistance from government or organization?

6.3. Is the assistance suitable? Why? Why not?

7. How do you cope with difficulties in lives?

8. In your opinion, what kind of support would that be the most appreciate after UXO accident (E.g. The support might be from government or NGO, local organisations, village etc) 


\section{Staff interview questions}

Organisation name:

Date

District:

Interviewee name

Sex:

Interviewer name:

1. What are UXO activities of your organisation?

2. Are activities created from your own interests?

2.1. Why and how

3. Are activities created from central government policy?

3.1. Why and how

4. Are activities created from the request from target area?

4.1. Why and how?

5. Are there tensions between them?

5.1. What are they?

5. Do you think that activities are effective?

6. Why or why not?

7. What are the key strengths of your work?

8. Why do you think it is important or a contribution?

9. What is not working or could be improved?

10. Why? 
11. Are they any difficulties to conduct the activities?

11.1. If yes, what are they?

12. In your opinion, what approaches/ activities about UXO issue should be focused on? 